\title{
QUALITATIVE METHODS USED TO DEVELOP AND CHARACTERIZE THE CIRCULATION CONTROL SYSTEM ON CAL POLY'S AMELIA
}

\author{
A Thesis \\ Presented to \\ the Faculty of California Polytechnic State University \\ San Luis Obispo
}

\author{
In Partial Fulfillment \\ of the Requirements for the Degree \\ Master of Science in Aerospace Engineering
}

by

Eric Nicholas Paciano

September 2013 
(C) 2013

Eric Nicholas Paciano

ALL RIGHTS RESERVED 
COMMITTEE MEMBERSHIP

TITLE:

Qualitative Methods Used to Develop and Characterize the Circulation Control System on Cal Poly's AMELIA

AUTHOR: $\quad$ Eric Nicholas Paciano

DATE SUBMITTED: September 2013

COMMITTEE CHAIR: David Marshall, Ph.D.

Associate Professor

Aerospace Engineering Department

COMMitTeE MEMBER: Jin Tso, Ph.D.

Professor

Aerospace Engineering Department

COMMitTeE MEMBER: Russell Westphal, Ph.D.

Professor

Mechanical Engineering Department

COMMITTEE MEMBER: Robert Fong, M.S.

Fluid Mechanics Laboratory

NASA Ames Research Center 


\begin{abstract}
Qualitative Methods Used to Develop and Characterize the Circulation Control System on Cal Poly's AMELIA

Eric Nicholas Paciano
\end{abstract}

The circulation control system onboard Cal Poly's Advanced Model for Extreme Lift and Improved Aeroacoustics was a critical component of a highly complex wind tunnel model produced in order to fulfill the requirements of a NASA Research Announcement awarded to David Marshall of the Aerospace Engineering Department. The model was based on a next generation, 150 passenger, regional, cruise efficient, short take-off and landing concept aircraft that achieved high lift through circulation control wings and over-the-wing mounted engines. The wind tunnel model was 10-ft in span, used turbine propulsion simulators, and had a functioning circulation control system driven from tunnel supplied high pressure air. Wind tunnel test results will be compiled into an open-source database intended for validation of predictive tools whose purpose is to advance the stateof-the-art in predictive capabilities for the next generation aircraft configurations.

The model's circulation control system produced highly directional, nonuniform flow, and required significant modification in order to generate flow suitable for representation in predictive software. The effort and methods used to generate uniform flow along the circulation control slots is detailed herein. Additionally the results of the system characterization are presented and include a thorough analysis of the slot height, the wing symmetry, and total pressure at the circulation control jet exit. These datasets are intended to aid in making adjustments to the simulation such that it accurately reflects the condition at which the model was tested.

Many flow visualization results from the wind tunnel test are also presented to serve as a medium of comparison for results from predictive tools. Oil flow visualization was conducted at many test conditions and provides insight to AMELIA's surface flow in blown and unblown regions. Of particular interest were streamlines at the wingblend, which exhibited some outboard turning, and streamlines 
on the lower surface where the leading edge stagnation point was investigated. Smoke flow visualization was also utilized to explore the flowfield. The deflection of a individual streamline, under the influence of a changing discharge coefficient was investigated along with the discharge coefficients effect on the extended flowfield. Collectively, the images depict the massive augmentation of the flowfield caused by the presence of the circulation control wing. 


\section{ACKNOWLEDGMENTS}

This research effort was sponsored by NASA's Subsonic Fixed Wing Program, NASA Research Announcement contract \#NNL07AA55C. Thank you to Craig Hange and Clif Horne for serving as technical monitors on this project. Mike Rogers and Bob Lockyer also deserve a special thanks for their enthusiastic support throughout the project.

Dr. Marshall, this has been one of the most fulfilling experiences of my life and I have you to thank for that. I greatly appreciate all of the opportunities you've provided me. Thank You.

Dr. Jameson, I have learned a lot from you, especially when it comes to dealing with high stress situations. You've have been a tremendous support, and guided me in a way that was effective, exciting, and fun. There's no one I would have rather worked with. Thank You!

To the crew at the Fluid Mechanics Lab-Rabi Mehta, Kurt Long, Jim Ross, Kevin James, Nate Burnside, JT Heineck, Dennis Acosta-thank you for all of the advice and hard work you contributed. I will not forget the many ways each of you went above and beyond to help out. The passion, drive, and brilliance of all of you at the FML certainly made me feel privileged to spend some time there. You are great people and role models that I will always admire. Thank You.

Rob Fong, Ted Garbeff, and Barry Porter, the previous goes for you too. I had a lot of great times with the three of you in particular. From how to prep the perfect tri-tip, to how to make the best LAN cables, to how to properly enjoy a beautiful afternoon in Santa Cruz. Thank you for making us feel at home.

To my friends in the CFD lab-Bobby, Rory, Bryan, Jay, John, Kevin, and even Jason and Hawkins-everyday you guys inspired me to work harder. Thank you all for the good times and the guidance you've left me with.

Mr. Jonathan Lichtwardt, we've certainly had some interesting times together. I look forward to many more. Thanks for putting up with me all these years, and being a great sounding board. 
To my family, thank you for the years of encouragement and support. Your positive energy really pushed me through the hard times. Thanks.

And finally to Denise, I could never have completed this without you. Through midterms, finals, presentations and countless late nights working on this research you've been incredibly supportive. I can not express how much I appreciate that. I look forward to everything the future has in store for us. 


\section{TABLE OF CONTENTS}

LIST OF TABLES xi

LIST OF FIGURES X xii

Nomenclature $\quad$ XV

1 Introduction 1

1.1 The Larger Body of Work . . . . . . . . . . . . . . . 1

1.2 Phase 1: Concept Design and Selection . . . . . . . . . . . 3

1.3 The AMELIA Configuration . . . . . . . . . . . . . 5

1.4 AMELIA-The Wind Tunnel Model . . . . . . . . . . . . . . 6

1.4.1 The High Pressure System . . . . . . . . . . . . . . . 9

1.4.2 The Low Pressure System . . . . . . . . . . . . . 11

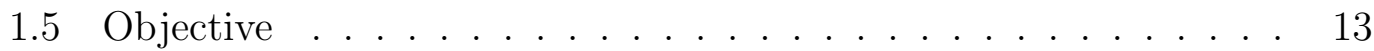

2 Circulation Control System Design $\quad 14$

2.1 Previous Circulation Control Research . . . . . . . . . . . . . . . 14

2.2 Design Considerations . . . . . . . . . . . . . . . . 16

2.2.1 Flow Conditioning ................ 19

2.3 System Design . . . . . . . . . . . . . . . . . 21

3 Flow Uniformity Calibration $\quad 25$

3.1 Background .......................... 25

3.2 Objective ............................ 26

3.3 Apparatus ....................... 26

3.3.1 Plenum Treatment Materials . . . . . . . . . . 30

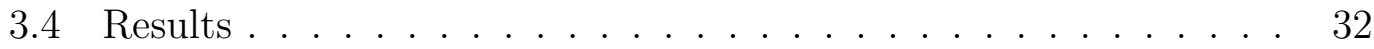


3.4 .1 Initial Inspection $\ldots \ldots \ldots \ldots \ldots$

3.4 .2 No Treatment . . . . . . . . . . . . . . . . . . . . . . 33

3.4.3 8\% Dense Aluminum Foam . . . . . . . . . . . . . . 33

3.4.4 15\% Dense Aluminum Foam . . . . . . . . . . . . . . . 35

3.4.5 Further Plenum Treatment . . . . . . . . . . . . . . . . 36

3.4.6 15\% Aluminum Foam With Metal Mesh . . . . . . . . . . 40

4 System Characterization 43

4.1 Slot Height Characterization . . . . . . . . . . . . . . . . . . . 44

4.1.1 Slot Height Measurement . . . . . . . . . . . . . . . . . 44

4.1.2 Slot Adjustment Accuracy . . . . . . . . . . . . . . . . 46

4.1 .3 Wing Symmetry _ . . . . . . . . . . . . . . . 48

4.1 .4 Slot Area . . . . . . . . . . . . . . . . . . . . 52

4.1.5 Slot Height Sensitivity to Pressurization _. . . . . . . . 53

4.2 Jet Total Pressure Survey . . . . . . . . . . . . . . . . 55

4.2 .1 Survey Set-Up . . . . . . . . . . . . . . . . . . . 56

4.2 .2 Survey Results . . . . . . . . . . . . . . . . . 57

4.3 Lessons Learned . . . . . . . . . . . . . . . . . . . . . . . . 65

5 Flow Visualization $\quad 66$

5.1 Oil Flow Visualization . . . . . . . . . . . . . . . 66

5.1 .1 Oil Preparation . . . . . . . . . . . . . . . . 67

5.1 .2 Oil Flow Visualization Results . . . . . . . . . . . . . . . 69

5.1 .3 Oil Flow Conclusions . . . . . . . . . . . . . . . . . 77

5.1.4 Oil Flow Lessons Learned . . . . . . . . . . . . . . . 78

5.2 Smoke Flow Visualization . . . . . . . . . . . . . . . . . 78

5.2 .1 Smoke Flow Apparatus . . . . . . . . . . . . . . . . . 79

5.2.2 Smoke Flow Visualization Results . . . . . . . . . . . . 80

5.2 .3 Smoke Flow Conclusions . . . . . . . . . . . . . . . . . 90

5.2.4 Smoke Flow Lessons Learned . . . . . . . . . . . . . . 90

5.3 Flow Visualization Conclusions _... . . . . . . . . . . . . . 91

6 Conclusions $\quad 92$ 
$\begin{array}{ll}\text { Bibliography } & 96\end{array}$

$\begin{array}{ll}\text { Appendices } & 102\end{array}$

A Additional Oil Flow Images 103

Oil Case 1 . . . . . . . . . . . . . . . . . . . . . 103

Oil Case $2 \ldots \ldots \ldots \ldots$

Oil Case 3 . . . . . . . . . . . . . . . . . . . . . . . . 109

Oil Case $4 \ldots \ldots \ldots \ldots$

Oil Case $5 \ldots \ldots \ldots \ldots$

B Additional Smoke Flow Images 116

Smoke Case 1 . . . . . . . . . . . . . . . . . . . . . . . . 116

Smoke Case 2 . . . . . . . . . . . . . . . . . . . . . . . . . . . 122

Smoke Case 3 . . . . . . . . . . . . . . . . . . . . . 125

Smoke Case $4 \ldots \ldots \ldots$. . . . . . . . . . . . . . 125

Smoke Case 5 . . . . . . . . . . . . . . . . . . . . . . . 126

Smoke Case 6 . . . . . . . . . . . . . . . . . . . . . 126 


\section{LIST OF TABLES}

1.1 NASA's Technology Goals for Future Subsonic Vehicles [1] . . . . 2

1.2 Phase 1 Conceptual Designs . . . . . . . . . . . . . . . 4

1.3 General wing dimensions . . . . . . . . . . . . . . . . . . 7

1.4 Plenum Designations . . . . . . . . . . . . . . . . . 13

2.1 Leading and trailing edge plenum design details . . . . . . . . . . 22

3.1 Plenum Treatment Composition . . . . . . . . . . . . . . . . . . 42

4.1 Capacitec Probe Specifications [2] . . . . . . . . . . . . . . . 45

4.2 Leading Edge Plenum Design Parameters . . . . . . . . . . . . . . 48

4.3 Slot Exit Area $\left(\right.$ inches $\left.^{2}\right)$. . . . . . . . . . . . . . . 52

4.4 Station as percent plenum span (TEIB) . . . . . . . . . . . . . 59

4.5 Station as percent plenum span (TEOB) . . . . . . . . . . . 62

4.6 Station as percent plenum span (TEOB) . . . . . . . . . . 65

5.1 Regions of Interest . . . . . . . . . . . . . . . . . . . . . . . 67 


\section{LIST OF FIGURES}

1.1 CAD Rendering of the AMELIA CESTOL Concept. . . . . . . . . 6

1.2 Internal layout of AMELIA . . . . . . . . . . . 8

1.3 High Pressure Air System of AMELIA. . . . . . . . . . . . . . . . 10

1.4 AMELIA's Low Pressure Air Supply . . . . . . . . . . . . . . . . 12

2.1 Elliptical Airfoil Notation \& Characteristic CC Flowfield. . . . . . 15

2.2 Cross section of a circulation control wing using a dual radius flap [3]. 17

2.3 Internals of the FAST-MAC model... . . . . . . . . . . . . . . . . 19

2.4 Detailed view of the circulation control plenums . . . . . . . . 22

2.5 Circulation control supply system inside the AMELIA model, each plenum supplied by a single source. . . . . . . . . . . . . . 23

2.6 The trailing edge slot of AMELIA's left wing with zero degree flap. 24

3.1 Sunbelt Model HP1600WCU Air compressor used for the circulation control calibration effort . . . . . . . . . . . . . 27

3.2 The critical flow nozzle used to measure mass flow rate. . . . . . . 28

3.3 Schematic of the slot flow calibration air delivery system . . . . . 29

3.4 Total probe location within AMELIA's CC plenums . . . . . . . . 29

3.5 Circulation control flow calibration set-up in Test Cell 1 . . . . . 30

3.6 Samples of metal foam and sintered metal mesh used in the circulation control plenums[30, 31]. . . . . . . . . . . . . . 31

3.7 Preliminary run using tufts . . . . . . . . . . . . . . . . . 32

3.8 Oil flow visualization: No Plenum Treatment . . . . . . . . . . . . 34

3.9 Oil flow visualization: $8 \%$ Dense Metal Foam . . . . . . . . . . . . 34 
3.10 Oil flow visualization: $15 \%$ Dense Metal Foam . . . . . . . . . . . 36

3.11 Oil flow visualization: Plenum Internal Flow . . . . . . . . . . 36

3.12 Oil Flow Visualization: Summary. . . . . . . . . . . . . . . . 38

3.13 Oil flow visualization: Heavy Grade Metal Foam and Rigimesh . . 41

3.14 Heavy grade metal foam with Rigimesh in trailing edge plenums . 42

4.1 Comparison of ideal trailing edge slot height to actual. . . . . . . 47

4.2 TEIB slot height comparison. . . . . . . . . . . . . . . . . . . . 49

4.3 TEOB slot height comparison. . . . . . . . . . . . . 50

4.4 LEIB slot height comparison. . . . . . . . . . . . . . . 50

4.5 LEOB slot height comparison. . . . . . . . . . . . . . . . . . 51

4.6 Pressurized vs Static Slot Height . . . . . . . . . . . . . . . 54

4.7 Total pressure survey set-up at the right wing trailing edge. . . . 57

4.8 Right wing trailing edge inboard total pressure . . . . . . . . . . 58

4.9 Left wing trailing edge inboard total pressure . . . . . . . . . . . 60

4.10 Right wing trailing edge outboard total pressure . . . . . . . . . . 61

4.11 Left wing trailing edge outboard total pressure . . . . . . . . . . 62

4.12 Right wing leading edge outboard total pressure profiles at $\frac{X}{c}=20 \% 63$

4.13 Left wing leading edge outboard total pressure profiles at $\frac{X}{c}=20 \% \quad 64$

5.1 Oil application before(above) and after(below) . . . . . . . . . 68

5.2 Oil Application in the NFAC . . . . . . . . . . . . . . . . 70

5.3 Oil Flow Visualization Case 1 . . . . . . . . . . . . . . . . 71

5.4 Oil Flow Visualization Case 2 . . . . . . . . . . . . . . . . . . . 72

5.5 Oil Flow Visualization Case 3 . . . . . . . . . . . . . . . . . . . 74

5.6 Oil Flow Visualization Case 4 . . . . . . . . . . . . . . . . . 75

5.7 Oil Flow Visualization Case 5 . . . . . . . . . . . . . . . 77

5.8 Smoke Flow Visualization Equipment . . . . . . . . . . . . . . . . 79

5.9 Target Location for Smoke Streamline . . . . . . . . . . . . . 80

5.10 Smoke Flow Visualization Case 1a. . . . . . . . . . . . . . . . . . 82

5.11 Smoke Flow Visualization Case 1b. . . . . . . . . . . . . 83

5.12 Smoke Flow Visualization Case 1c. . . . . . . . . . . . . . 83 
5.13 Smoke Flow Visualization Case $2 \ldots$. . . . . . . . . . . . . . 85

5.14 Smoke Flow Visualization Case 3 . . . . . . . . . . . . . . . 86

5.15 Smoke Flow Visualization Case 4 . . . . . . . . . . . . . . . . . 87

5.16 Smoke Flow Visualization Case 5 . . . . . . . . . . . . . . 88

5.17 Smoke Flow Visualization Case 6 . . . . . . . . . . . . . . . . . . 89

6.1 Crew Photo for the award winning AMELIA test team. . . . . . . 95 


\title{
Nomenclature
}

\author{
Acronyms \\ AMELIA Advanced Model for Extreme Lift and Improved Aeroacoustics \\ $B W B \quad$ Blended-Wing-Body \\ $C A D \quad$ Computer Aided Design \\ $C C \quad$ Circulation Control \\ CESTOL Cruise Efficient, Short Take-Off and Landing \\ CFD Computational Fluid Dynamics \\ FML NASA Ames Fluid Mechanics Lab \\ GTRI Georgia Tech Research Institute \\ $H B W B \quad$ Hybrid-Blended-Wing-Body \\ LEIB Leading Edge Inboard Circulation Control Plenum \\ LEOB Leading Edge Outboard Circulation Control Plenum \\ LaRC NASA Langley Research Center \\ NFAC National Full-Scale Aerodynamics Complex \\ NRA NASA Research Announcement \\ $R P M \quad$ Revolutions per Minute \\ $S A E \quad$ Society of Automotive Engineers \\ $S F W \quad$ Subsonic Fixed Wing \\ TEIB Trailing Edge Inboard Circulation Control Plenum \\ TEOB Trailing Edge Outboard Circulation Control Plenum \\ TPS Turbine Propulsion Simulator

\section{English Symbols}
$a$
Ellipse Semi-Major Axis
$b$
Ellipse Semi-Minor Axis 


$\begin{array}{ll}c & \text { Wing Chord Length } \\ C_{l} & \text { Lift Coefficient } \\ C_{\mu} & \text { Discharge Coefficient } \\ C_{T} & \text { TPS Thrust Coefficient } \\ h & \text { Local Height } \\ \dot{m} & \text { Mass Flow Rate } \\ q & \text { Dynamic Pressure } \\ S_{r e f} & \text { Wing Reference Area } \\ V & \text { Velocity } \\ w & \text { Jet Width }\end{array}$

\section{Greek Symbols}

$\begin{array}{ll}\alpha & \text { Angle of Attack } \\ \gamma & \text { Stagnation Point Angle } \\ \eta & \text { Non-Dimensional Semi-Span Location } \\ \rho & \text { Density }\end{array}$

\section{Subscripts}

$\begin{array}{ll}\infty & \text { Freestream Property } \\ j & \text { Circulation Control Jet Property } \\ L E & \text { Leading Edge Property } \\ r e f & \text { Reference Property } \\ \text { slot } & \text { Circulation Control Slot Property } \\ T E & \text { Trailing Edge Property }\end{array}$




\section{Chapter 1}

\section{Introduction}

\subsection{The Larger Body of Work}

During the summer of 2007 a collaborative research effort began when a NASA Research Announcement (NRA) was awarded to California Polytechnic State University, San Luis Obispo. The NRA was issued through NASA Aeronautic's Subsonic Fixed Wing (SFW) program, which focuses on conducting research to improve prediction methods and technologies that will produce subsonic aircraft designs that have less noise, fewer emissions, and higher performance for the next generation air transportation system. The next generation of passenger aircraft (technology readiness level of 4-6 by the year 2020, or $N+2$ ) will be operating in an arena that demands more capacity to transport passengers and cargo, while creating less environmental impact. One solution to this issue involves the use of small regional airports to service larger capacity aircraft which are currently limited to more centralized hubs. In order to achieve this without extending runways and impacting local communities, the next generation aircraft (with greater capacity) will need to be capable of short takeoff and landing while remaining 
efficient during cruise. Thus the NRA outlines the need for further research into Cruise Efficient Short Takeoff and Landing (CESTOL) aircraft designs that fit the $\mathrm{N}+2$ metrics provided in Table 1.1.

Table 1.1: NASA's Technology Goals for Future Subsonic Vehicles [1]

\begin{tabular}{|c|c|c|}
\hline Parameter & $\mathrm{N}+1=2015^{\dagger} \mathrm{N}+\mathbf{2}=\mathbf{2 0 2 0 ^ { \ddagger }}$ & $\mathrm{N}+3=2025$ \\
\hline Noise (Cum. below Stage 4) & $-42 \mathrm{~dB}$ & $-71 \mathrm{~dB}$ \\
\hline LTO $N O_{x}$ Emissions & $-75 \%$ & better than $-75 \%$ \\
\hline Performance: A/C Fuel Burn & $-50 \%$ & better than $-70 \%$ \\
\hline Performance: Field Length & $-50 \%$ & exploit metro-plex conc \\
\hline \multicolumn{3}{|c|}{$\ddagger$ Relative to a twin aisle reference configuration (TRL 4-6) } \\
\hline \multicolumn{3}{|c|}{$\S$ Concepts that enable optimal use of runways at multiple airports within the metropolitan area } \\
\hline \multicolumn{3}{|c|}{ To aid in achieving this goal, NASA issued this two-phase NRA. During the } \\
\hline \multicolumn{3}{|c|}{ first phase, Cal Poly would produce four conceptual designs for a 150 passenger, } \\
\hline \multicolumn{3}{|c|}{ regional, CESTOL airliner. Cal Poly would then select and refine one design } \\
\hline \multicolumn{3}{|c|}{ around which a large scale (greater than 8-ft span) wind tunnel model would } \\
\hline \multicolumn{3}{|c|}{ be manufactured and tested (Phase 2). The results of this effort would be } \\
\hline \multicolumn{3}{|c|}{ extensive open-source dataset of high fidelity, to be used for the validation of } \\
\hline \multicolumn{3}{|c|}{ predictive tools. In addition to the typical aerodynamic and performance data } \\
\hline \multicolumn{3}{|c|}{ generated in a wind tunnel test, the dataset would include acoustic measurements } \\
\hline
\end{tabular}




\subsection{Phase 1: Concept Design and Selection}

In the first year of the grant, four radically different conceptual designs were studied. Table 1.2 shows each concept with a few relevant configuration details. A thorough description of each concept is provided by Marshall (see Reference [4]), and thus will not be included herein.

Upon the conclusion of Phase 1, these designs were compared to find the most suitable concept for Phase 2 of the research. Configurations 2 and 3 were favored for their applicability to the 2020 time frame. At the time (2008), The Boeing Company was conducting research into a similar Blended-Wing-Body design through a competing NRA[5]. In order to broaden the research foundation for $\mathrm{N}+2$ concepts, configuration 2-the Hybrid-Blended-Wing-Body-was selected. 


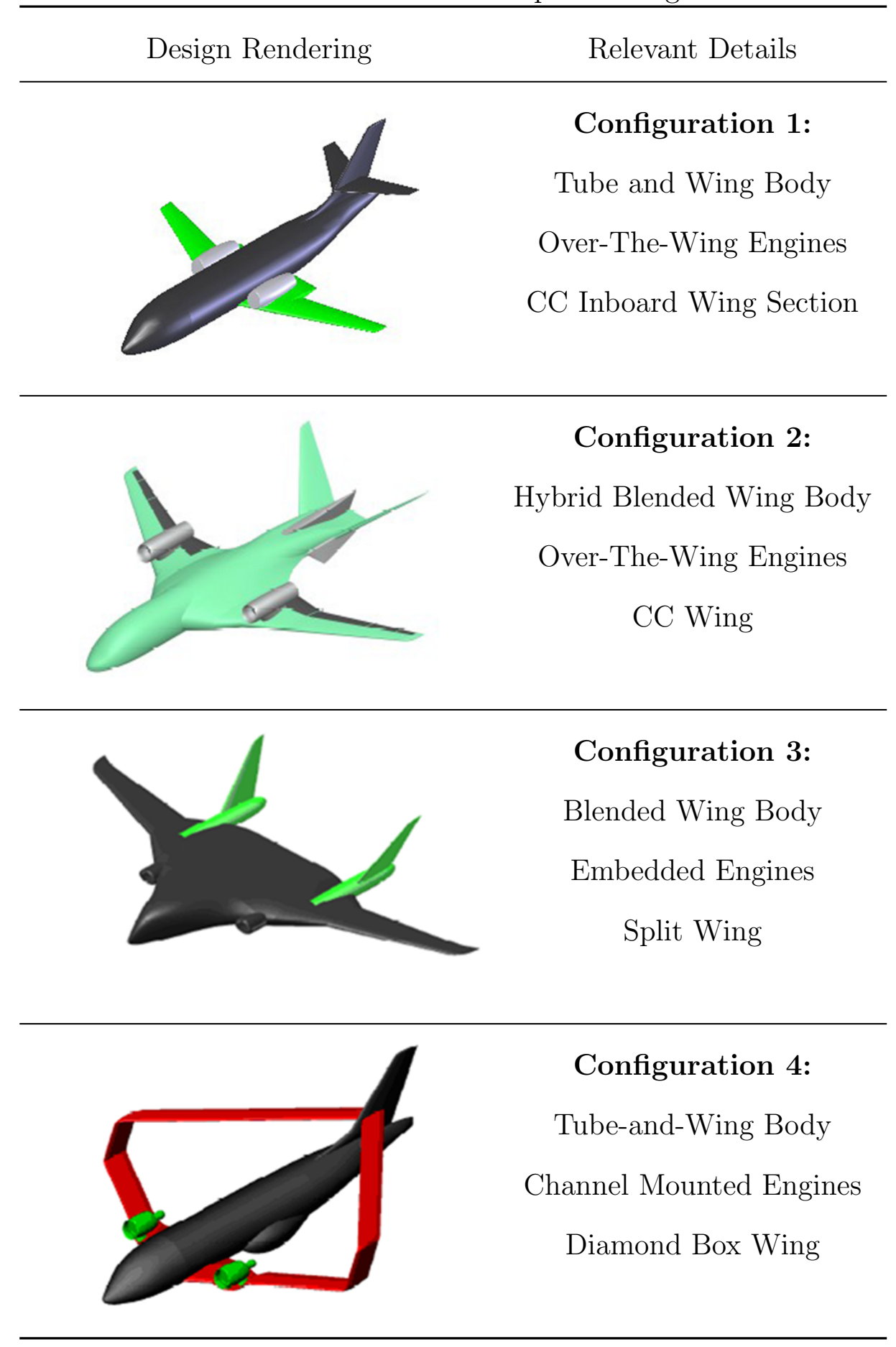




\subsection{The AMELIA Configuration}

The hybrid blended wing body configuration provided a basis for the Phase 2 effort, and thus it should be thoroughly understood by the reader. This section provides some explanation of the concept such that the reader can fully understand the motivation behind the wind tunnel effort.

The selected concept utilizes a hybrid-blended-wing-body (HBWB) with a 110-ft span. The HBWB reduces parasitic wetted area, which could potentially improve cruise performance. It also serves to provide a comfortable transition to the full BWB aircraft of the future, without many of the associated concerns (passenger egress, stability and control, cargo/passenger layout). The HBWB has a leading edge wing sweep of $55^{\circ}$ that transitions sharply at the quarter-span to $34^{\circ}$. The wing's thickness-to-chord ratio at the root is 0.185 and at the tip is 0.134 , while the mean aerodynamic chord is 22 -ft 7 -in. The aircraft's reference area of $1912-\mathrm{ft}^{2}$ is defined as a projected wing planform area bridging the fuselage at the wing root.

The 150-passenger concept achieves STOL through high lift generation using circulation control(CC). This technology involves the ejection of high momentum air over the upper surface of the flap from plenums residing in the flap/wing intersection. With this additional momentum near the trailing edge, a leading edge device is typically needed to counteract separation of the upper surface flow. The selected concept uses a second slot at the leading edge to actively blow the upper surface. Although the slots are incredibly narrow, the flow control system places high demands on the aircraft for auxiliary air. The concept leaves the source of air open-ended, as a strong case can be made for using either engine bleed air or dedicated compressors[4]. 
The benefits of the concept's over-the-wing mounted engines are two-fold. During takeoff the engine exhaust will be entrained by the circulation control flow, the downward deflection of the additional momentum will result in greater lift[6]. There is also an acoustic benefit to mounting the engines above the wings, as the wing itself provides noise shielding to the community below[7]. This feature of the engine location aids in achieving the noise reduction metrics required by $\mathrm{N}+2$.

The selected configuration couples advanced systems to make the CESTOL and $\mathrm{N}+2$ definitions achievable. As research transitioned from Phase 1 to Phase 2 the selected configuration was renamed the Advanced Model for Extreme Lift and Improved Aeroacoustics (AMELIA). A CAD rendering of the final conceptual design is provided in Figure 1.1.

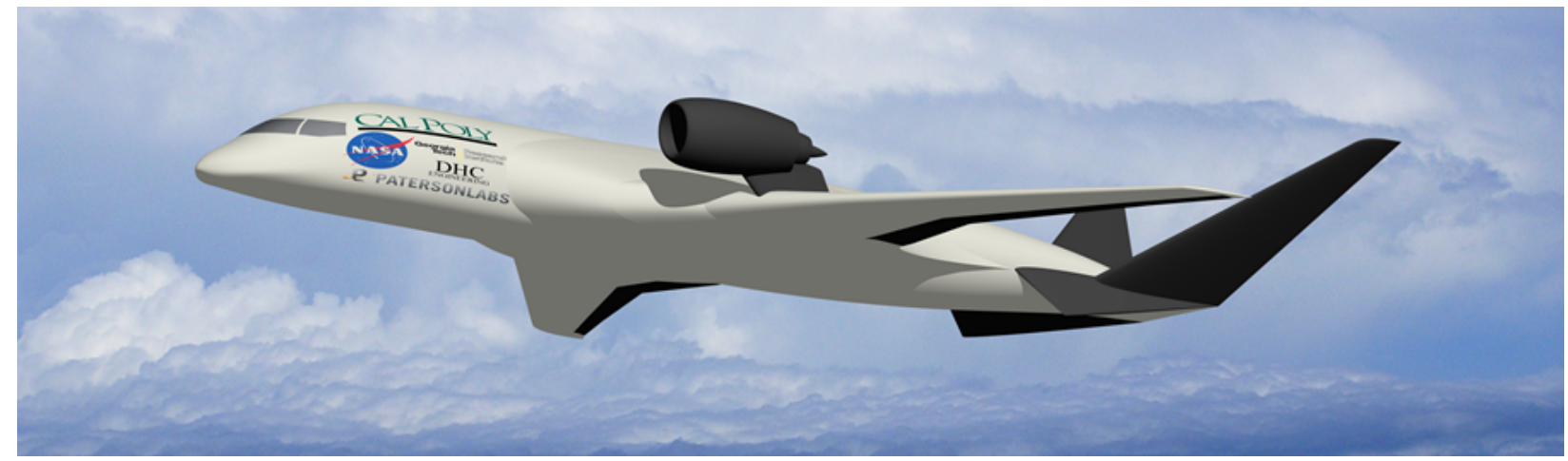

Figure 1.1: CAD Rendering of the AMELIA CESTOL Concept.

\subsection{AMELIA-The Wind Tunnel Model}

After considerable research and guidance from our collaborators (NASA, and Georgia Tech Research Institute), Cal Poly entered into a contract with PatersonLabs, Inc. to design and manufacture a wind tunnel model based on the 
AMELIA concept. AMELIA became a full span model with a wingspan of $10-\mathrm{ft}$ in order to comply with the NRA requirements. To minimize adverse flow affects on the aft end, it was determined that the model's internal balance would be sting mounted via a streamlined offset. The wind tunnel model's circulation control system would be supplied with air from the tunnel facility, but would otherwise operate in the same manner as the concept. In order to capture potential coupling between the propulsion system and the circulation control system, much consideration was spent determining the most accurate method of simulating the turbofan engines. Turbine propulsion simulators (or TPS units) were selected over injectors and flow-through nacelles for their ability to most accurately represent flow fields at the inlet and exit of the engine. The air supplied to each TPS unit would also need to be fed into the model from the facility. The multiple systems required to accurately represent the concept greatly effected the complexity of the wind tunnel model and the risk involved in its testing. The AMELIA CAD assembly is presented in Figure 1.2 along with a list of relevant model dimensions (Table 1.3). For further discussion of the wind tunnel model design decisions the reader is referred to Reference [8].

\begin{tabular}{cc} 
Table 1.3: General wing dimensio & \multicolumn{2}{c}{ Parameter } & Value \\
\hline Wing span & $10 \mathrm{ft}$ \\
Wing area, $S_{\text {ref }}$ & $15.8 \mathrm{ft}^{2}$ \\
Aspect ratio & 6.33 \\
MAC & $22.4 \mathrm{in}$ \\
Taper ratio & 0.174 \\
Tip chord & $5.7 \mathrm{in}$ \\
Root chord & $32.7 \mathrm{in}$ \\
\hline
\end{tabular}

PatersonLabs spent nearly 18 months turning a rough CAD model into a stainless steel and aluminum masterpiece. Stainless steel was used in critical areas 


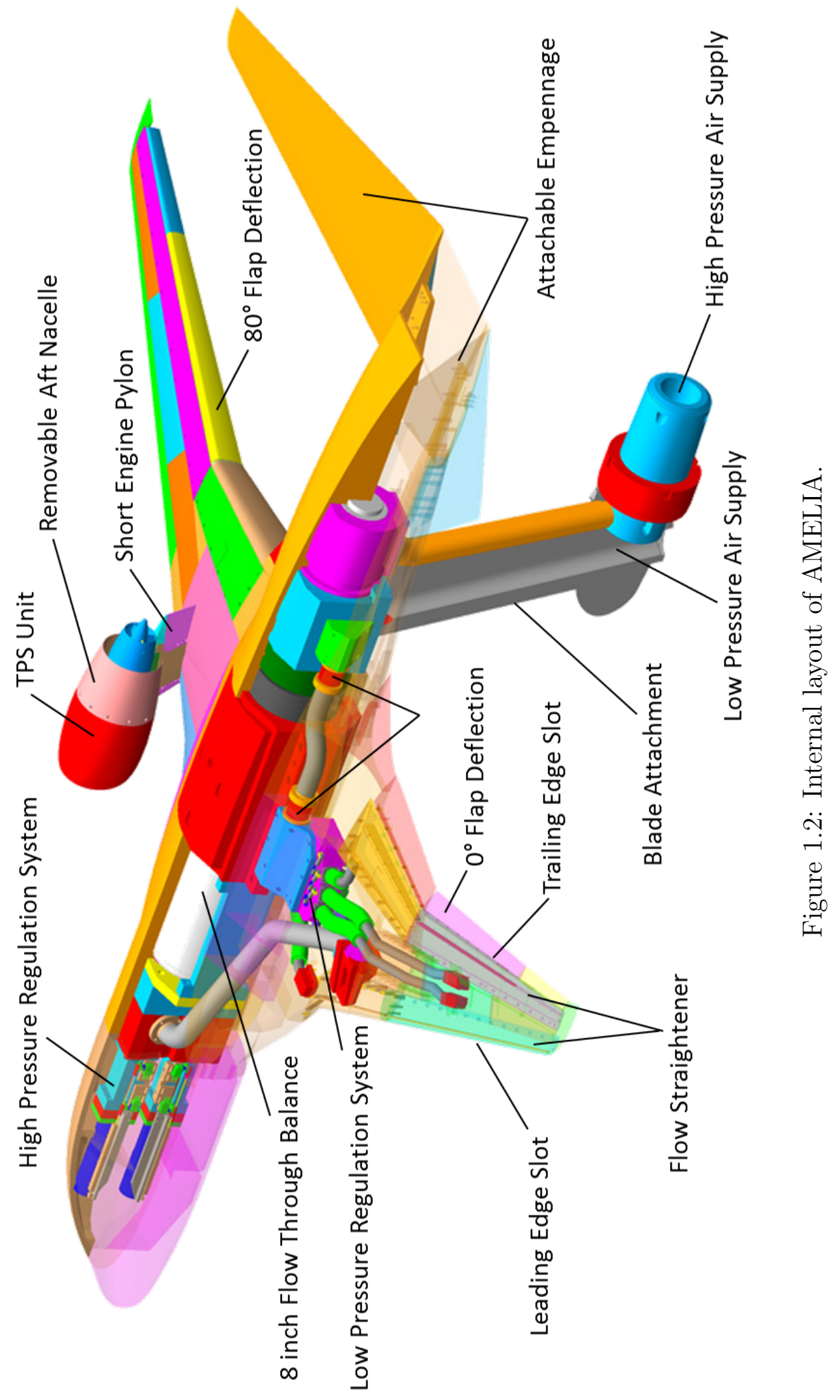


(near slots and plenums) and aluminum was used for many of the larger body panels. For simplicity and cost, flaps of fixed angles $\left(0^{\circ}, 30^{\circ}, 60^{\circ}\right.$, and $\left.80^{\circ}\right)$ were manufactured and attached to the model using socket head cap screws, which were the primary fasteners throughout the model. Although the concept's v-tail and strakes were manufactured, they were seldom used as all of the wind tunnel testing was done with a "clean" aft end. The model's forces and moments were measured on a massive flow-through balance-Triumph Aerospace's MC-130 air balance[9]. Except for the airframe itself, the majority of components shown in Figure 1.2 can be categorized into supporting one of the following two primary systems: the low pressure (circulation control) or high pressure (propulsion simulation). These two systems are described in the following sections.

\subsubsection{The High Pressure System}

The high pressure system (shown in Figure 1.3) is in place to provide a controlled flow of air to AMELIA's two TPS units. The engine simulators, on loan from NASA Langley Research Center, are Tech Development Inc.(TDI) model441 turbine propulsion simulators. Two simulators were required for the testing, however a third was acquired to function as a replacement in the case of a failure during operation. Manufactured in 1966, these units have been used in many previous tests and each required refurbishing and calibration ${ }^{1}$. Refurbishment of the units was completed by TDI, while the calibration was conducted by GTRI. During the calibration, one unit (serial number 1) suffered a slight mechanical failure preventing that unit's complete calibration. It was determined that serial number 1 would be selected for stand-by use only and could be calibrated post test if needed. The calibration included both aerodynamic and acoustic datasets

\footnotetext{
${ }^{1}$ Correspondence with TDI Oct. 2009 'Checkout run of Model 441 Simulators'.
} 
for the two remaining units with their nacelles and pylons installed[10].

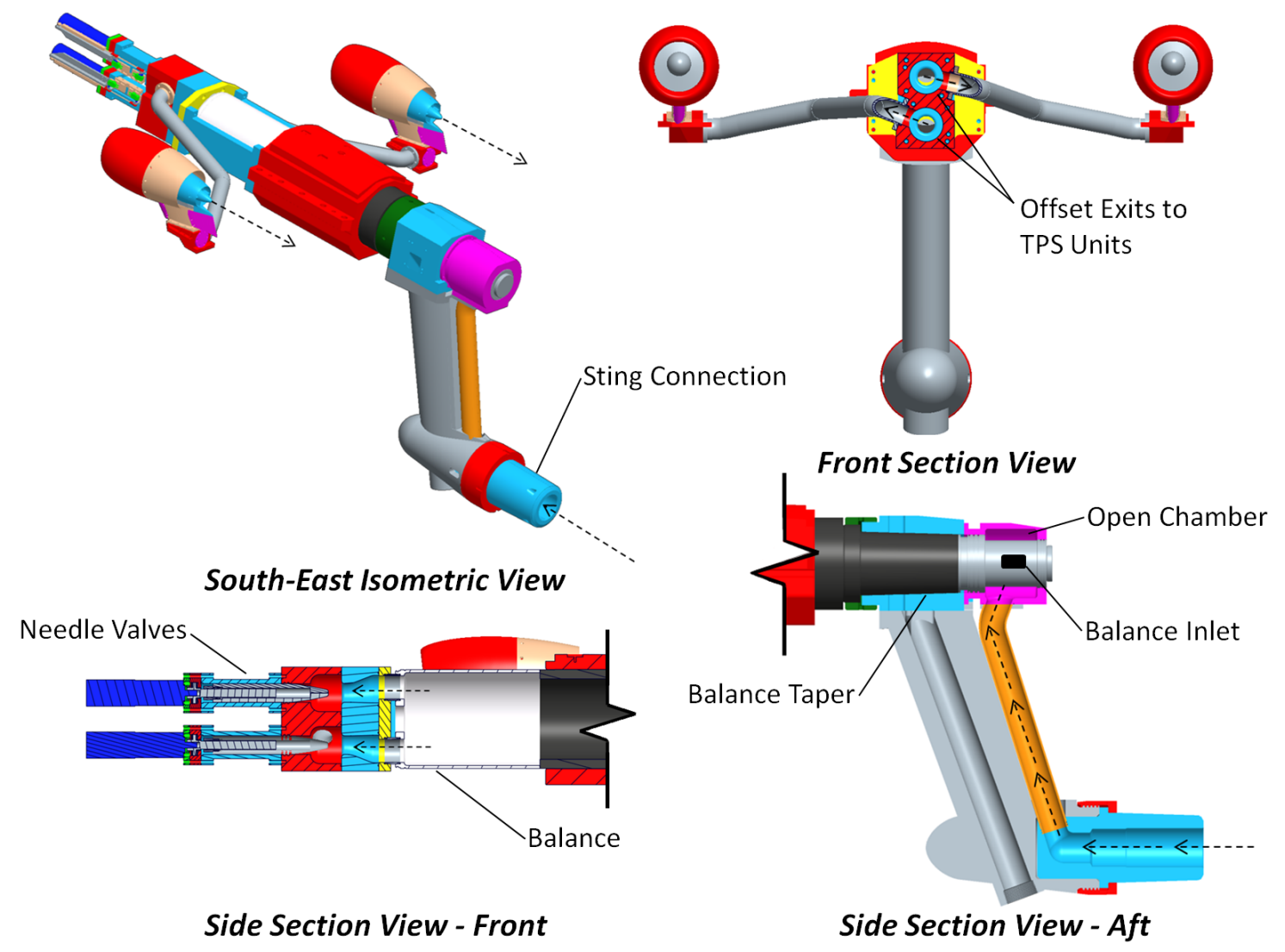

Figure 1.3: High Pressure System of AMELIA.

The high pressure air system was designed to deliver as much as $2.10 \frac{\mathrm{lb} m}{\mathrm{~s}}$ of heated and dry air at 425 psig to each of the TPS units. Air enters the model through a single inlet at the sting support/model interface located on the tunnel's centerline. The flow traverses up the 2 -ft offset to the model centerline where it enters an open chamber that feeds into the air balance. At the metric end of the balance (shown in 1.3 as Side Section View - Front) the flow exits via two passages. Each passage (shown in blue in the figure) leads to a small plenum (shown in red), where a needle valve resides. A linear actuator moves the needle valve forward and into the orifice feeding the plenum. The tapered plug provides a low resolution method of controlling the mass flow rate of air supplied to each 
TPS unit and thus control of each unit's RPM. From the needle valves, the flow exits the plenum and passes through a series of elbows before it finally enters the stainless steel pylon at the base of each unit.

\subsubsection{The Low Pressure System}

The low pressure system exists to support AMELIA's circulation control wings and is shown in Figure 1.4. The system was designed to deliver as much as 2.80 $\frac{l b_{m}}{s}$ of heated air at 150 psig to AMELIA's circulation control plenum network(see Table 1.4 for plenum designations). Connection to the tunnel air supply occurs at the base of the offset - on the underside of the sting. Once the air reaches the top of the offset it encounters a wye that divides the flow into the left and right wings. Unlike the high pressure system, the low pressure system does not pass through the balance, and thus requires its own force and moment isolation. In order to reduce momentum effects and isolate forces to the balance, each flow path includes two welded Inconel alloy bellows with flange connections separated by two opposing turns[9]. Upon exiting the second bellow, the flow enters the distribution plenum-a single-inlet manifold with four exits. The manifold has a small chamber for pressure recovery and flow settling. A butterfly valve resides in each of the four plenum exits and controls the flow as it travels out to the circulation control plenums.

Like the plenums themselves, the pathway leading to each plenum varies in geometry. The close proximity of the inboard plenums provides a short route from the distribution plenum, however both include a $90^{\circ}$ turn with small radius

of curvature. Furthermore, in the case of the LEIB plenum, an out-of-plane turn provides the transition leading into the circulation control plenum. Each 


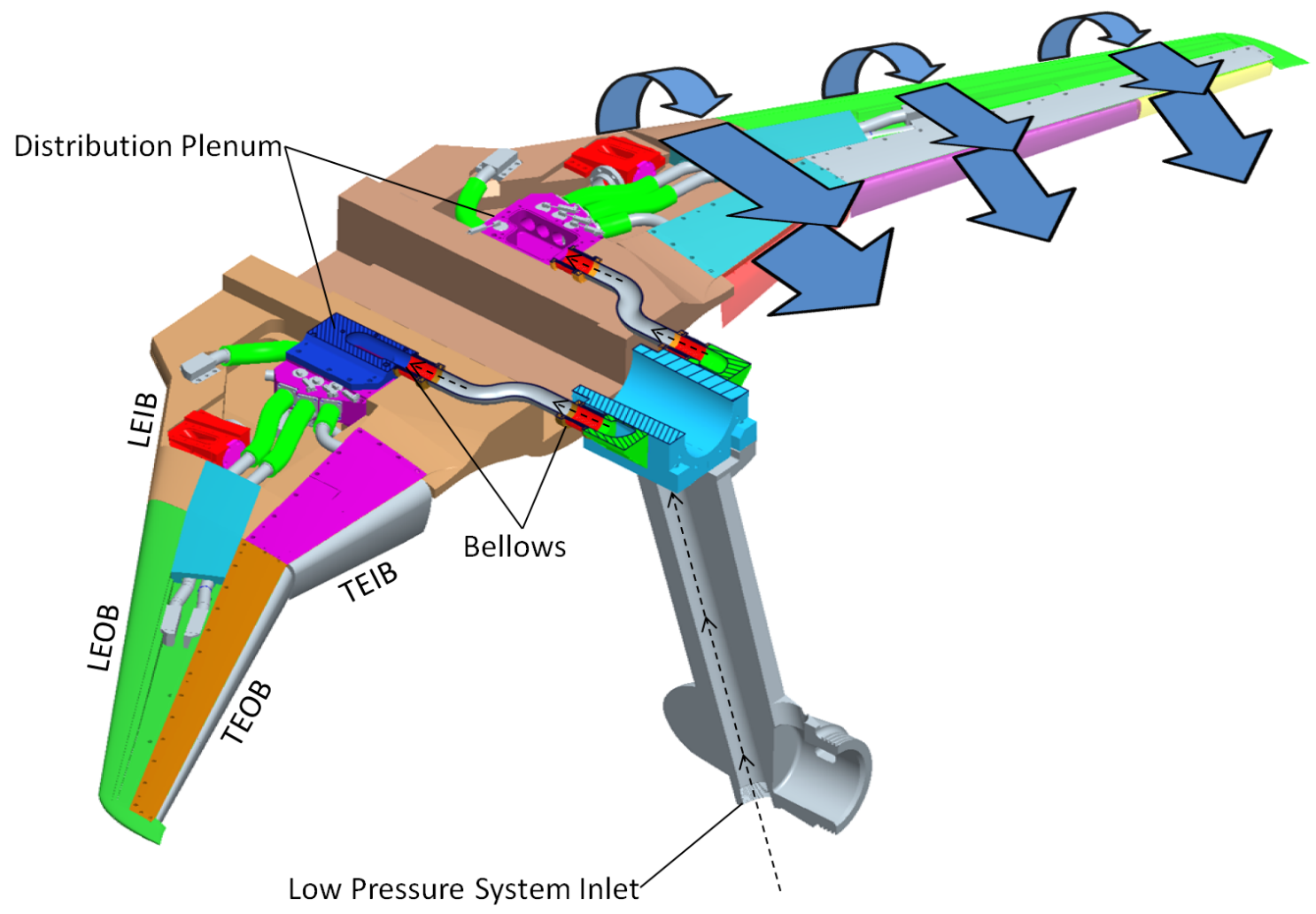

South-East Isometric View

Figure 1.4: AMELIA's Low Pressure Air Supply.

inboard plenum is supplied from the inboard side, which-despite the plenum's short length and ample volume-has potential to create flow nonuniformity. The outboard plenums share similar supply geometry, in that both are a "straight shot" from the distribution plenum and include a sharp $90^{\circ}$ turn just prior to the circulation control plenums. The inlet to each outboard plenum is located approximately midway along its length. Although inlet placement is ideal for these plenums, each plenum is roughly 31-in long and contain little volume for flow settling. 
Table 1.4: Plenum Designations

\begin{tabular}{cc}
\hline Designation & Plenum \\
\hline LEIB & Leading Edge In-Board Plenum \\
LEOB & Leading Edge Out-Board Plenum \\
TEIB & Trailing Edge In-Board Plenum \\
TEOB & Trailing Edge Out-Board Plenum \\
\hline
\end{tabular}

\subsection{Objective}

This thesis focuses on the performance of AMELIA's circulation control system. An unanticipated and appreciable effort was expended to bring the system to its final and ideal state. The previous discussion has been a quick look into the goals of the project, the concept aircraft and the systems onboard the wind tunnel model. The following will be a in-depth look at the circulation control system design, modification, and performance along with an explanation of the many ways this information can be utilized. Throughout this thesis details are provided to allow better accuracy in a computational prediction. Although aerodynamic and performance results are thoroughly reviewed in Reference [11], the final chapter of this thesis provides many flow visualization results captured during the wind tunnel test that serve as an additional medium of comparison. 


\section{Chapter 2}

\section{Circulation Control System Design}

\subsection{Previous Circulation Control Research}

The Coanda effect-an integral component of circulation control flow-was inadvertently discovered around 1910 by a Romanian named Henri Coanda. Using curved metal plates, Coanda was attempting to deflect engine exhaust away from the wooden wings of his aircraft, when he discovered the flow adhered to the surface rather than deflect $[12,13]$. It's this property-flow adhering to a curved surface-that enables the augmentation (or control) of the circulation around an airfoil. Contemporary circulation control technology utilizes the Coanda effect to manipulate the rear stagnation point of the airfoil.

The principle behind circulation control can be conceptualized by applying potential flow theory to an elliptical airfoil. The rounded trailing edge provides no Kutta condition, thus the rear stagnation point is solely a function of the 
boundary layer. With knowledge of the rear stagnation point location and the angle of attack, the lift coefficient can be calculated from Equation 2.1.1, which follows the notation provided in Figure 2.1 and assumes $\gamma$ is small[12]. Also shown in Figure 2.1 are the computed streamlines for a research model depicting the typical flowfield effect of a circulation control airfoil[14].
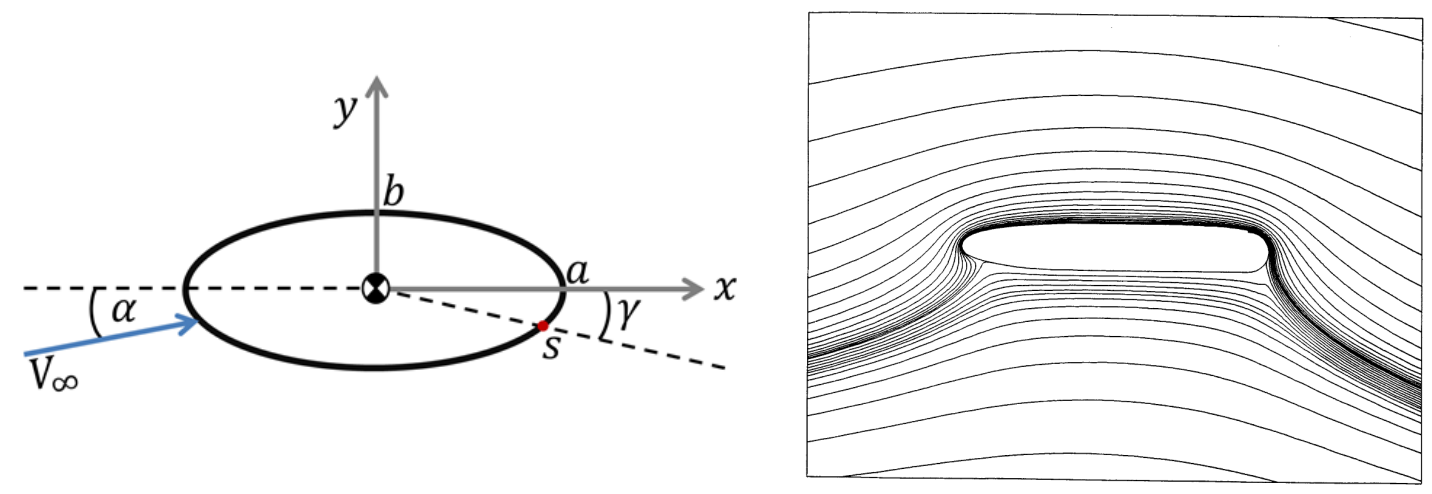

Figure 2.1: Elliptical Airfoil Notation \& Characteristic CC Flowfield.

$$
c_{\ell}=2 \pi\left(1+\frac{b}{a}\right)\left(\frac{a}{b} \gamma+\alpha\right)
$$

For an ellipse with 15\% thickness at zero angle of attack, Wood and Nielsen have shown that moving the rear separation point to the lower surface by only $2 \%$ of the chord will produce a lift coefficient of 2[12]. The adjustment of the separation point creates effective camber on the symmetric airfoil, allowing it to create lift at zero angle of attack. Although this increase in lift coefficient was found using potential flow theory, similar results were obtained in experimental efforts[15]. In application, circulation control involves moving the rear stagnation point using additional momentum or blowing. A slot near the aft section of the airfoil emits pressurized air in the form of a sheet-the greater the momentum of the sheet of air, the greater the effect on the stagnation point and surrounding flowfield. 
The elliptical airfoil geometry has provided a fascinating and extensive foundation for circulation control research, and while some scientists prefer to delve deeper into the details surrounding this configuration, others have moved on to develop a wide variety of applications for circulation control technology. Some of the more interesting applications include a $\mathrm{CC}$ helicopter rotor, an X-Wing aircraft with CC wings, a CC heat exchanger for a Formula 1 car, and a heavy vehicle (semi-truck) with $\mathrm{CC}$ drag reduction modifications[16]. In addition to these applications, the performance benefits of incorporating circulation control onto flight vehicles has been proven via flight tests onboard a J-52-P8Aa and BD$4[17,18,19,20,21,22,23]$. Ground tests have also shown the STOL capability of a circulation control modification to NASA's Quiet Short-Haul Research Aircraft (QSRA) [24]-although the modification was somewhat crude. For further information on past circulation control research efforts the reader is encouraged to turn to the excellent collection of papers found in Reference [17] and Reference $[25]$.

After reviewing past research it was apparent that a properly designed plenum and nozzle is integral to the effective application of circulation control. Therefore much time and effort was expended in identifying and mitigating possible design issues relying heavily on knowledge gained from the research cited above.

\subsection{Design Considerations}

The resurgence of interest in circulation control applied to fixed wing aircraft has largely taken place due to the steady progress of Englar(GTRI) and Jones(NASA LaRC). Englar, who served as Cal Poly's collaborator at GTRI, had several recommendations when it came to designing the circulation con- 
trol system onboard AMELIA. One aspect Englar helped to incorporate on the AMELIA design was the dual radius flap. The dual radius flap allows designers to abandon the bluff trailing edge of the previous generation of CC airfoils-perhaps the most important development in the successful application of CC to transonic fixed wing aircraft. In principal the dual radius flap enables the preservation of plenum geometry while simultaneously permitting exterior flap deflections. The cross section of a circulation control wing using a dual radius plain flap can be seen in Figure 2.2 [3]. It was determined that AMELIA would employ a simplified version of the dual radius flap shown in the figure, for which flap deflection would be fixed.

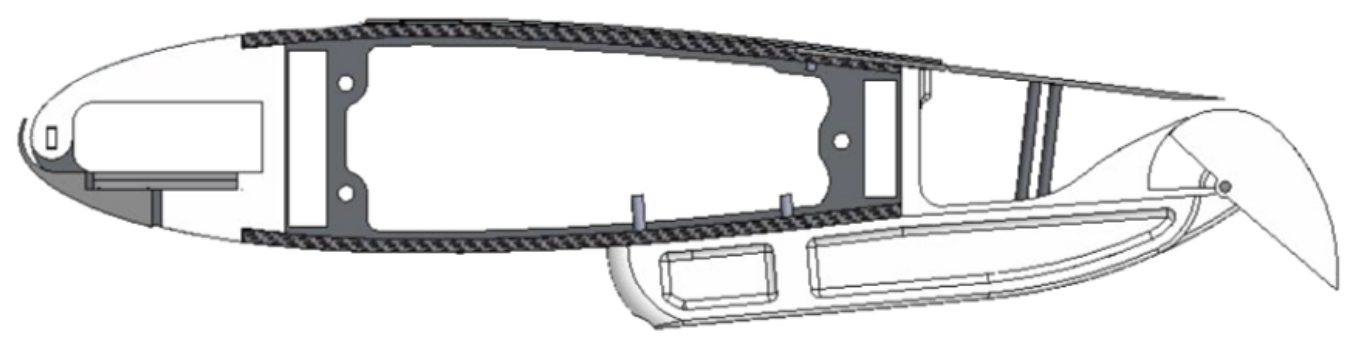

Figure 2.2: Cross section of a circulation control wing using a dual radius flap [3].

The fixed flap design reduced the overall complexity of the wind tunnel model, however introduced a new concern. A continuous jet expansion surface was desired that would allow the boundary layer to grow from the plenum inlet, throughout the slot, and onto the Coanda surface. In order to achieve a continuous surface, each flap would need to extend into the plenum where it would attach near the beginning of the converging section of the nozzle. This design, although ideal with respect to the flow quality, proved problematic in that the slot height (a critical value in the determination of the discharge coefficient and flap performance) would need to be remeasured after each flap change. Alternatively, the flap could be manufactured to attach outside of the circulation control plenum, however any 
discontinuity in the surface at the junction between the plenum and flap would need to be minimized during manufacturing or smoothed during model build-up.

Other significant design considerations included the resistance of the plenum structure in expansion under the force of pressurization and local temperature gradients. Maintaining the desired slot height throughout the wind tunnel test was a top priority, as an expansion of only a few thousandths of an inch could be a large increase relative to the nominal slot height, which would increase the uncertainty in the calculation of the discharge coefficient, $\mathrm{C}_{\mu}$. Two methods were considered to maintain the desired slot height. The first used a pair of setscrews and tie-downs placed at close intervals along the length of the plenum. This method would allow the restricting structural device to be placed within the plenum at a distance (from the exit) sufficient to minimize flow effects. It would also allow for local slot height adjustability, permitting precision control on-the-fly (including when the system is under pressure). The set-screw/tie-down method had prior success in wind tunnel tests executed by many engineers including Englar and Cattafesta [3, 26, 17, 27]. The second method fixed slot height through rigid supports within the plenum at intervals along the span of the slot. These thin supports would originate in the open chamber of the plenum and extend throughout the nozzle into the slot-making this support system much longer in the flow-wise direction [28]. Although this method would sacrifice the ability to easily adjust the slot height, it would allow the supports to double as flow-straightening vanes. This second method did not have the proven history of the set-screw/tie-down method, but was being designed concurrently on NASA Langley's FAST-MAC model(shown as the "standoffs" in Figure 2.3). The primary concerns with this method of support was lack of adjustability on-the-fly, and lack of applications in previous tests with similar models. 


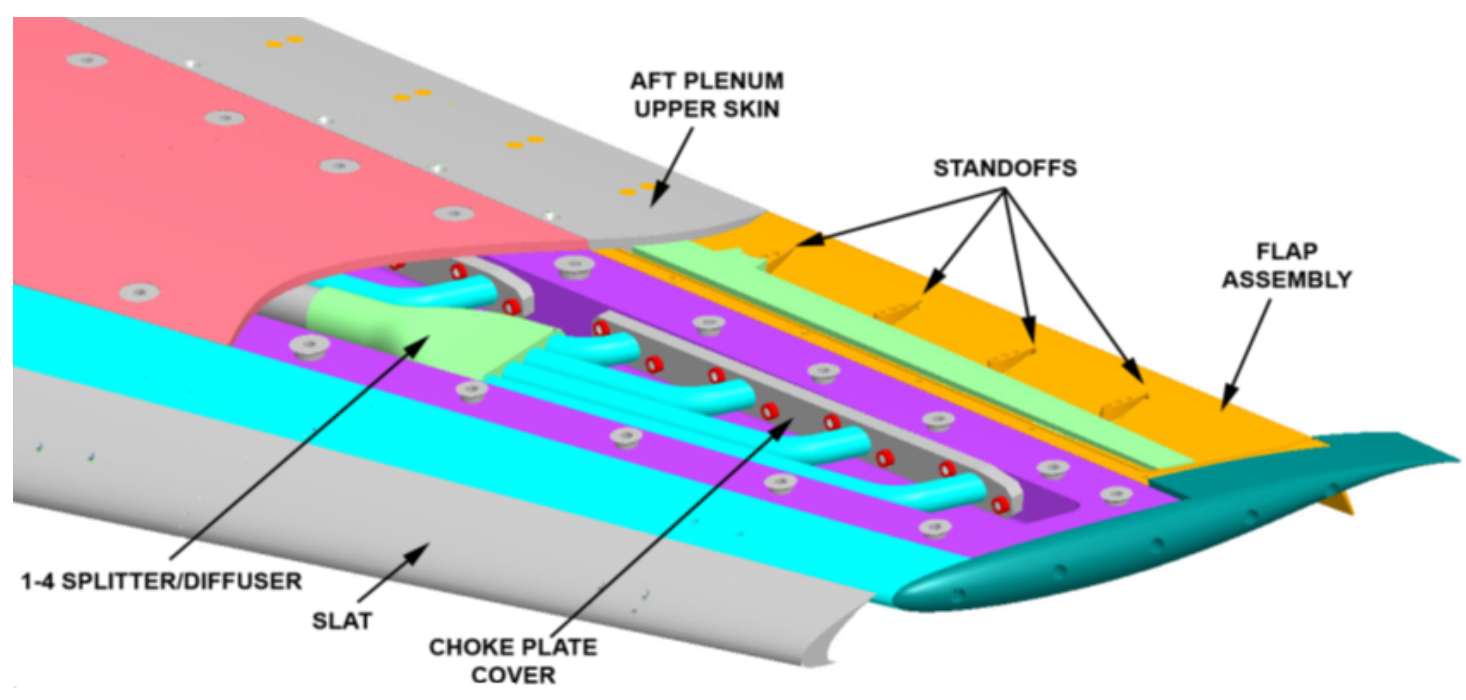

Figure 2.3: The Internals of the FAST-MAC wind tunnel model, with multiple plenum supply locations and choke plates [28].

Minimizing discontinuity in the slots caused by the boundaries of the plenums was a high priority in terms of providing clean circulation control flow across the upper surface of the wing and flaps. In order to achieve this, many plenum layouts were considered, including designs that used a single plenum supplied via multiple inlets (as used on the FAST-MAC shown in Figure 2.3). Another design utilized two plenums at the leading edge and trailing edge and included a passage for transmission of air between inboard and outboard chambers. A third design separated the wing into four independent plenums where the mass flow rate of air supplied to each could be controlled. In this layout the separating structure, would taper as it approached the slot face in order to minimize unblown regions.

\subsubsection{Flow Conditioning}

Despite thorough research and the counsel of the circulation control experts on the design of the system, there could be no certainty that the circulation control system onboard AMELIA would perform as desired. Given the many conflicting 
constraints (i.e. wing structure v.s. plenum volume v.s. space for instrumentation), limited volume within the wing could be allotted to each plenum-this is problematic, as each slot needs to be supplied from an "infinite reservoir" in order to create uniform conditions across the length of the slot. Understandably, this is an issue that occurs frequently on circulation control wind tunnel models and would presumably also occur in a full size aircraft. Typically this problem is dealt with in one of two ways: by carefully designing a manifold to supply equal outlet conditions to the plenums at numerous locations [29], or by using a flow restriction device within the plenum itself (interestingly the FAST-MAC model in 2.3 uses both). Due to the instrumentation requirements within AMELIA, it was determined that-should flow uniformity be an issue-a flow restriction device would be employed.

Many past experiments found success in creating uniform flow by inserting porous, orifice, or choke plates within the plenum. These devices would restrict flow enough to simulate an "infinite reservoir" creating constant pressure conditions throughout the length of the plenum. Although their proven history in this application was appealing, many of the consulting experts worried that these treatments would resonate at frequencies similar to the circulation controls slots. Unable to distinguish slot noise from plenum treatment noise, the acoustic dataset would be severely reduced-leaving only data of peripheral interest.

Metal foam-a relatively new material-was also considered as a flow conditioning device. Although the material did not have a proven history, the manufacturer (ERG Aerospace Corporation) advertised its ability to restrict flow, and acousticians advising on the test preferred the flow travel through the foam rather than the plates mentioned previously. The foam is created from, "a three-dimensional, perfectly packed array of similar sized bubbles... Once the foam has solidified the 
thin membrane of each [bubble] is removed, creating an 'open cell', leaving only the thick outer perimeters behind" [30]. The resulting structure is a network of open and interconnected cells that enable fluids to pass into and out of the foam. It was suspected that an appropriately dense layer of this material would serve the flow conditioning needs of the model, without confounding the acoustic data.

\subsection{System Design}

The final design of the circulation control system onboard AMELIA is presented in Figure 2.4. Illustrated by the figure is a nominal cross section of the wing showing both the full airfoil and the details at the fore and aft end. Further details are presented in Table 2.1. The design decisions were made based on input from the experts, past circulation control research, and input from the model manufacturer.

The dual-radius flap is fastened to the model's trailing edge and has been machined to provide an acceptably smooth transition from the nozzle to the flap surface. The set-screw/tie-down system was employed to resist pressurization effects on the slot height. The thin portion of the aft plenum cover also assists in the adjustment of slot height by acting as a flexure. Grooves were machined into the upper and lower surfaces of all plenums to provide a rigid location for the mounting of a flow conditioning device. Should a flow conditioning device be required, two porosities of the metal foam product from ERG Aerospace Corporation were manufactured to fit perfectly within the grooves.

The slot height to chord ratios shown in Table 2.1 were determined via analysis conducted by Mark Waters (a faculty member of the Cal Poly Aerospace Department who was subcontracted for this purpose). The leading edge slot 

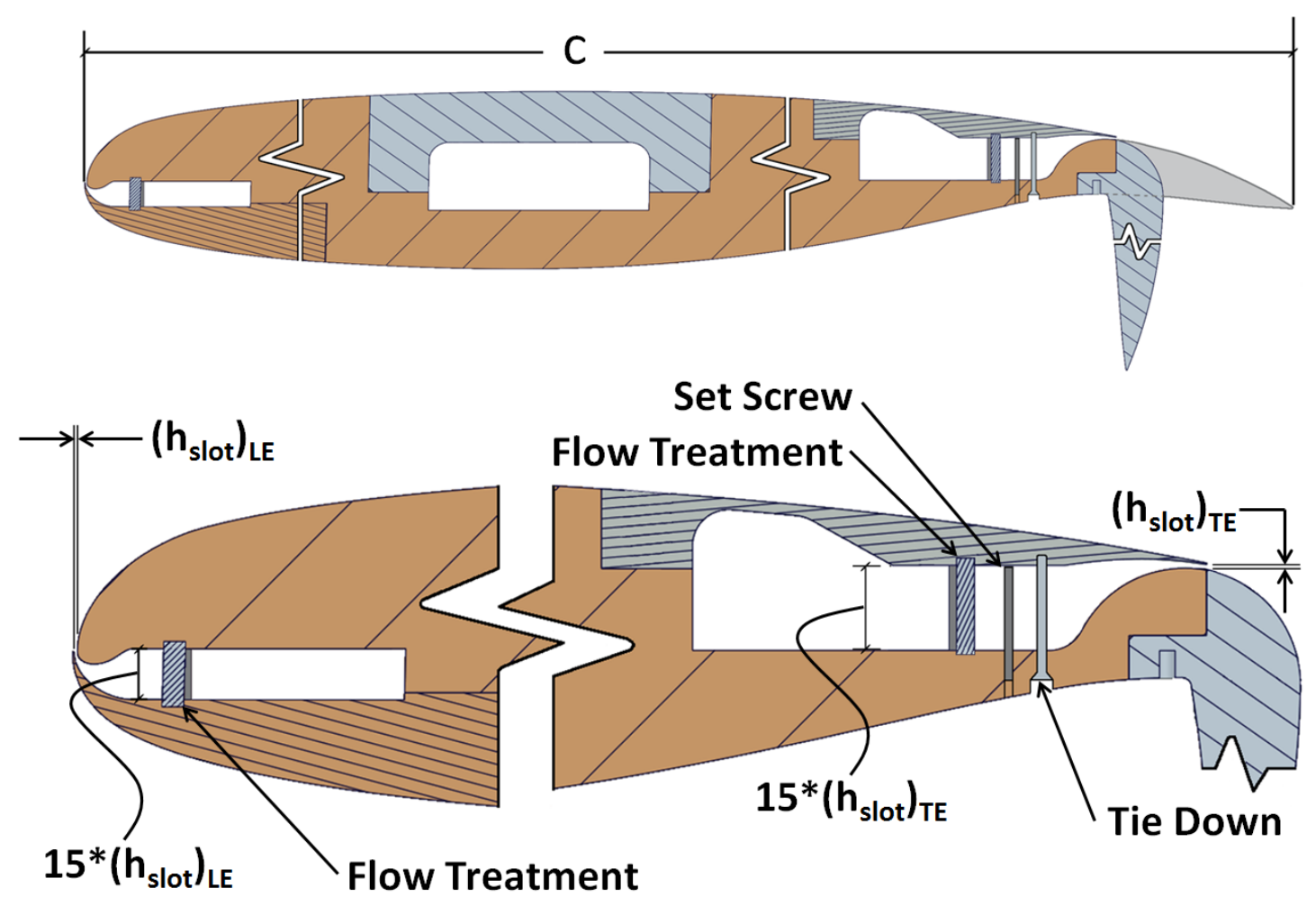

Figure 2.4: Detailed view of the circulation control plenums.

Table 2.1: Leading and trailing edge plenum design details

\begin{tabular}{ccc}
\hline \hline Parameter & Leading Edge & Trailing Edge \\
\hline$h_{\text {slot }} /$ c Ratio & $0.001428^{*}$ & 0.00238 \\
Contraction Ratio & $15: 1$ & $15: 1$ \\
Minimum Lip Thickness & $0.01 "$ & $0.01 "$ \\
\hline
\end{tabular}

deviates from the design ratio due to a manufacturing limit. This limit occurs when the chord is approximately 8-in and the slot height is reduced to only 0.012 in. From this location to the end of the slot the slot height remains a constant 0.012-in. A generous contraction ratio of 15:1 aides in creating a near stagnant condition within each plenum. At both the leading and trailing edge the lip creating the outer wall terminates with an appropriate internal angle to produce a converging nozzle. The lip itself was chosen to be squared off with a thickness 
of 0.01-in in order for accurate representation in CAD and CFD software. Lastly, each circulation control plenum cover uses an o-ring seal.

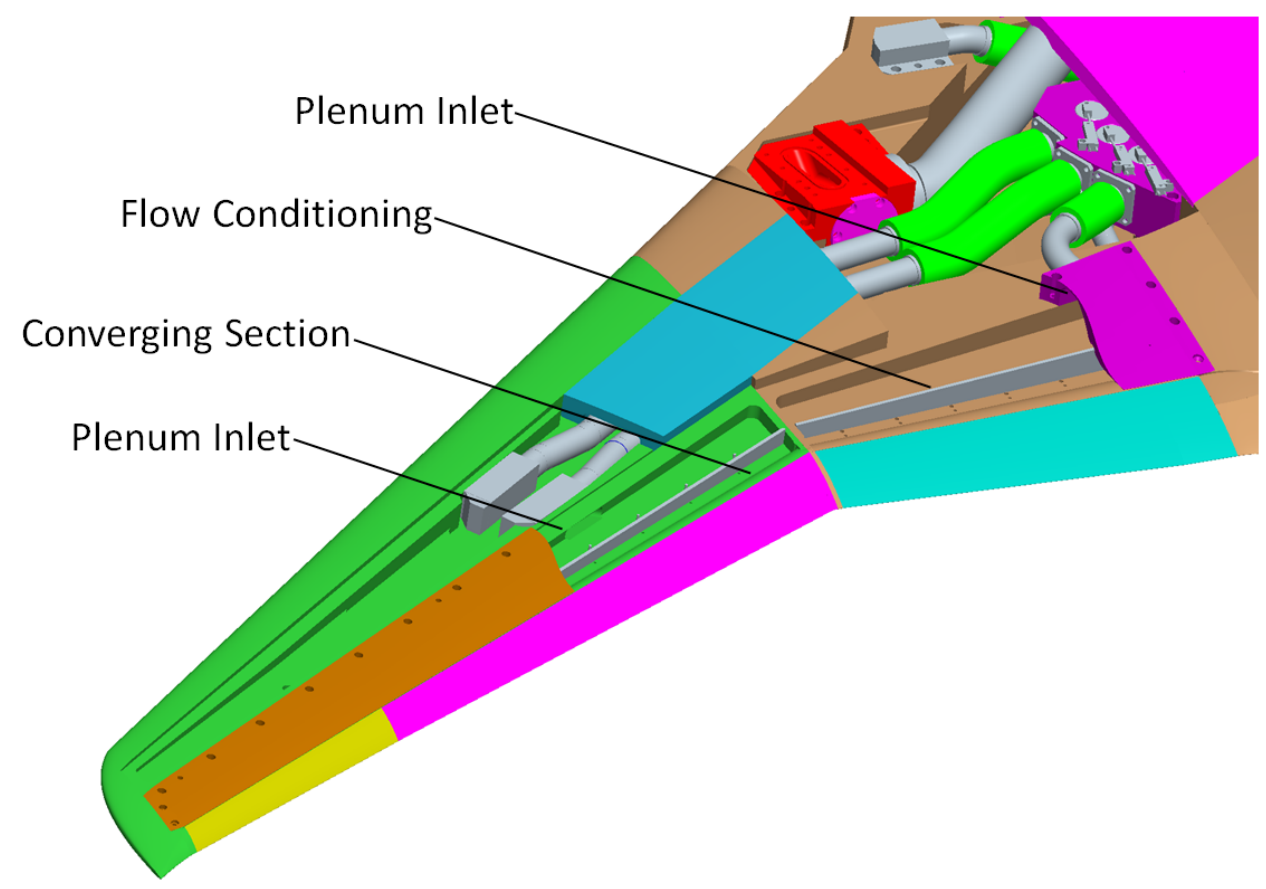

Figure 2.5: Circulation control supply system inside the AMELIA model, each plenum supplied by a single source.

As briefly covered in Section 1.4.2, the circulation control system onboard AMELIA uses four plenums in each wing. The two leading edge plenums are accessed from the model's lower surface, while the plenums supplying the trailing edge are accessed via the upper surface. Each plenum is supplied via a single inlet. A rendering of the system at the trailing edge is provided in Figure 2.5notice the intersection of the inboard and outboard plenums which occurs at the break in the wing planform. The intersection and additional material required for the fastening of the plenum covers creates a small unblown region which also occurs at the leading edge (again at the break in the wing planform). Although these regions could not be eliminated, they were minimized as much as possible. The unblown region is shown in more detail in Figure 2.6. 


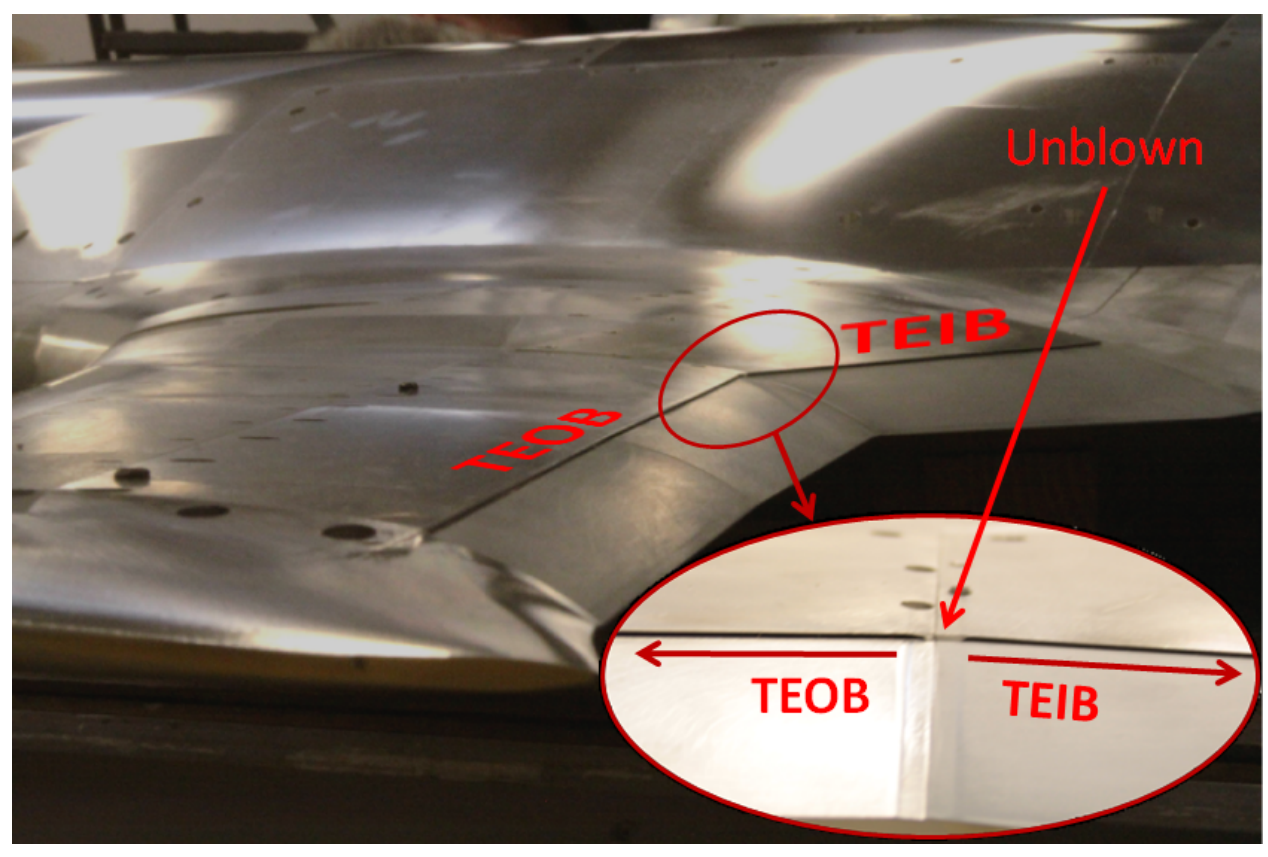

Figure 2.6: The trailing edge slot of AMELIA's left wing with zero degree flap.

The information presented in the above section described the design parameters used in the manufacturing of AMELIA and for most analysis prior to the execution of the wind tunnel test(i.e. CFD predictions conducted by Cal Poly). During the characterization of the circulation control system, adjustments were made to the model's slot height and plenum system in an effort to achieve these design parameters. The results of that effort are presented in the following chapters. 


\section{Chapter 3}

\section{Flow Uniformity Calibration}

\subsection{Background}

In the spring of 2011 PatersonLabs delivered the wind tunnel model to Cal Poly. After a few weeks of familiarization with the systems and parts of the model, the Cal Poly research team began a preliminary (benchtop) circulation control plenum checkout. There were significant limitations on the amount of compressed air available to the Cal Poly team which resulted in a frustrating and inconclusive investigation. In discussing these issues with the collaborating parties, the decision was made to transport the model to NASA Ames prior to the test date in order to conduct the system level checkouts and model preparation. Our partners at NASA arranged for this effort to be conducted at the Fluid Mechanics Lab(FML)-operated by a uniquely versatile and driven group of engineers working under the Experimental Aerophysics branch or AOX. In June of 2011, AMELIA was transported to the FML and housed in Test Cell 1 for a 6-month stay prior to tunnel entry. 


\subsection{Objective}

To ensure the accurate representation of circulation control flow theory onboard the wind tunnel model and within the resulting dataset, the flow properties along the span must vary in a repeatable and predictable manner. By eliminating vorticity or directionality in the circulation control flow, the end user of the dataset (a CFD analyst) has the best probability of matching prediction to data. Although the calibration was conducted in a wind off environment, the uniformity of the circulation control flow is assumed to be minimally effected by the presence of external flow, and thus success in achieving uniform flow in the benchtop environment will translate directly to the subsequent wind tunnel environment.

Over the course of this calibration flow uniformity was evaluated via flow visualization, total pressure measurements within the plenum, and the research team's engineering judgment.

\subsection{Apparatus}

The calibration was performed by simulating the "full" circulation control

test condition, the full condition corresponds to $2.80 \frac{\mathrm{lb} m}{\mathrm{~s}}$ of air supplied at an estimated pressure of 80 psig-not a trivial rate of airflow to achieve. In order to halve the flow rate requirements, the calibration was performed on one wing at a time. Once the plenums were modified to provide sufficiently uniform flow, the treatment was repeated in the remaining wing and flow uniformity was verified.

To address the airflow requirements of the calibration, a Sunbelt instrument quality air compressor was rented. The 500-horsepower diesel compressor (capable of providing more than enough mass flow) was positioned outside of the back 
door to Test Cell 1, as presented in Figure 3.1.

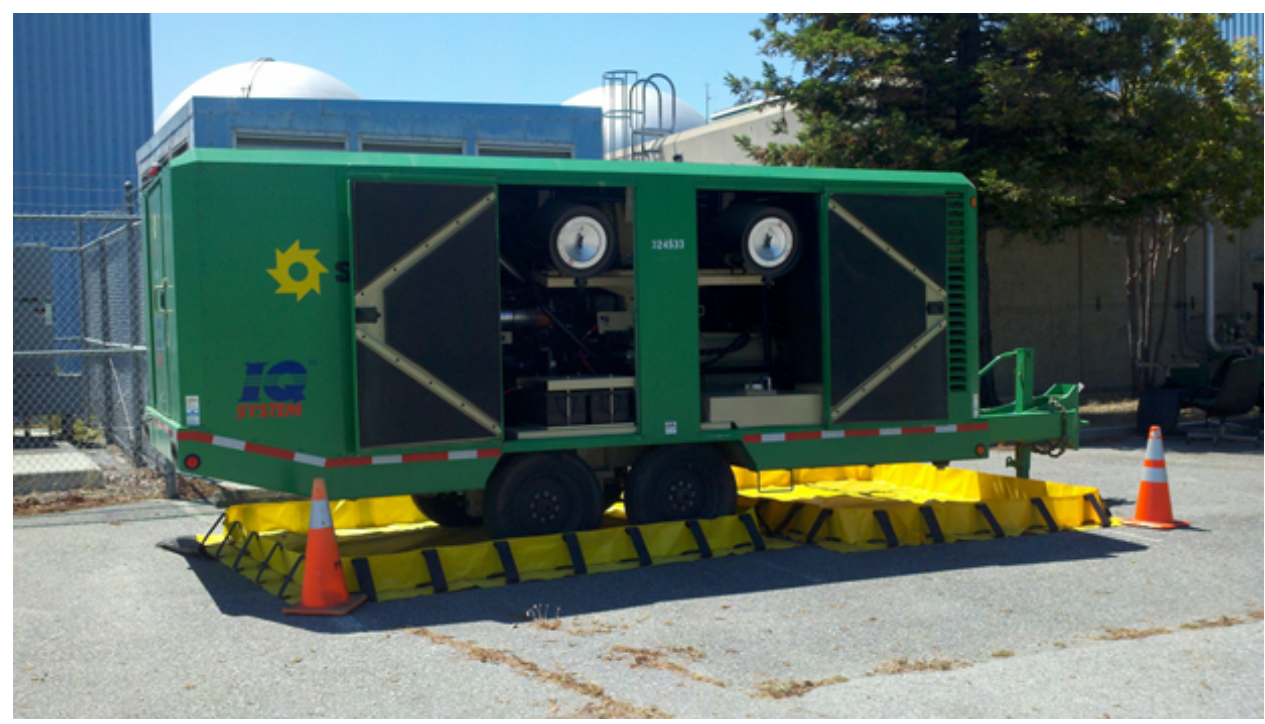

Figure 3.1: Sunbelt Model HP1600WCU Air compressor used for the circulation control calibration effort.

A Flow-Dyne critical flow nozzle, with a 1.004-in throat diameter, was installed between the compressor and the wind tunnel model as a means of measuring mass flow rate. The nozzle included an approach tube with taps for upstream temperature and pressure measurements. A second pressure tap (located downstream of the diffusing section) allowed for the verification of the pressure ratio required for critical flow. Pressure measurements were obtained using Omegadyne transducers (model PX209-100G5V) with a range of 100 psig and an accuracy of $0.25 \%$ full scale according to the calibration. The output of each transducer was displayed using an Omega digital display (model DP25B-E), and was not digitally recorded. Temperature was measured using a K-type thermocouple connected to a Fluke 17B digital multimeter displaying temperature in ${ }^{\circ} \mathrm{C}$. Figure 3.2 shows the critical flow nozzle and digital readouts for pressure(psi) and temperature.

In order to choke the flow at the throat and obtain an accurate flow rate measurement, an upstream to downstream pressure ratio of 1.2 was required 


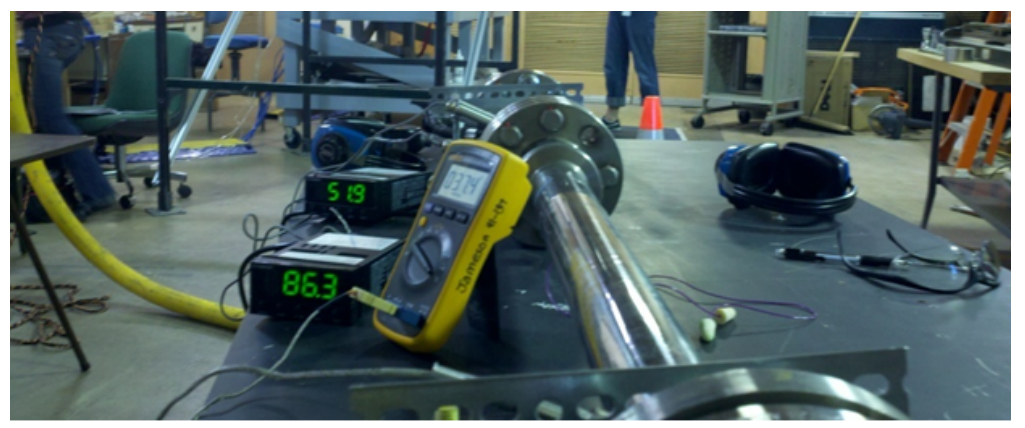

Figure 3.2: The critical flow nozzle used to measure mass flow rate.

across the nozzle. The slot flow calibration required a mass flow rate of $1.4 \frac{\mathrm{lb} m}{\mathrm{~s}}$, as each wing was calibrated independently. At the typical air supply temperature, this mass flow rate corresponds to an upstream pressure of approximately 77 psia (at a downstream pressure of 64 psia). With the addition of resistive materials in the plenum (flow treatment), an increase in nozzle pressure occurred which caused the upstream pressure to increase in order to maintain the 1.2 ratio. This higher upstream pressure forced the calibration mass flow rate to be slightly higher than required (approximately $1.58 \frac{\mathrm{lb} m}{\mathrm{~s}}$ ). The goal of the calibration-to achieve uniform slot flow-would be minimally effected by the difference in mass flow rate, however the secondary effort (to characterize the system by investigating the slot height, and jet total pressure) may suffer additional error due to the higher supply flow rate.

Many components, besides the critical flow nozzle, were required including a reducer, two safety relief valves, and two globe valves for flow control. The calibration system schematic can be seen in Figure 3.3.

The air was delivered directly to the low pressure distribution plenum, where an analog static pressure gauge provided a quick indication of the delivered pressure. From this location flow was channeled into one of the four pathways leading to the circulation control plenums. At the inlet to each pathway a butterfly valve, 


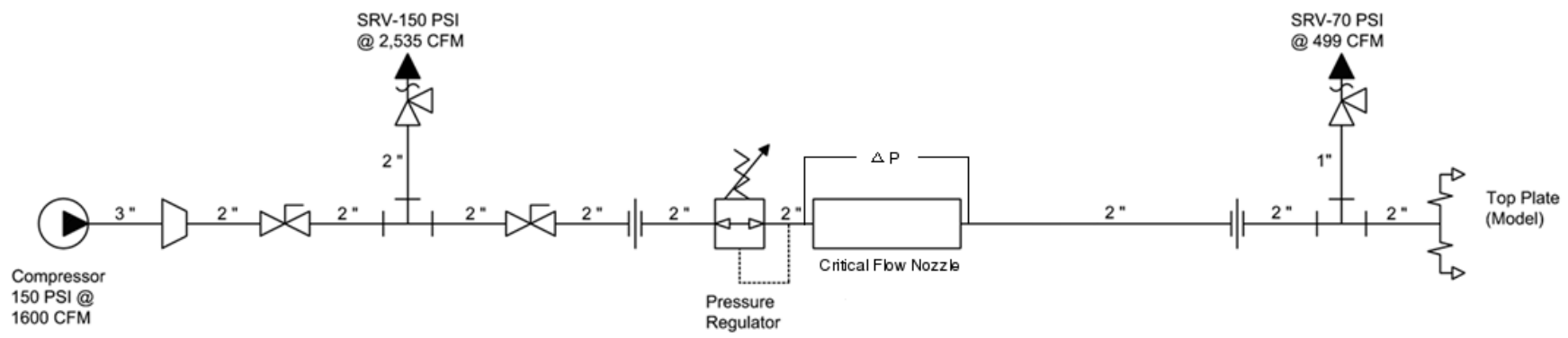

Figure 3.3: Schematic of the slot flow calibration air delivery system.

connected to a LabView controller, allowed the research team to limit the amount of mass flow directed to each plenum. The butterfly valves were adjusted using Maxon brushed DC gearmotors (model 149048) with valve position verified by linear potentiometers (Bourns model 3048 L-5-103). Each circulation control plenum housed three total pressure probes as shown (in red) in Figure 3.4. The total probes were connected to 30 psid Omegadyne pressure transducers (model PX142-030D5V) and displayed for real-time use only. These measurements provided an indication of the pressure distribution within each individual plenum as well as across the plenum network.

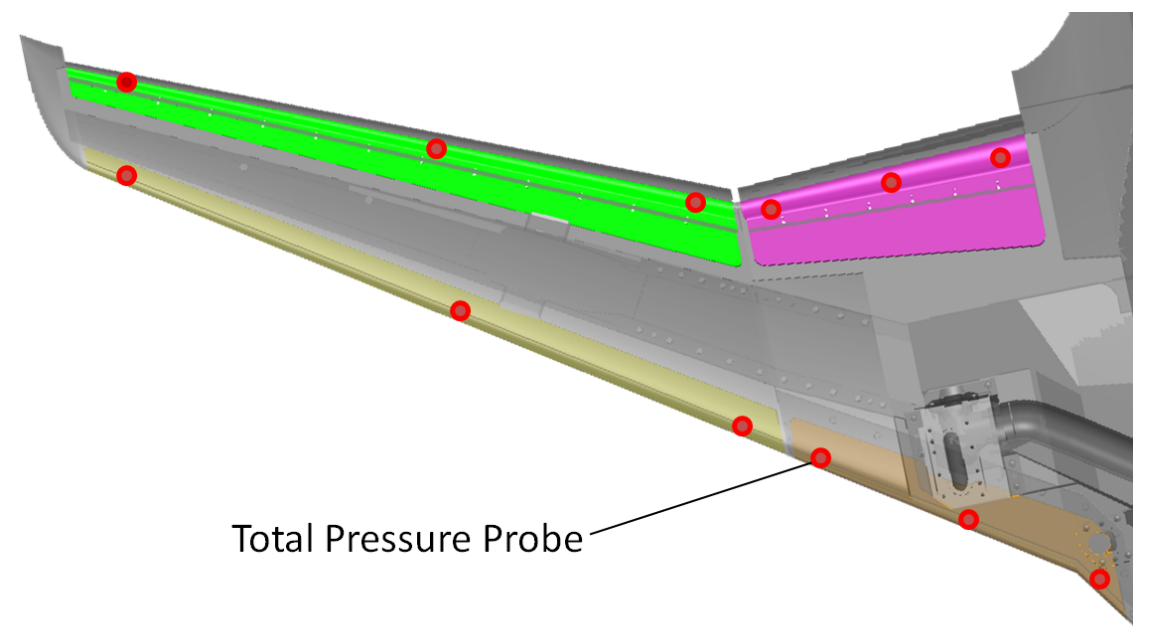

Figure 3.4: Total probe location within AMELIA's CC plenums. 
During the calibration AMELIA was mounted to the steel frame it was delivered upon. The frame was fixed to a reinforced work table which rested on several locked casters. An additional metal frame was used to position the flexible supply hose appropriately. Figure 3.5 shows the position of the model during the calibration.

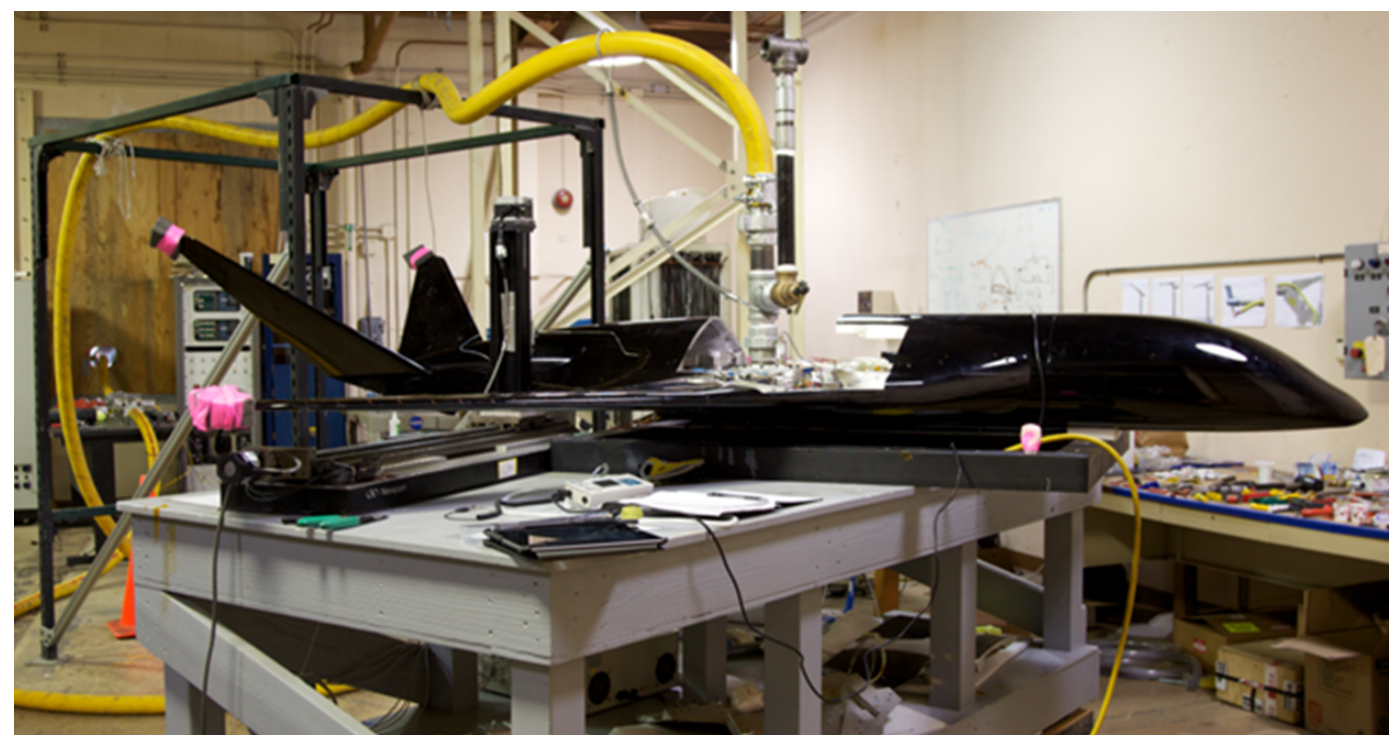

Figure 3.5: Circulation control flow calibration set-up in Test Cell 1.

\subsubsection{Plenum Treatment Materials}

\section{Metal Foam}

The metal foam product mentioned in Section 2.2.1, was selected as the primary flow restriction material. Two grades (or relative densities) of Aluminum foam were purchased for use within the plenums. In this instance relative density is defined as follows for a given volume of material:

$$
\text { Foam Relative Density }=\frac{\text { Final Mass of Foam }}{\text { Mass of Solid Volume }}
$$


Foam inserts with densities of $8 \%$ and $15 \%$ were custom manufactured to fit inside the grooves in AMELIA's eight plenums. Despite the different densities, each set of foam inserts contained approximately 40 pores per inch. The foam was secured within the plenums using a combination of superglue and room temperature vulcanizing silicon (RTV), which also aided in creating a proper air seal. An example of the metal foam is provided on the left in Figure 3.6.
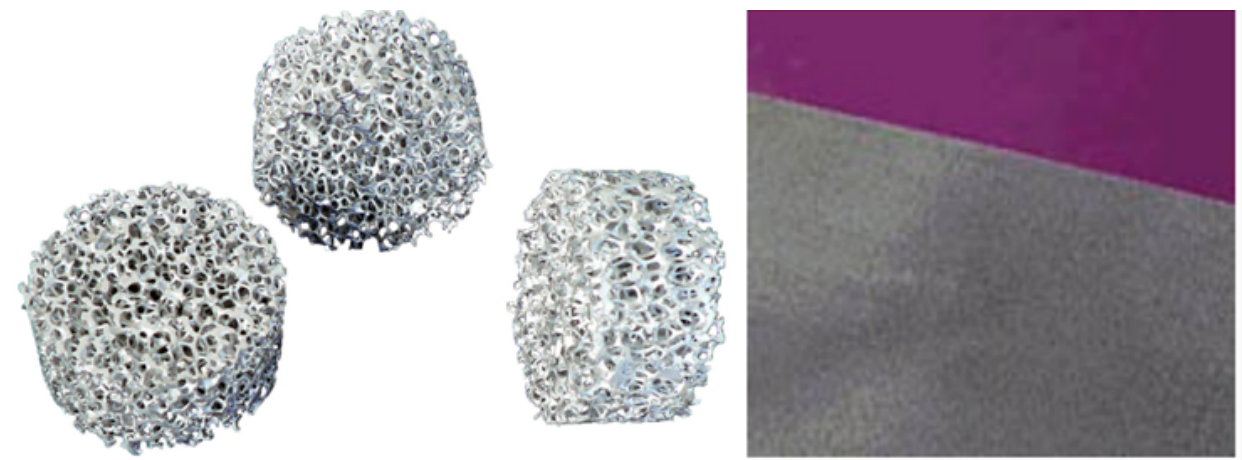

Figure 3.6: Samples of metal foam and sintered metal mesh used in the circulation control plenums[30, 31].

\section{Metal Mesh}

The metal mesh in Figure 3.6 is a product manufactured by the Pall Corporation known as Rigimesh. It is typically used as a filtering medium and can sometimes be found as screening material in wind tunnels(among other applications). Engineers with experience in circulation control testing suggested the Cal Poly research team obtain a few grades of the sintered mesh to provide an alternative flow restriction medium in case the metal foam proved unsatisfactory. A dense mesh (Grade K) and a more porous mesh (Grade J) were purchased and remained on-hand during the calibration effort. 


\subsection{Results}

Initial circulation control system runs were conducted to evaluate the safety and functionality of the system components. Once the functional limits of system were well understood (i.e. operation without triggering a safety relief valve), the research team was able to turn its attention to the slot flow quality.

\subsubsection{Initial Inspection}

Upon initial inspection-using only our hands as indicators of flow directionalitythere appeared to be significant vorticity on the upper surface of the wing, however the source of the vorticity was unclear. During the subsequent run fluorescent tufts were used to further explore the poor flow coming form the slots (an example is provided in Figure 3.7). Under ultra-violet light the tufts revealed the general trends of the flow on the upper surface, however the tufts failed to provide the resolution desired to investigate the quality of the system. Engineers from the FML suggested that a mixture of gear oil pigmented with titanium dioxide applied to the model surface would provide better flow visualization. Oil flow visualization was used for the remainder of the calibration.

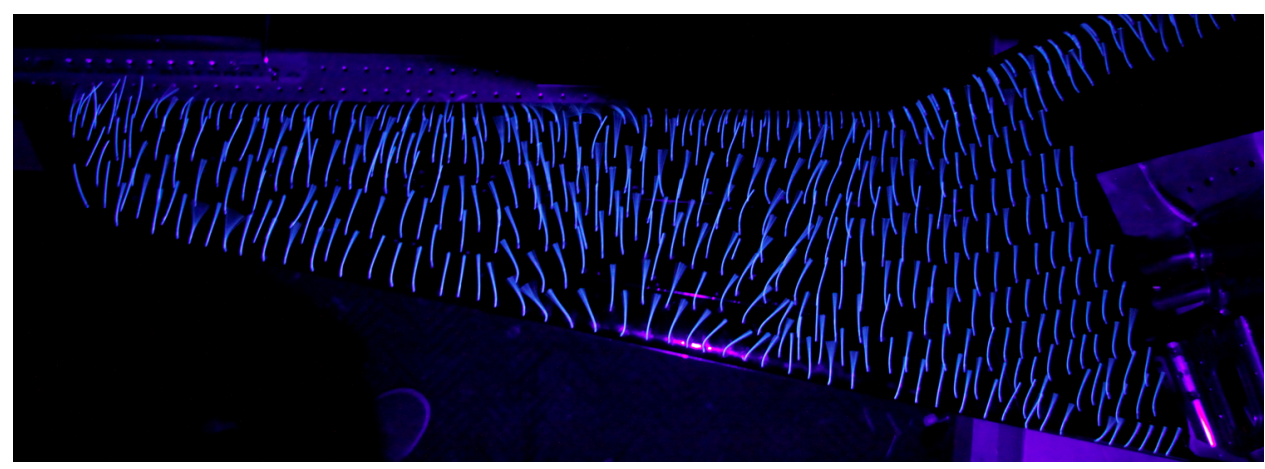

Figure 3.7: Preliminary run using tufts.

Although mentioned previously, the author is compelled to remind the reader 
that the mass flow rate directed to the wing in each run was $1.58 \mathrm{lb} m / \mathrm{s}$ with no external flow. It should also be noted that the research team primarily focused on the leading edge outboard plenum as it seemed to be the most non-uniform.

\subsubsection{No Treatment}

Initial calibration runs served to identify the baseline performance of the circulation control system without flow treatment in the plenums. The results of one such run are shown in Figure 3.8. The oil flow reveals clear non-uniformity on the upper surface, which seems to be primarily caused by a lack of flow from the leading edge outboard plenum. With nothing in place to restrict the flow, the pressurized air travels from the plenum inlet, through the plenum and nozzle and finally expands across the Coanda surface. Very little flow is supplied inside the plenum to regions beyond the inlet (i.e. the wingtip and plenum intersection), as indicated in both the oil and total pressure measurements (the latter was not recorded). Furthermore, although the oil indicates attachment to the upper surface, the flow was highly three-dimensional. A hands-on inspection of the flow revealed that two powerful vorticies were present over the wing surface. These vortical structures aligned with the edges of the jet swath visible in the oil.

\subsubsection{8\% Dense Aluminum Foam}

The more porous grade of aluminum foam (relative density of $8 \%$ ) was installed within the plenums in the location marked for "Flow Treatment" in Figure 2.4. The treatment's influence on the circulation control flow is shown in Figure 3.9. Despite the flow resistance provided by the foam, inlet effects remain, although a comparison to 3.8 reveals that the jet swath has been slightly 


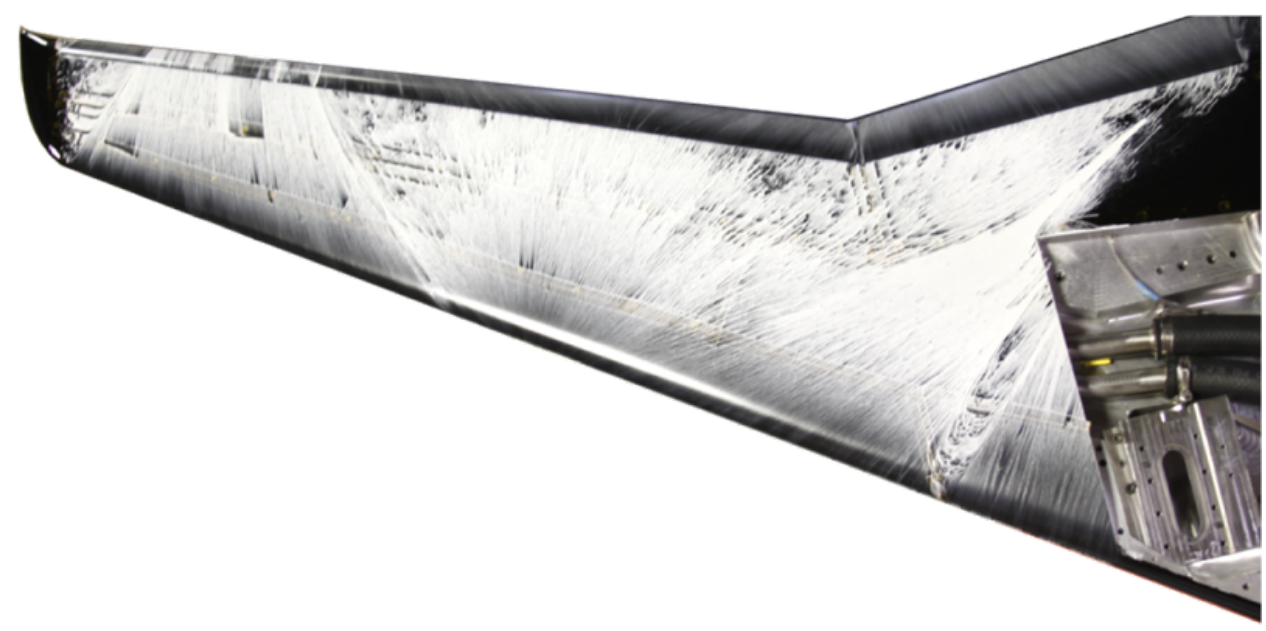

Figure 3.8: Oil flow visualization: no plenum treatment

reduced. Furthermore, an increased amount of mass flow seems to be directed to the wingtip and inboard sides of the LEOB plenum-evidence that the foam is succeeding at providing some degree of flow resistance. A comparison of total pressure measurements between this case and the "No Treatment" case also suggest more flow at the wingtip and inboard sections, however the total probe nearest the inlet reads significantly higher values. Although this case did not provide uniform circulation control flow, the improved slot flow was promising.

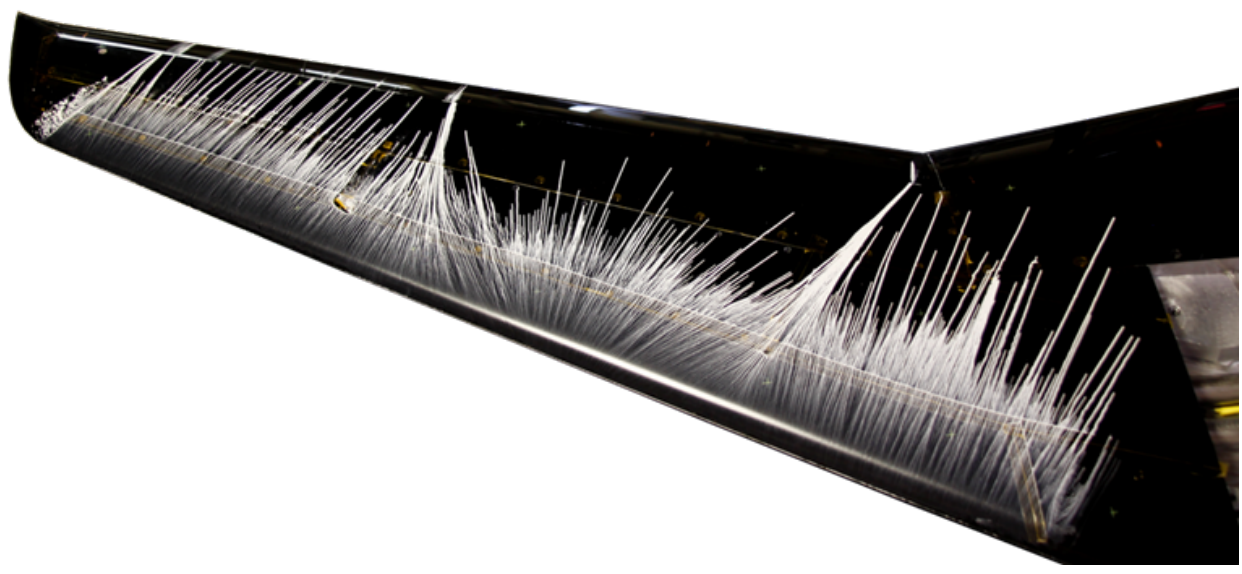

Figure 3.9: Oil flow visualization: 8\% Dense Metal Foam 


\subsubsection{5\% Dense Aluminum Foam}

The additional density of this treatment was presumed to enhance the positive characteristics provided by the $8 \%$ foam treatment. The $15 \%$ treatment, however, produced a very similar flowfield-as shown in Figure 3.10. Despite the difference in porosity, the $15 \%$ aluminum foam treatment provided a negligible change on the circulation control flow. The jet emitted from the plenum inlet remains present on the upper surface, as does the vorticity above the wing. The total pressure probes indicated no appreciable change from the previous case.

The lack of improvement of the $15 \%$ as compared to the $8 \%$ metal foam inspired further investigation of the flow within the plenums. The same pigmented oil applied to the wing upper surface was then applied inside the LEOB plenum (this was also done during the $8 \%$ dense metal foam runs). The oil flow visualization of the flow within the plenum is provided in Figure 3.11. The lack of oil directly downstream of the inlet is further evidence of the unperturbed high speed jet shown on the upper surface. Branching away from the inlet in both directions is a tight line of oil caused by coalescing streamlines-an indication of the internal vorticity. The vorticity appears to be strongest towards the outboard section of the plenum (indicated by more tightly gathered streamlines or a more defined line), and is the result of the plenum supply geometry, and inlet geometry. Each vortex dissipates at approximately the same location as the coalescing streamlines on the upper surface (or the extent of the jet swath).

At this point in the flow uniformity calibration, the research team had exhausted the planned plenum treatment options and achieved unacceptable flow uniformity. Further improvements in the circulation control flow quality were completed by gathering readily available materials, and experimenting with new 


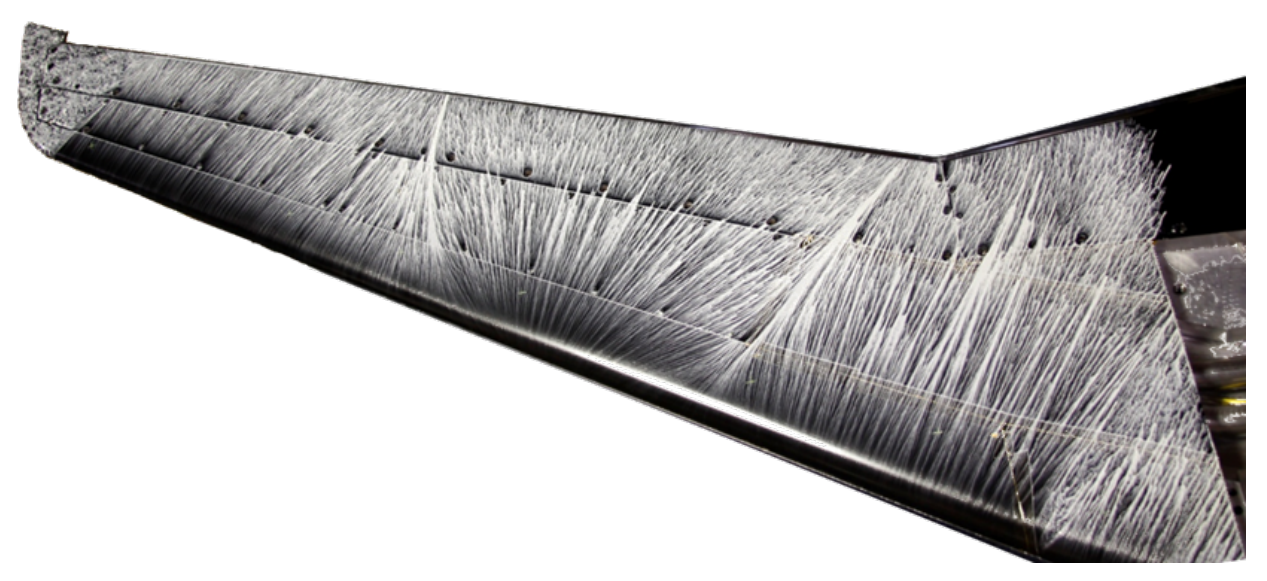

Figure 3.10: Oil flow visualization: 15\% Dense Metal Foam

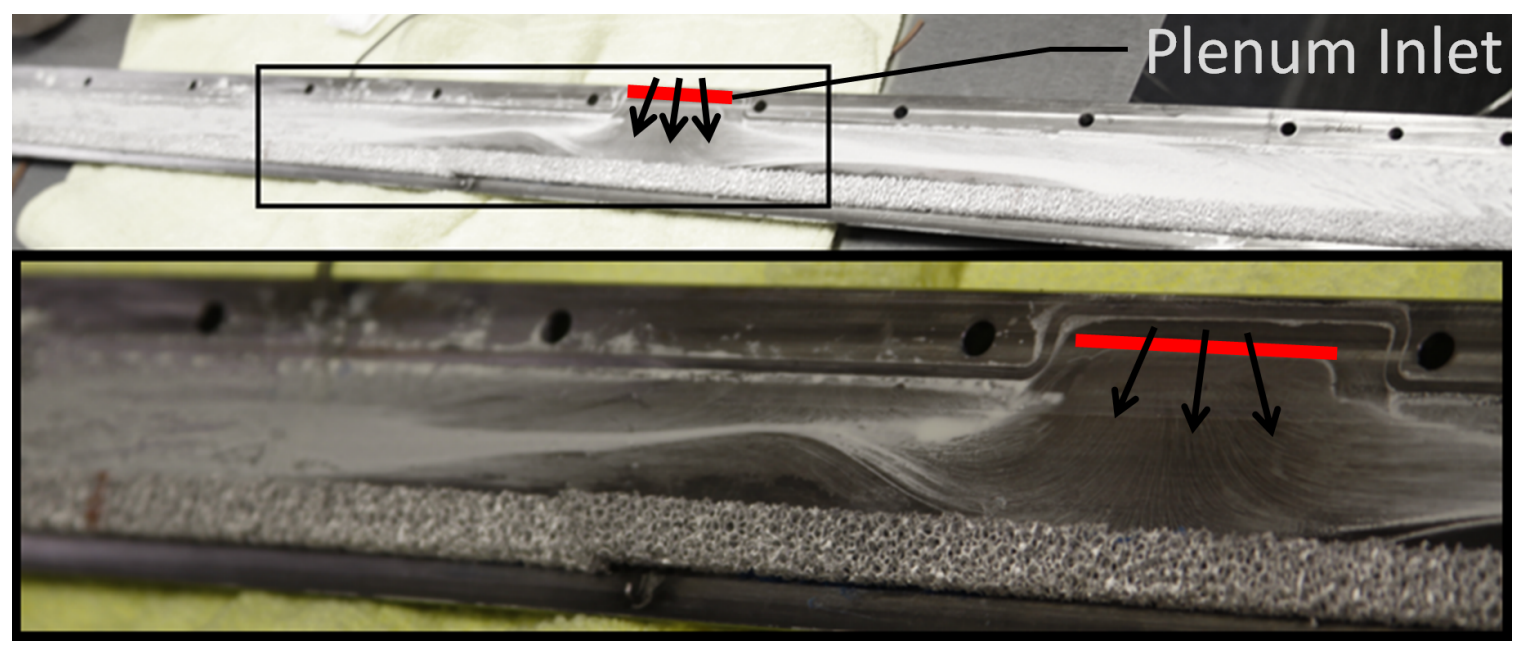

Figure 3.11: Oil flow visualization: Plenum Internal Flow

treatments based on advice from the engineers at the FML, as well as Greg Jones (NASA LaRC), and Bob Englar (GTRI).

\subsubsection{Further Plenum Treatment}

Although the aluminum foam alone did not provide acceptable flow uniformity, it did appear to provide some benefit to the flow quality in the regions unaffected by the jet and vorticies. In applying further flow treatment, the goal was specifically to retard the jet (allowing more even flow distribution) and dissipate 
the rotational energy of the peripheral flow thus preventing vortex formation.

Various treatment designs were tested until acceptable flow uniformity was achieved. A visual summary showing the results of a few different treatments is provided in Figure 3.12. In addition to surface oil flow, during many of these cases internal oil flow visualization was used to aid in diagnosing flow quality issues and further investigate flow behavior.

To resist the jet flow coming from the plenum inlet, a "wedge" resembling an obtuse isosceles triangle was cut from additional stock of $15 \%$ aluminum foam. The tip of the wedge was placed in the center of the inlet leaving an unobstructed flow path approximately 0.5 " wide on either side of the wedge. The additional resistance of the foam wedge was intended to reduce the influence of the jet coming from the inlet and encourage more mass flow to the plenum extremities. When actually tested, however, it seemed an excess of flow was diverted to the plenum extremities and the flow near the inlet experienced too great a pressure loss. In an attempt to balance flow qualities in the plenum a less aggressive wedge was designed with a decreased flow wise dimension to lessen the pressure reduction near the inlet. The results of this modified wedge treatment were an improvement in terms of balancing internal pressure, however the visualization indicated that flow directionality issues remained as did much of the vorticity over the wing.

Attention was then turned to the plenum inlet itself-specifically the sharp edges around the perimeter. It was suspected that removing these edges might aid in reducing rotational energy as the jet expands to fill the plenum cavity. A grinder was used to smooth the stainless steel inlet, followed by a small degree of hand sanding and polishing. The results (not shown in the Figure) indicated slight (if any) improvement in mitigating internal vorticity. 


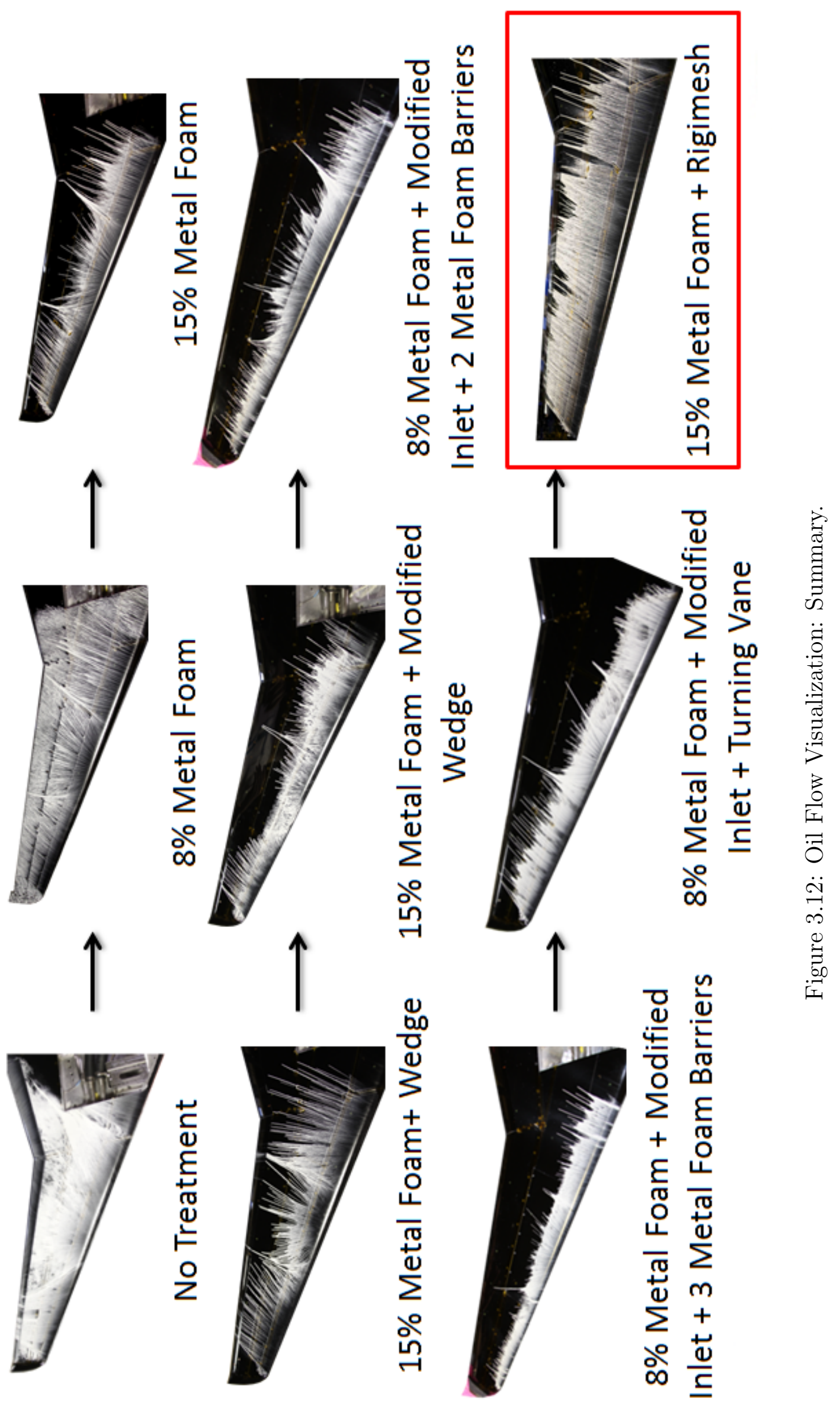


Further attempts to mitigate the internal vorticity focused on dissipating the rotational energy using tabs or barriers (also constructed of aluminum foam). Critical points in the formation of the vorticies were identified based on the internal oil flow visualization. A tab placed at these critical locations would presumably absorb some of the rotational energy, thus reducing the vortex strength and overall influence on the circulation control flow. Figure 3.12 shows two cases using a combination of tabs and the $8 \%$ aluminum foam. With two tabs a strong vortex remains on the inboard side of the inlet, while the outboard vortex has been broken into two smaller vorticies (as indicated by the merging of surface streamlines). When three tabs are in use there is a long run of reasonably uniform flow at the inboard side of the plenum, but the outboard side exhibits qualities that remain less than ideal.

Next, a rudimentary turning vane was fashioned from brass shim-stock and was fastened into place in the plenum inlet. The channels formed by the vanes encouraged equal flow distribution throughout the plenums span, however the results indicate a bias towards the outboard section. Along with the uneven flow distribution the turning vane had little influence on the vorticity.

Other treatments tested and not shown in 3.12 included numerous rudimentary choke plates (fashioned from the same brass shim-stock). Treatments were placed within close proximity to the plenum inlet and were typically 4 to 8 inches in length. Hole size and frequency varied from treatment to treatment along with overall shape of the plate. A few provided some improvements to the flow quality but the majority of treatments produced results similar to the previous cases. 


\subsubsection{5\% Aluminum Foam With Metal Mesh}

Having exhausted many resources and most of our patience, the research team turned away from attempting to couple local treatments with the aluminum foam and instead focused on further restricting the overall plenum flow. Purchasing additional aluminum foam with higher density was considered, however the manufacturing process was time consuming and costly. The metal mesh could provide the resistance, but a very limited amount was available. A layer of the mesh was attached to the upstream side of the aluminum foam in the LEOB plenum. The results of this treatment are highlighted in Figure 3.12 .

Uniform circulation control flow was achieved using 15\% dense aluminum foam combined with layers of metal mesh. One layer of metal mesh spanned the entire length of the plenum and was secured with adhesive to the plenums lower surface. A secondary layer of mesh (approximately $20 \%$ of the plenum length) was placed in the inlet region to further retard the flow. In some cases an additional layer of mesh was used at the downstream side of the foam for further flow restriction. A detailed view of the flow visualization results is provided in Figure 3.13. The additional flow restriction provided by the mesh, unified the flow conditions and allowed the plenum to act as a true stagnation chamber for the first time. Uniform internal conditions were evident in the total pressure probe readings. The lack of vorticity in the flow also indicated acceptably uniform plenum conditions. This treatment produced highly 2-dimensional plenum flow that properly adhered to the wings upper surface in the form of a jet sheet that cleanly represented the flow qualities desired for circulation control.

The final plenum treatment (used for the remainder of the calibration and test) is shown inside the TEIB and TEOB plenums of the right wing in Figure 


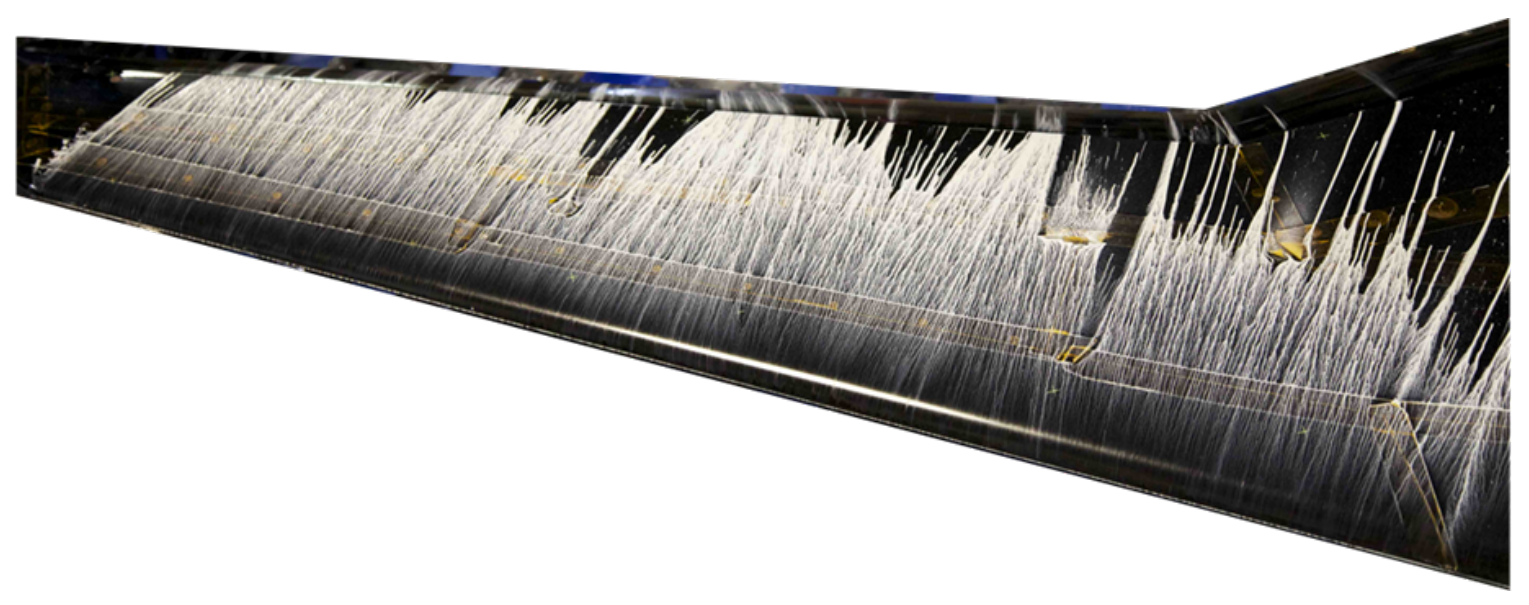

Figure 3.13: Oil flow visualization: Heavy Grade Metal Foam and Rigimesh

3.14. Unlike the outboard plenums, the inboard foam is lined with mesh on both the upstream and downstream faces. This double layer is not due to local inlet effects, and is instead a result of the limited quantity of mesh. The poor flow quality from the leading edge plenums was resolved using the entire quantity of available Grade K Rigimesh (the mesh with greatest flow resistance properties). Of the Grade J Rigimesh, only enough remained to line one side of the foam on each of the trailing edge plenums. Further testing showed that flow from the inboard plenums would benefit from additional flow restriction and thus a third mesh of unknown density was added. Although this third mesh was visibly more permeable than the other grades, when combined with the Grade J or Grade K mesh it provided sufficient flow restriction. The final composition of materials that provide flow conditioning in each plenum is shown in Table 3.1, where Grade $\mathrm{X}$ Rigimesh is the unknown mesh provided by the facility. 


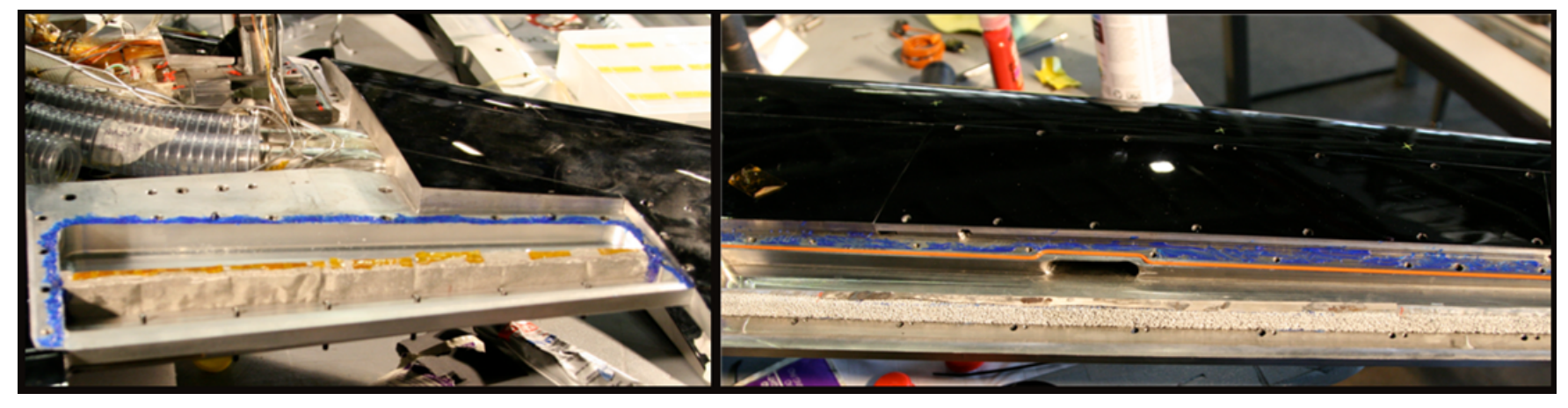

Figure 3.14: Heavy grade metal foam with Rigimesh in trailing edge plenums

Table 3.1: Plenum Treatment Composition

\begin{tabular}{ccccc}
\hline \hline Plenum & Layer 1 & Layer 2 & Layer 3 & Layer 4 \\
\hline LEIB & Grade X & Grade K & 15\% Foam & Grade X \\
LEOB & Grade K & Grade K & 15\% Foam & - \\
TEOB & Grade J & Grade J & $15 \%$ Foam & - \\
TEIB & Grade X & Grade J & $15 \%$ Foam & Grade X \\
\hline
\end{tabular}




\section{Chapter 4}

\section{System Characterization}

A predictive tool's ability to accurately simulate wind tunnel data is largely dependent on input parameters like model geometry and boundary conditions. Therefore the research team invested the remaining compressor time in the characterization of the circulation control system, giving the end user of the dataset (a CFD analyst) better documentation of the experimental boundary conditions. A large portion of this effort was concentrated on the slot height, as it not only plays a role in defining geometry for prediction tools, but also is a factor in computing the circulation control momentum coefficient. The momentum coefficient (sometimes referred to as discharge coefficient, or blowing coefficient) is used as an indicator of circulation control performance and is defined as follows

$$
C_{\mu} \equiv \frac{\text { Jet Momentum }}{q_{\infty} S_{r e f}} \approx \frac{\dot{m}_{j} V_{j}}{q_{\infty} S_{r e f}} \approx \frac{2 h_{j} w}{S_{r e f}} \frac{\rho_{j}}{\rho_{\infty}} \frac{V_{j}^{2}}{V_{\infty}^{2}}
$$

where subscript $\mathrm{j}$ denotes jet properties and $V_{j}$ is assumed to expand isentropically. In the small scale experiments of the past, the slot height or $h_{j}$ typically

contributes the majority of uncertainty associated with the calculation of $C_{\mu}$ 
[26]. And thus it was with the utmost care that the research team attended to the measurement of AMELIA's slot height.

\subsection{Slot Height Characterization}

In order to fully characterize AMELIA's circulation control slot height, data was required for all instances of operation. This includes static measurements (where no circulation control flow is supplied) as well as pressurized measurements (where full circulation control flow was supplied). A comparison of these datasets would provide evidence of the effectiveness of the set-screw/tie-down system in restraining expansion due to pressure.

Additionally, data for AMELIA's slot height would be gathered initially (during the system calibration) as well as during the wind tunnel test, and upon the model's removal from the tunnel. Sporadically acquiring slot height data would alert the team to undesired changes (perhaps due to material fatigue, loss of a setscrew or tie-down, or other unforeseeable events), as well as provide a thorough amount of repeat measurements to reduce overall uncertainty.

\subsubsection{Slot Height Measurement}

The measurement of a small gap or slot has received little attention in the history of technology. In fact, many of the engineers and researchers who have previously worked on blowing systems similar to AMELIA's may have employed a feeler gauge for this purpose. The use of a feeler gauge (or rather a set of feeler gauges) involves inserting various gauges of prescribed thickness inside a gap and selecting the gauge with the best fit. Although the thickness of each 
gauge is known precisely, the process of identifying the gauge with the best fit is subjective and thus produces a high amount of uncertainty. Being forewarned of the difficulties associated with feeler gauge measurements, the Cal Poly research team looked to methods that offered greater accuracy.

In discussion with our collaborators, many suggested the use of a capacitance based gap measurement device that had recently proven useful in circulation control tests conducted by GTRI and NASA Langley. Manufactured by Capacitec, the Gapmaster3 is a hand-held computer and display unit that receives an input signal from one of the many thin gap sensors compatible with the unit. With help from our NASA advisers, the Cal Poly research team was permitted use of NASA LaRC's Gapmaster3. The unit was delivered to the Fluid Mechanics Lab with two flexible probes (or wands). The specifications of each wand are provided in Table $4.1[2]$.

Table 4.1: Capacitec Probe Specifications [2]

\begin{tabular}{rcccc}
\hline \hline Serial Number & $\begin{array}{c}\text { Nominal Thickness } \\
\text { (inches) }\end{array}$ & $\begin{array}{c}\text { Usable Length } \\
\text { (inches) }\end{array}$ & $\begin{array}{c}\text { Width } \\
\text { (inches) }\end{array}$ & $\begin{array}{c}\text { Measurement Range } \\
\text { (inches) }\end{array}$ \\
\hline$\$ \mathbf{4 4 1 5}$ & 0.008 & 9.843 & 0.551 & 0.008 to 0.100 \\
\hline $\mathbf{6 2 7 2}$ & 0.009 & 5.905 & 0.551 & 0.010 to 0.050 \\
\hline
\end{tabular}

AMELIA's slots ranged from 0.050-in at the inboard to 0.012-in at the wingtip and despite both wands having an appropriate measurement range, serial number 6272 was preferred. This flat tipped, double sided, probe was found to produce measurements with an instrument accuracy of \pm 0.05 -mils $\left(5.0 \times 10^{-5}\right.$-in $)$ according to its calibration. The wand connected to main unit via a serial cable and was outfitted with a probe-stop. The probe-stop ensured each measurement was made inside the plenum nozzle by preventing over-insertion of the wand. 


\subsubsection{Slot Adjustment Accuracy}

In order to accurately reflect the concept and preliminary performance predictions, it was required that the wind tunnel model's slot height follow the slot height to chord ratio defined in Table 2.1. Although the leading edge slot was fixed as it lacked the ability to adjust slot height, much time and effort was spent adjusting the trailing edge slot. The set-screw/tie-down system proved capable of manipulating the slot height with good resolution, however regions near the ends of the plenum cover were not as easily adjusted due to the additional structure at the cover's fastening locations. A comparison of the ideal and actual slot heights for both the right and left wing is shown in Figure 4.1. Each data point corresponds to a set-screw/tie-down pair and is presented against its location along the semispan (in percent), which has total length of 60 inches or 5 feet. The separation between inboard and outboard plenums occurs at roughly $48 \%$.

The figure reveals a large discrepancy from the ideal slot height at station 1 ( $52 \%$ span) of the outboard plenums on both wings. A variance of approximately 8 mils from ideal exists on the right wing, while the variance on the left wing is nearly double at one location. In both cases this large slot height was due to the inability of the tie-down to overcome the local stiffness of the plenum cover. In the case of the left wing, attempts to further tighten the cover resulted in a permanent tie-down failure in one place (marked in red as Damaged). The same region of the inboard plenum also proved too stiff to allow for slot height manipulation by the set-screw/tie-down system, however unadjusted was close to ideal.

The actual slot height values were used to calculate a new slot height-to-chord ratio, as well as a new slot height to radius ratio. These values are shown in Table 


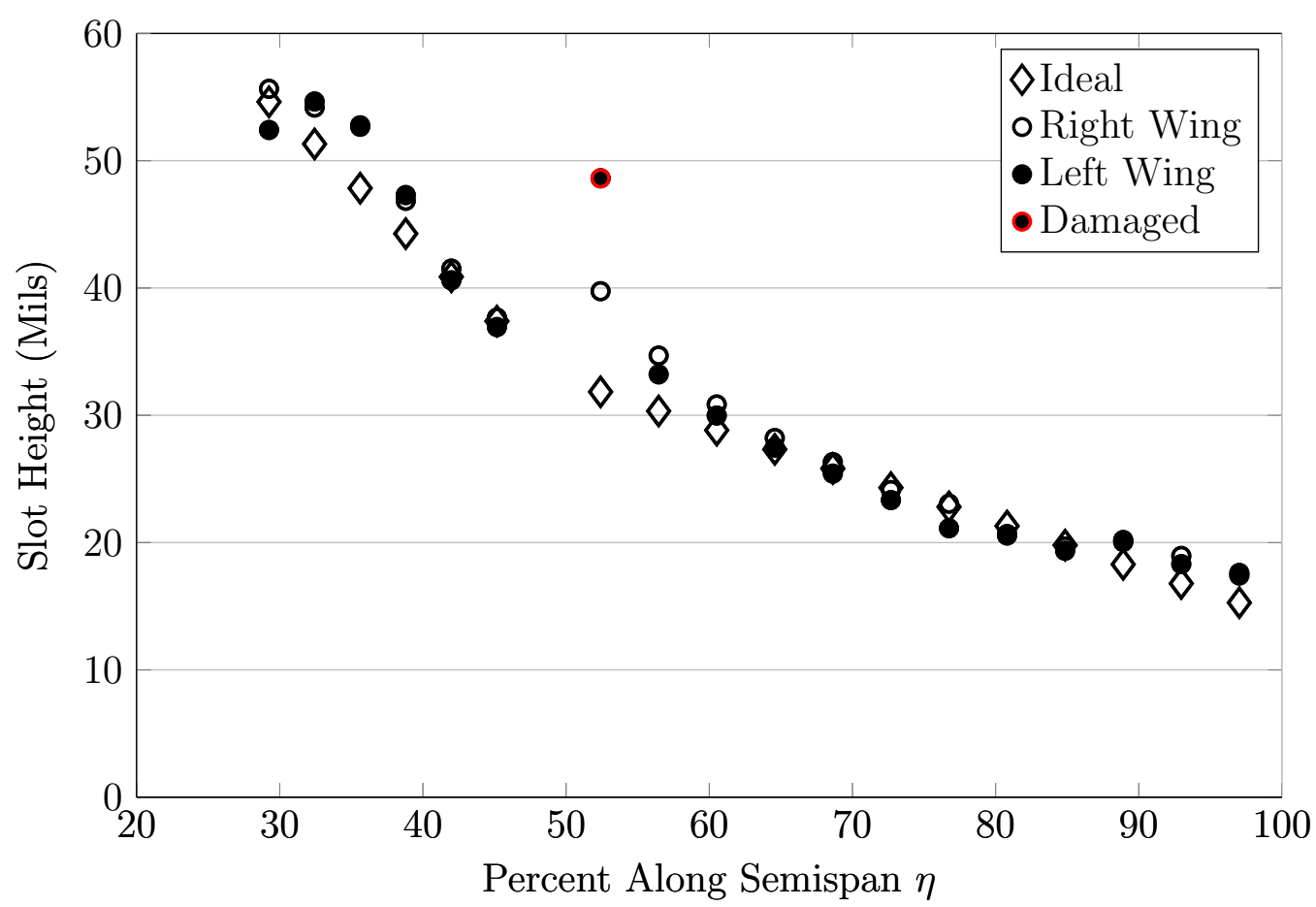

Figure 4.1: Comparison of ideal trailing edge slot height to actual.

4.2 , and were used to verify agreement between the test configuration and the original concept design configuration. A $6 \%$ difference exists between ideal and actual values for slot height to chord ratio. Although in theory this difference will effect the ability to match performance predictions, it was deemed insignificant as many of the early predictions relied on a simplified AMELIA geometry and were thus only used as indicators of performance trends during the wind tunnel test. Furthermore, so long as these differences were documented for the CFD analyst (the future user of the test data), appropriate adjustments to the geometry or boundary conditions can be easily implemented. 
Table 4.2: Leading Edge Plenum Design Parameters

\begin{tabular}{ccc}
\hline \hline Parameter & Ideal & Actual \\
\hline$h_{\text {slot }} /$ c Ratio & 0.00238 & 0.00252 \\
$h_{\text {slot }} /$ r Ratio & 0.049 & 0.052 \\
\hline
\end{tabular}

\subsubsection{Wing Symmetry}

Often CFD simulations take advantage of planes of symmetry in order to reduce computational requirements. For traditional unpowered and symmetric wind tunnel models (lacking a blowing system or injection based propulsion simulation) natural symmetry is assumed to occur at test conditions where no sideslip angle exists $\left(\beta=0^{\circ}\right)$. The circulation control system and TPS units onboard AMELIA make the model susceptible to unbalanced momentum addition. While flow to each TPS unit is precisely controlled and can thus be easily balanced, the butterfly valves leading to each circulation control plenum offer only limited control of the flow making balanced flow much more difficult to achieve. To aid in producing balanced circulation control flow, the slot height of each wing was further adjusted to provide symmetry about the fuselage center-line (these adjustments were limited to locations that deviated from the ideal slot height to chord ratio).

The results of the adjustments on the trailing edge inboard plenum are shown in Figure 4.2, where each measurement has an associated uncertainty of \pm 1.1 mils. In this instance, symmetry is achieved at all locations barring the most inboard where a deviation of $4 \sim 5$-mils is present. Although the left wing would benefit from an increase in slot height at this location, the effect on the overall plenum flow was considered to be minor as the deviation occurs at only one instance. 


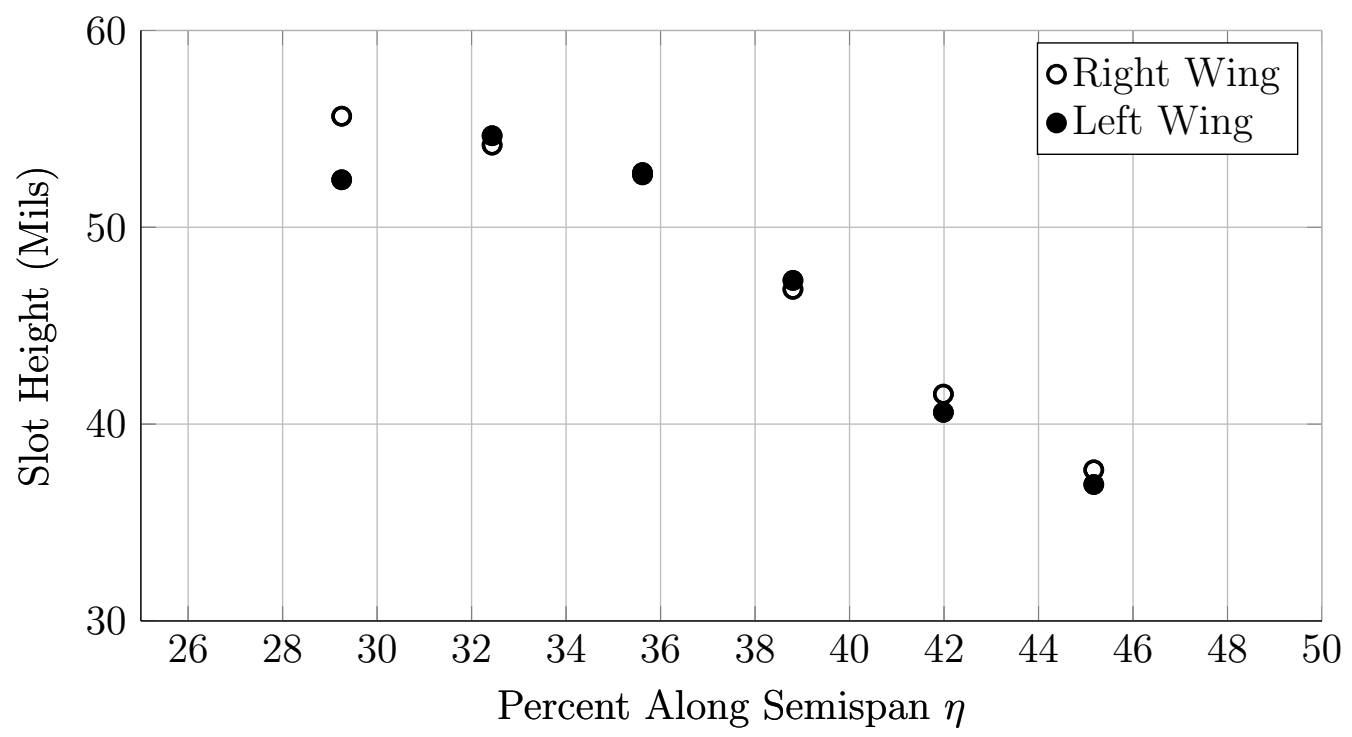

Figure 4.2: TEIB slot height comparison.

The trailing edge outboard comparison is shown in Figure 4.3 and the reader is encouraged to recall that the inboard most tie-down of the left wing suffered permanent damage during adjustment. Again the deviation may cause some additional flow to be directed to the region of the broken tie-down, however the region is small relative to the length of the plenum and thus has little effect on the entire plenum flow and further has less of an effect on the circulation control system balance. Beyond the damaged tie-down the remaining locations are in good agreement with only small deviations of $\sim 3$-mils. 


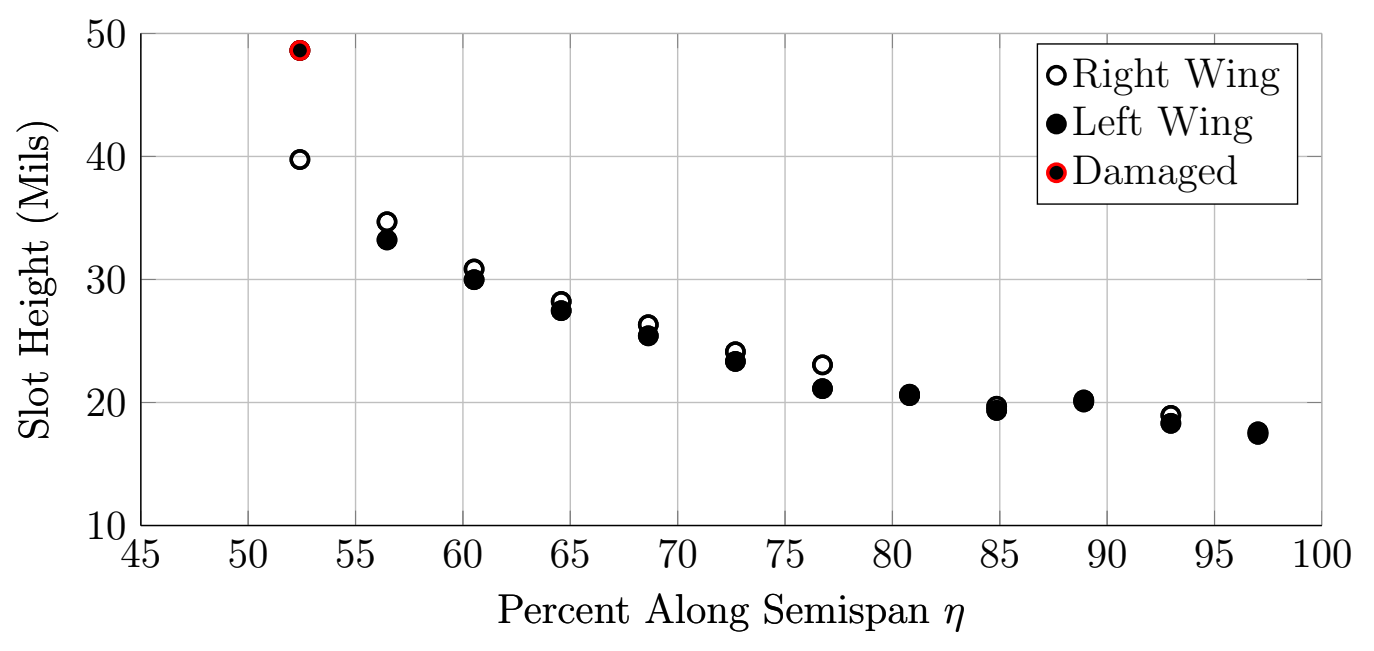

Figure 4.3: TEOB slot height comparison.

Although far less could be done about creating symmetric slot heights at the leading edge, measurements were acquired to verify that no large discrepancies exist that would adversely effect the aerodynamic performance data. Values gathered for each wings leading edge slot height would also be implemented into the CAD model, providing the CFD analyst with an accurate geometry for the computation. The comparison for the leading edge inboard plenum is shown in 4.4 .

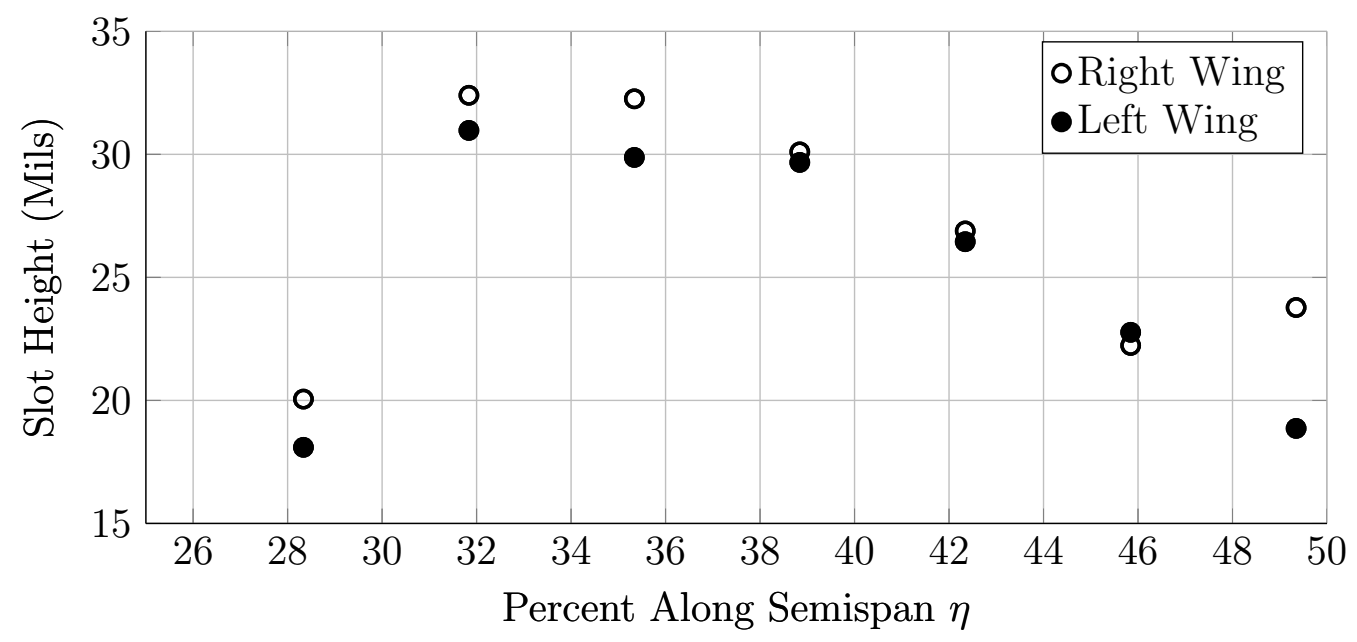

Figure 4.4: LEIB slot height comparison. 
At three locations the slot height of the right wing is greater than that of the left by approximately 3 mils. The reason for this deviation remains unknown, it is not likely a difference in manufacturing of the model pieces, nor is it likely a function how well fastened each cover is to AMELIA's main body-as both covers were torqued to the same value. Perhaps the o-ring seal of the right wing became misaligned during the fastening of the cover, however a thorough leakcheck around the plenum ensured the o-ring was functioning.

A comparison of the leading edge outboard slot is provided in Figure 4.5.

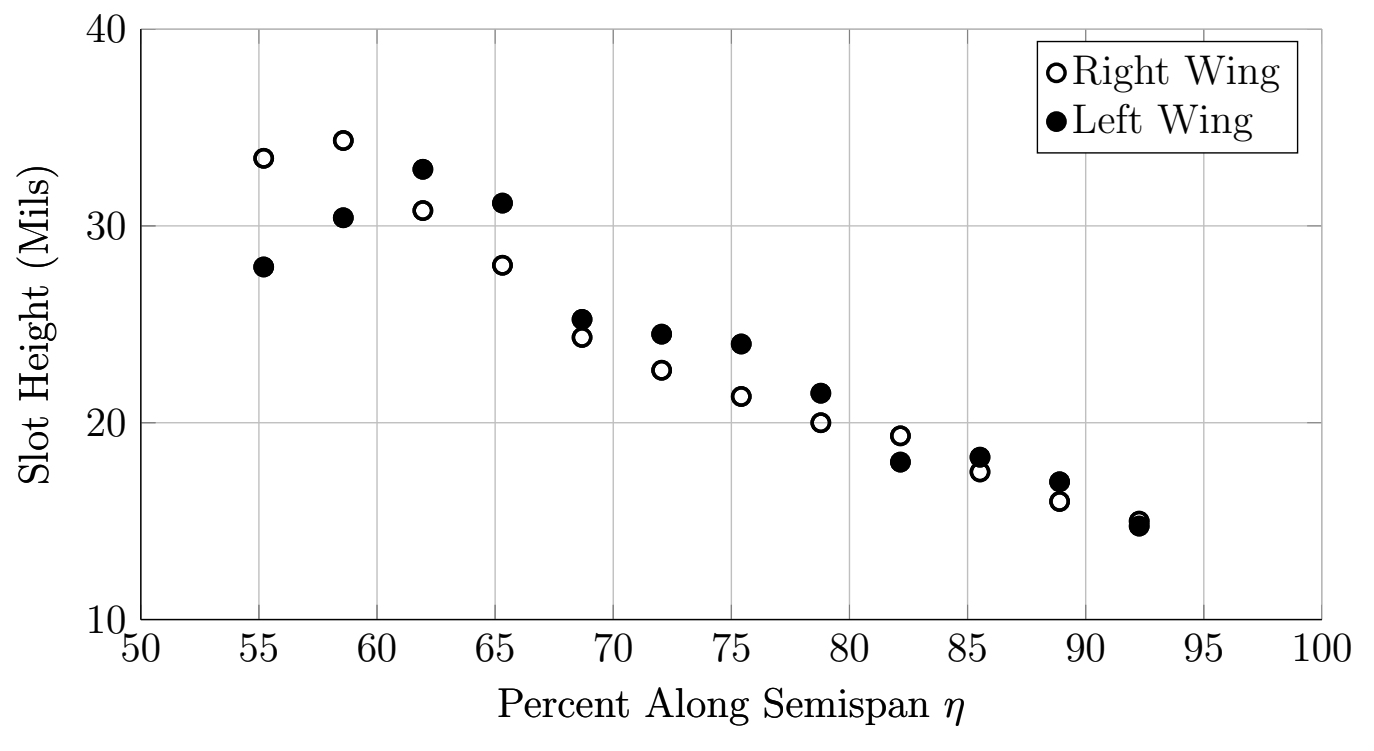

Figure 4.5: LEOB slot height comparison.

Although the largest deviation between the right and left wing's LEOB slot height is only 6 mils (about the thickness of two sheets of paper), overall these slot heights match poorly. The length of the plenum (about 33 inches) and lack of intermediate supports make it particularly susceptible to deformation. This deformation could be caused by the metal foam inside each plenum as the foam is relatively rigid and spans the entire height of the plenum. It was determined 
that rather than investigate the foam and risk compromising the flow uniformity results, the right and left wing LEOB slot heights would remain in the state shown in Figure 4.5.

\subsubsection{Slot Area}

To further evaluate the effect of slot height differences between the right and left wings, the exit area of each plenum was calculated. Consideration of the exit area-rather than the slot height itself-provides more insight to the general performance of the circulation control system. The exit areas for each circulation control plenum are provided alongside their ideal values in Table 4.3. The table also includes the percent difference between the right and left wing(R/L \% Diff), and the percent error of the left and right wing compared to the ideal (L\%Error and R\%Error). Total exit area for the leading and trailing edge are also included along with the combined total.

Table 4.3: Slot Exit Area (inches ${ }^{2}$ )

\begin{tabular}{ccccccc}
\hline \hline & Ideal & Left Wing & Right Wing & L/R \%Diff & L\%Error & R\%Error \\
\hline LEIB & 0.710 & 0.700 & 0.730 & 4.30 & 1.60 & 2.70 \\
LEOB & 0.760 & 0.920 & 0.940 & 2.70 & 20.40 & 23.70 \\
TEIB & 0.600 & 0.610 & 0.620 & 1.30 & 2.70 & 1.30 \\
TEOB & 1.110 & 1.190 & 1.160 & 2.20 & 7.20 & 4.80 \\
\hline Total $_{L E}$ & 1.480 & 1.620 & 1.670 & 3.40 & 9.750 & 13.50 \\
Total $_{T E}$ & 1.700 & 1.800 & 1.780 & 1.00 & 5.590 & 4.540 \\
\hline Total & $\mathbf{3 . 1 8 0}$ & $\mathbf{3 . 4 2 0}$ & $\mathbf{3 . 4 6 0}$ & $\mathbf{1 . 1 0}$ & $\mathbf{7 . 5 0}$ & $\mathbf{8 . 7 0}$ \\
\hline
\end{tabular}

When comparing individual plenums, the leading edge outboard plenum deviates most drastically from the ideal particularly in the case of the right wing. It 
does, however, match well between wings with a percent difference of only $2.70 \%$. The greatest asymmetry exists at the leading edge inboard slot, where exit areas differ by nearly 0.030 -in ${ }^{2}$. The benefits of the slot height adjustment system are realized when considering the exit areas of the trailing edge plenums.

The $\operatorname{Total}_{L E}$ and Total $_{T E}$ values for slot exit area are most revealing when simultaneously considering circulation control performance theory. More allowance for deviation from the ideal exists at the leading edge, as its sole requirement is to maintain flow attachment in the presence of the trailing edge jet. The additional area may lower the velocity at which air is issued from the leading edge, however the decrease would have negligible effect on its ability to maintain flow attachment. For this reason (despite the variation from ideal and slight asymmetry) the total slot exit area for the leading edge can be considered acceptable. The total trailing edge exit area matches very well with ideal (varying by only 0.10 -in ${ }^{2}$ in the greatest instance).

In total the actual blowing system area is greater than the ideal by $8.70 \%$ at most-with the majority of that error contributed by the leading edge. Asymmetry is limited to $1.10 \%$ between the wings which means jet mass flow rate and velocity should be well balanced.

\subsubsection{Slot Height Sensitivity to Pressurization}

Past circulation control experiments have outlined the importance of documenting the behavior of the slot height under pressure. During pressurization, a small change in the slot height could have serious consequences in the uncertainty associated with the calculation of the discharge coefficient. An investigation into the effect of pressurizing the plenum (turning on circulation control flow) was 
conducted using the trailing edge of the right wing. The experiment was performed prior to the wind tunnel test, using the existing setup from the slot flow uniformity work. The comparison between static and pressurized slot height for the right wing trailing edge can be seen in Figure 4.6.

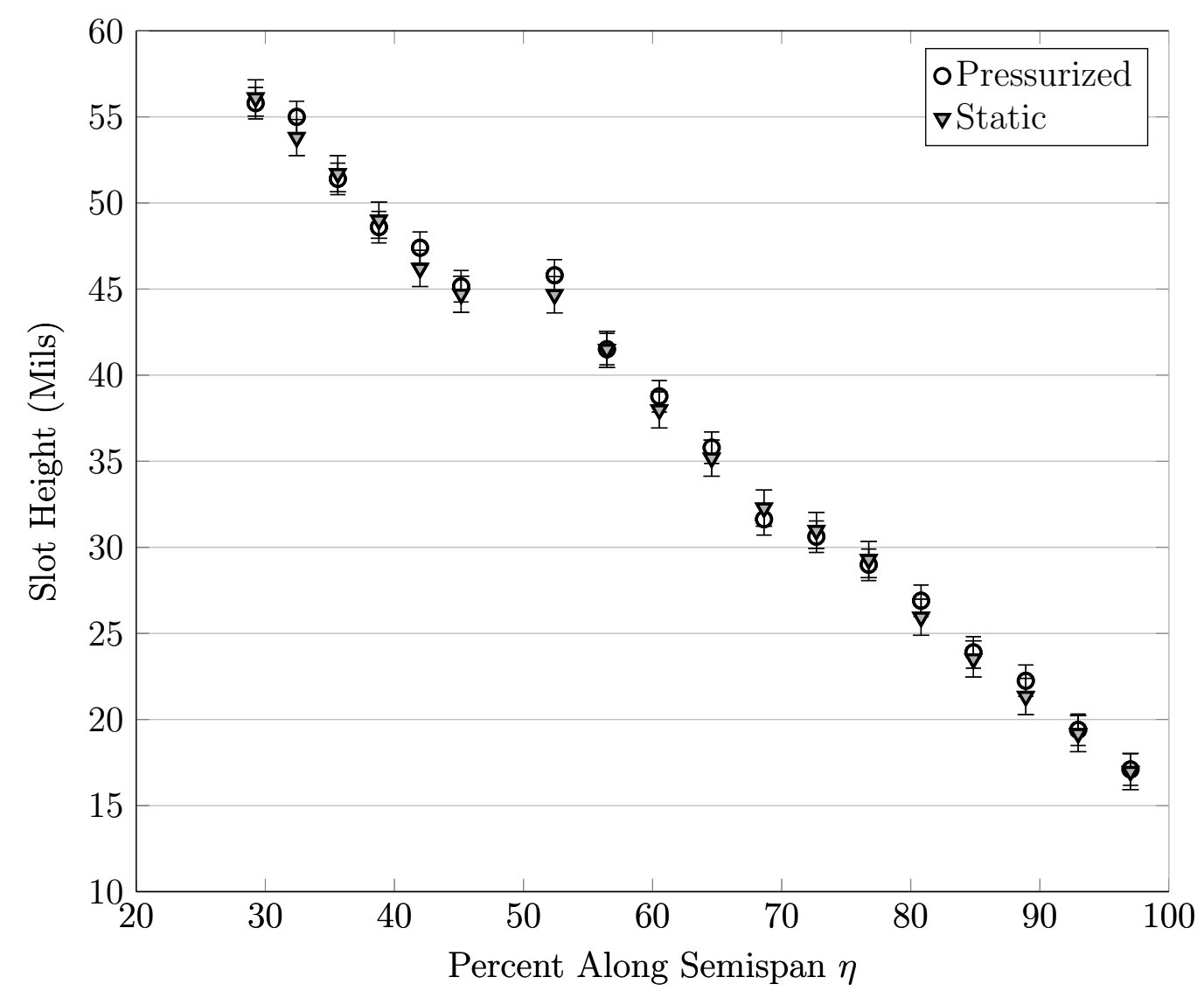

Figure 4.6: Pressurized vs Static Slot Height.

Repeat measurements of the slot height in a static and pressurized state were used to calculate the uncertainty of the measurements based on a $95 \%$ confidence interval. Under static conditions the Gapmaster probe was capable of obtaining measurements with a precision of 1.1-mils. In a pressurized state the confidence limits on a given measurement are 0.9-mils (slightly less than static error due to a greater number of repeat runs). 
The importance of the error calculations may not be readily apparent in Figure 4.6, however these results had a profound effect on the efficiency of the wind tunnel test. Error in the measurements is greater than the scatter between data sets for any corresponding pair, which means that no significant difference exists between slot height measurements taken in a static state or pressurized state. Not only does this result verify the success of the set-screw/tie-down system at securing the slot height, but it also alleviates the need for further pressurized measurements. Static slot height measurements were preferred as they greatly reduced the risk of damaging the delicate Gapmaster probe, and could be conducted without the support of the compressor. Further measurements including the pretest, during test, and post-test slot height datasets were obtained under static conditions.

\subsection{Jet Total Pressure Survey}

Many computational predictions are subject to simplifications due to lack of information, however with accurate slot height data a CFD analyst has the ability to accurately reflect the precise geometry used in testing the AMELIA configuration. In order to remove further need for simplification, the AMELIA test team endeavored to establish measurements that could provide a boundary condition for the circulation control system. At the conclusion of recording pressurized slot height data a small window of opportunity (of only 3 days or so) presented itself.

Ideally an instrument that could provide velocity components (like a 5-hole probe or 2-axis hotwire) would be used to fully characterize the slot flow. However, due to the relative haste at which the measurements needed to be taken and the size of the jet itself, a simpler total pressure probe would suffice, relying 
on the previous flow visualization work for flow directionality.

\subsubsection{Survey Set-Up}

Conducting a survey across a slot ranging from 60 to 12 mils requires an unusually small instrument in order to record measurements with acceptable resolution. Stainless steel tubing with an outer diameter of 0.020 -in was used to fashion a rudimentary total probe for this investigation. The thin tubing was supported by a housing of concentric tubes of increasing diameter, which protected the probe from deforming under the force of the circulation control jet.

The total probe was mounted to a 2-axis traverse which was secured to a second work bench just behind AMELIA's circulation controls slots-the flaps were removed to permit better access to the slot face. The traverse was controlled via LabView software, which would input a grid of datapoints. MATLAB was used to create a uniform grid for each plenum. Readings were taken using an Omega pressure transducer (model PX142-030D5V) with a range of 0 to 30 psid, which was linked to a lab computer providing data storage.

Capturing total pressure data at the leading edge was particularly difficult. The upper surface skin prevented the ability to fully traverse the jet. Furthermore the orientation of the slot itself was problematic as the two axis traverse would need to be mounted on its side to traverse the slot face(or a third axis would need to be incorporated). Consideration of the time and equipment constraints lead to a compromise in the leading edge data. The total probe would survey the jet along the $20 \%$ chord line (this corresponds to a model panel junction that could easily be traced with the probe). Data at this location would rely on the success of the Coanda surface to relay the total pressure of the jet and would, of course, 
experience some total pressure decay as the jet expands.

The test configuration used during the flow uniformity calibration was repeated in this effort. Unfortunately, as the reader may recall, the upper surface panel aft of the leading edge inboard plenum could not be incorporated due to the mass flow supply piping. Consequently measurements of the leading edge inboard total pressure were not recorded. The test set-up is shown in Figure 4.7. During each run a mass flow rate of $1.58 \frac{\mathrm{lb} m}{s}$ was used (approximately the "Full $C_{\mu}$ " wind tunnel test condition).

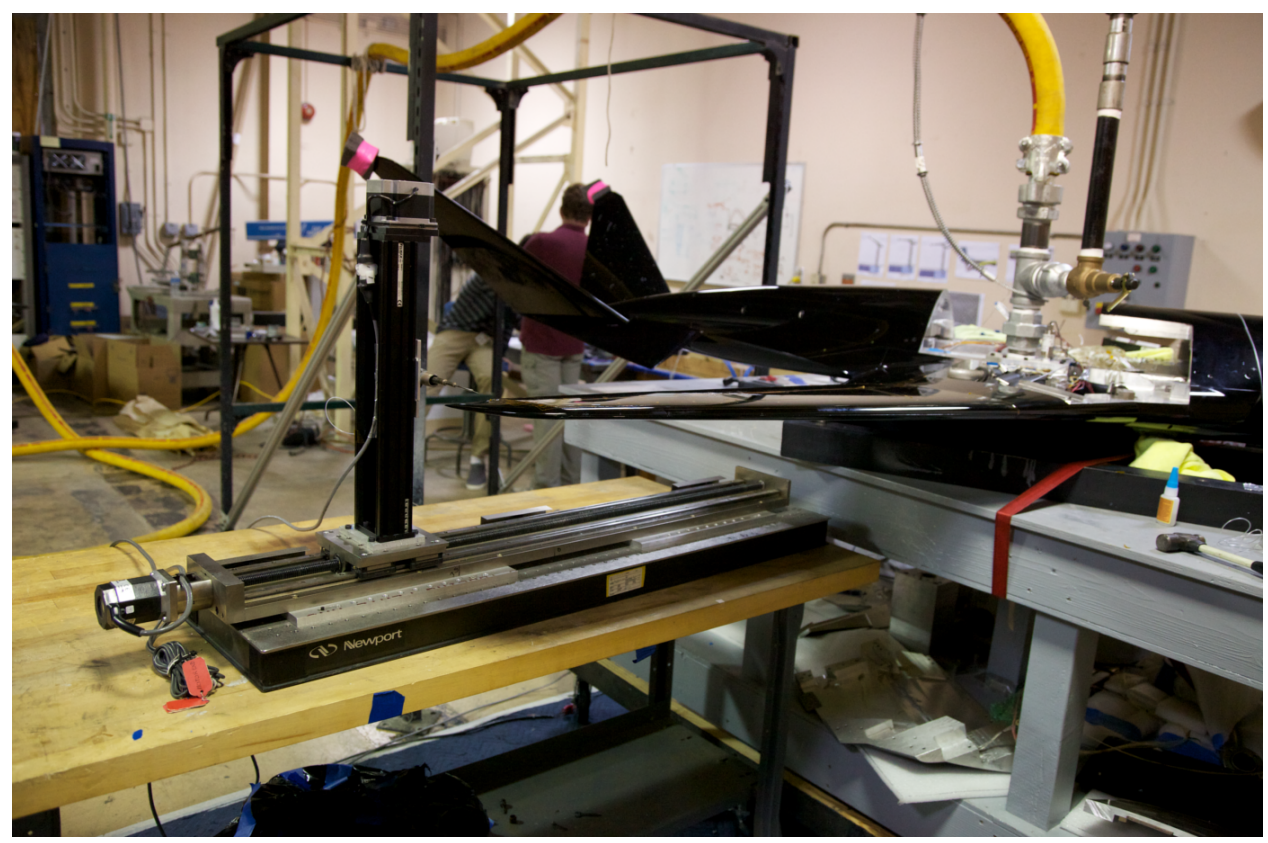

Figure 4.7: Total pressure survey set-up at the right wing trailing edge.

\subsubsection{Survey Results}

The total pressure profiles for the right wings trailing edge inboard plenum are presented in Figure 4.8. The profiles were recorded at various locations along the span of the plenum, these are indicated by the station number shown in the 
legend. (Table 4.4 provides a quantification of the station number as a percentage along the span of the individual plenum.) The vertical axis represents vertical probe position and is presented in mils from the jet centerline. Total pressure can be read from the horizontal axis in psid. The measurements presented in the figure were taken roughly 60 thousandths of an inch from the slot face. As expected the highest total pressure occurs at the inboard most station where the slot height is greatest. The pressure continues to decrease as the probe travels outboard and the slot height tapers. This is consistent with the readings from the internal total probes, which were 11.92, 11.10, and $10.75 \mathrm{psig}$ from the inboard- to the outboard-most probe. The variation in pressure is likely due to the plenum inlet location's alignment with the inboard-most probe. Total pressure could have been made equal by the addition of more plenum treatment, however the test team considered the results presented here acceptable.

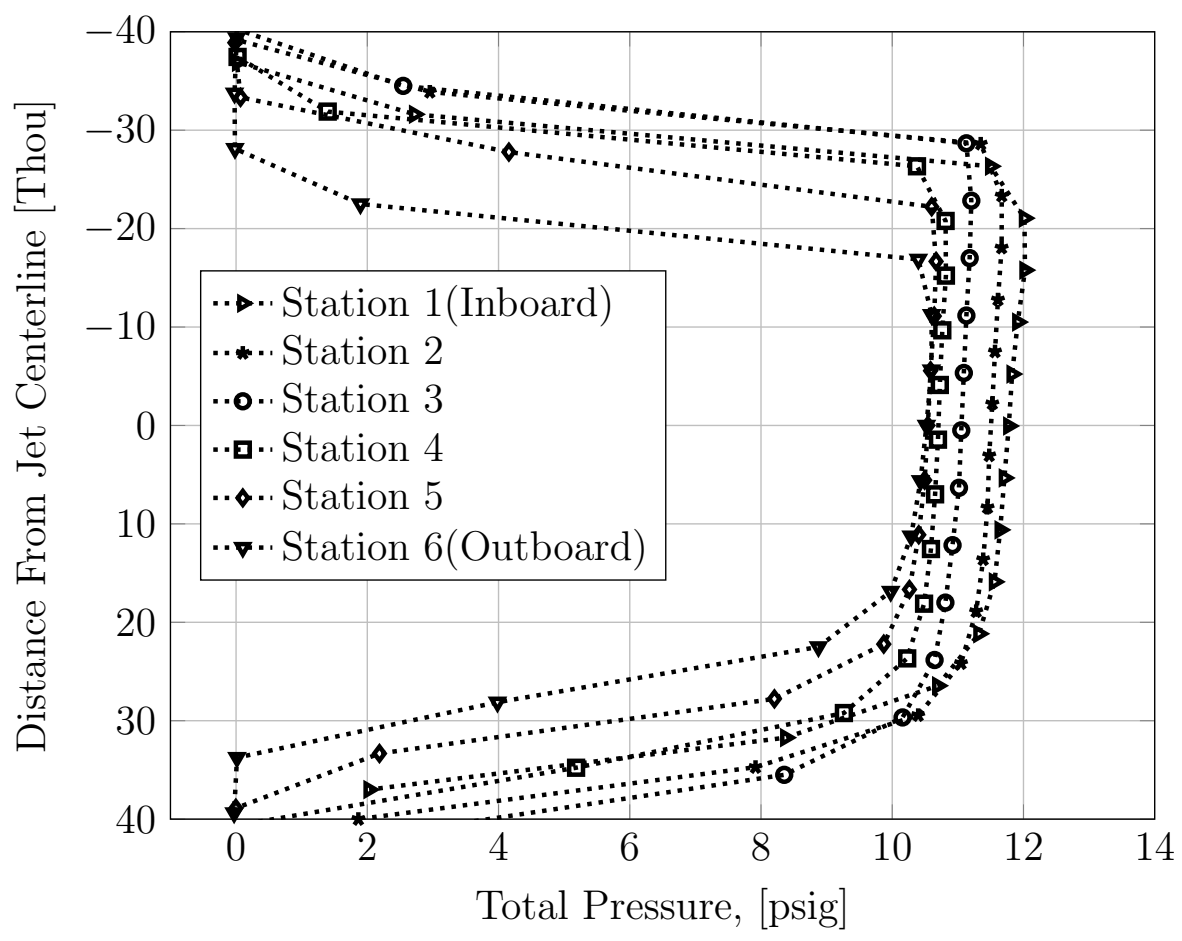

Figure 4.8: Right wing trailing edge inboard total pressure. 
Table 4.4: Station as percent plenum span (TEIB)

\begin{tabular}{cc}
\hline \hline Station Number & Percent Along Plenum Span \\
\hline Station 1 & $2 \%$ \\
Station 2 & $23 \%$ \\
Station 3 & $45 \%$ \\
Station 4 & $68 \%$ \\
Station 5 & $90 \%$ \\
Station 6 & $99 \%$ \\
\hline
\end{tabular}

The corresponding total pressure survey for the left wing is shown in Figure 4.9 (the legend corresponds to the same values in Table 4.4). The maximum total pressure is achieved at the inboard most station as expected, however it is nearly 2 psi less than the maximum of the right wing. This can be explain best considering the internal total pressure probe measurements, which were 10.30, 9.45, and 9.10 psig (again from inboard- to outboard-most probe). A small degree of variation may exist from differences in traverse alignment. It was very difficult to align the traverse on the left wing precisely as it had been on the right, primarily due to the traverse/model frame interference. It is suspected that as the probe head traveled outboard, it also traveled slightly away from the slot face, causing the decayed profiles shown at the outboard stations. Unfortunately, this survey did not capture the upper portion of the jet. 


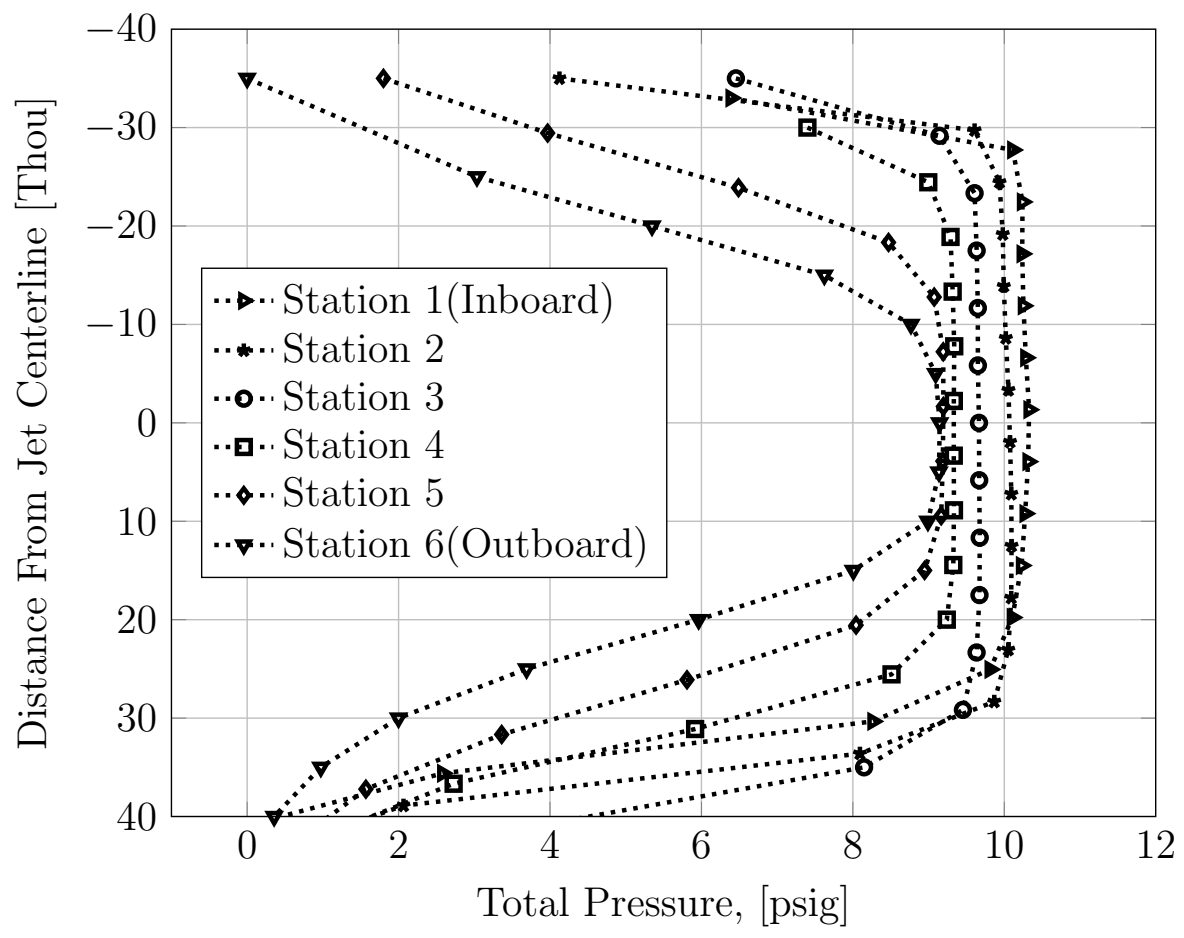

Figure 4.9: Left wing trailing edge inboard total pressure.

A survey of the right wing trailing edge outboard plenum (shown in Figure 4.10 ) shows similar rounded profiles (the corresponding station definitions are presented in Table 4.5). In this instance, however, the lack of definition may be caused by poor grid resolution as the test team had a difficult time creating grids for the outboard slots. A greater degree of total pressure variation existed inside the plenum (readings from the internal probes were 12.70, 9.30, and $12.10 \mathrm{psig}$ for inboard, midboard, and outboard probes respectively) due to the additional layer of flow treatment in the inlet vicinity. The total pressure profiles near the wingtip show more decay than expected, which may indicate another instance of traverse misalignment. Although ideally these profiles would align as well as those from the trailing edge inboard plenum, these were found to be sufficient given that the flow directionality issues had been solved. 


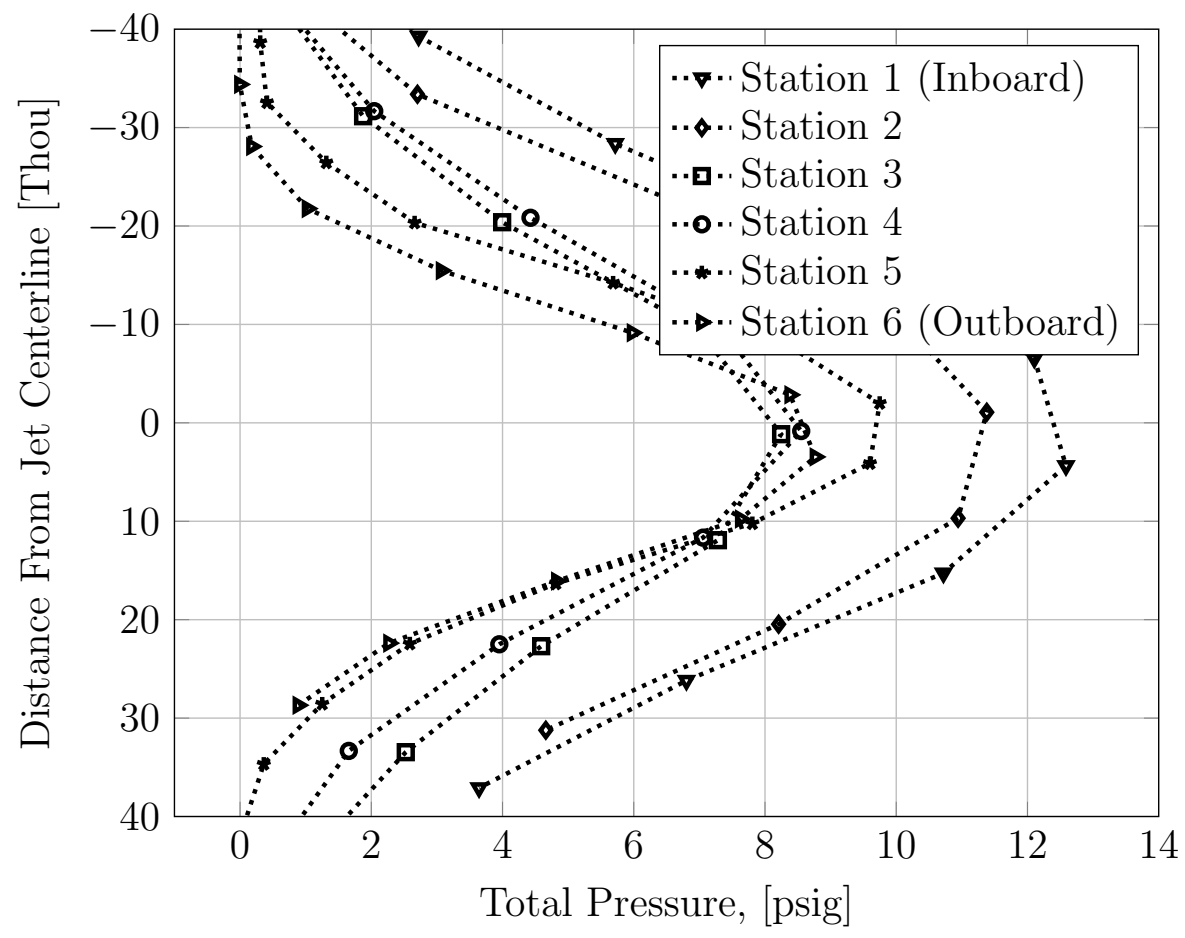

Figure 4.10: Right wing trailing edge outboard total pressure.

The left wing trailing edge outboard total pressure profiles are presented in Figure 4.11 and also correspond to Table 4.5. During this case total probes read 10.10, 9.40, and 9.00 psig (inboard to outboard). Grid selection difficulties lead to the exclusion of some stations, as well as partial results at station 3 , however the results show some interesting trends. An unusually low total pressure exists at station 2, the cause of which is unknown. Additionally the outboard profiles were captured with good resolution, but contain greater total pressure magnitude than expected. With nearly identical slot height as the corresponding location on the right wing, perhaps this provides more evidence of traverse misalignment on the right wing. 


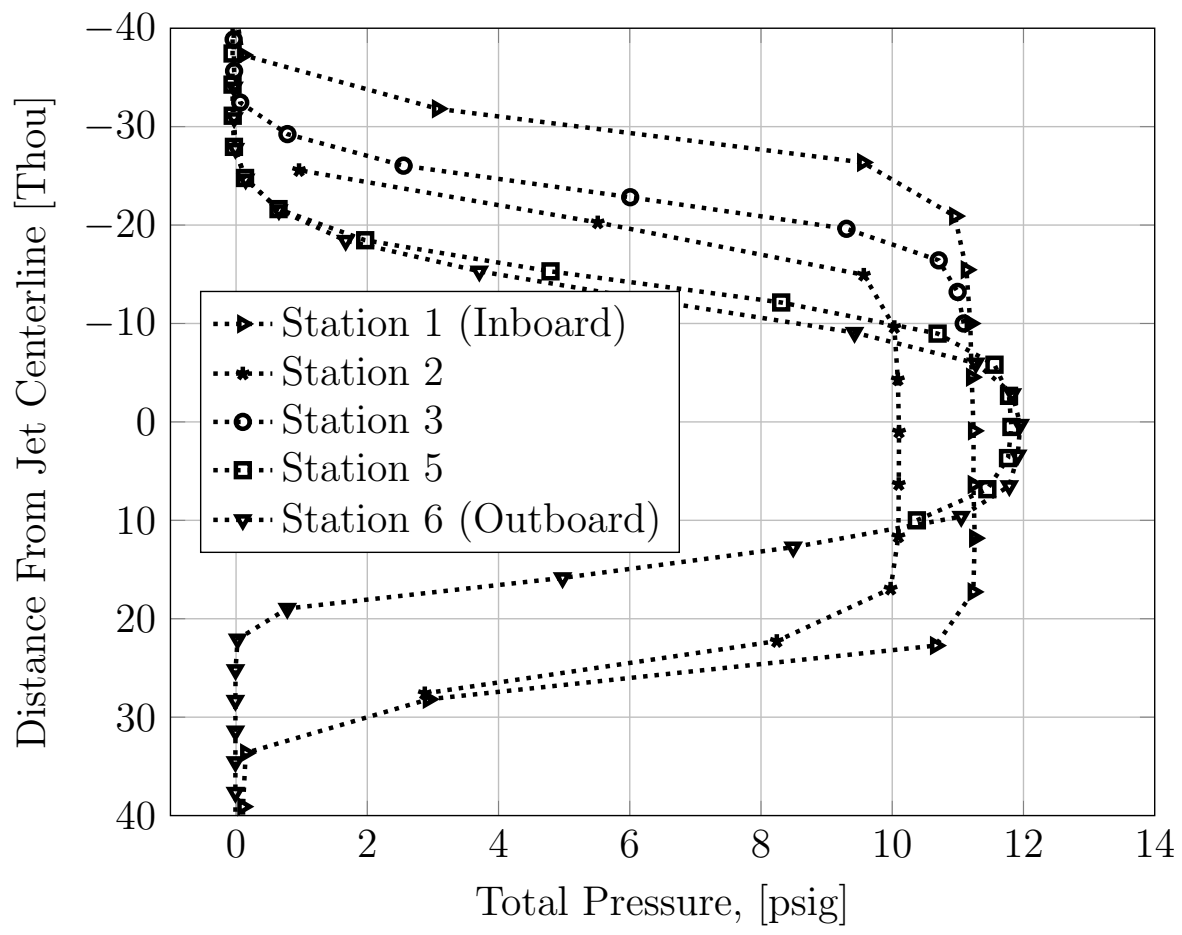

Figure 4.11: Left wing trailing edge outboard total pressure.

Table 4.5: Station as percent plenum span (TEOB)

\begin{tabular}{cc}
\hline Station Number & Percent Along Plenum Span \\
\hline Station 1 & $3 \%$ \\
Station 2 & $23 \%$ \\
Station 3 & $42 \%$ \\
Station 4 & $61 \%$ \\
Station 5 & $80 \%$ \\
Station 6 & $98 \%$ \\
\hline
\end{tabular}




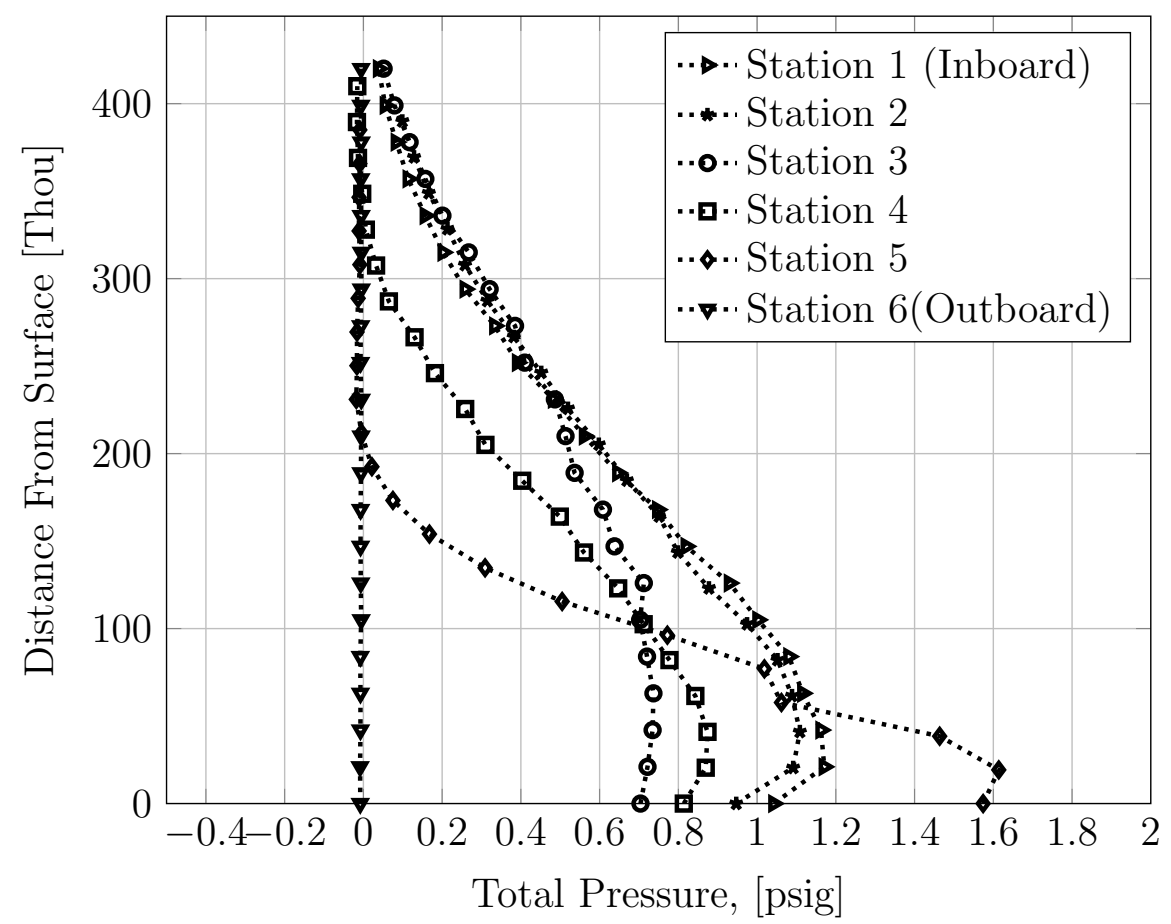

Figure 4.12: Right wing leading edge outboard total pressure profiles at $\frac{X}{c}=20 \%$.

An upper surface survey of the right wing, showing the jet decay from the leading edge slot, is presented in Figure 4.12. As mentioned in the previous section, surveys of this type were taken along the $20 \%$ chord line. The 20 thousandths OD probe was unable to resolve total pressure close to the wall, however the profiles show good agreement along the span, given the distance from the jet. Similar to the behavior of the trailing edge outboard plenum, at the leading edge mid span region (stations 3 and 4), there is a slight loss of pressure due to the second layer of Rigimesh required near the plenum inlet. The profile at station 5 has the greatest maximum total pressure this is most likely a result of the orientation of the traverse and slightly higher pressure at the end of the plenum (similar to that at the trailing edge outboard plenum). Station 6 captured no profile because this station was beyond (outboard) the influence of the leading edge plenum. 


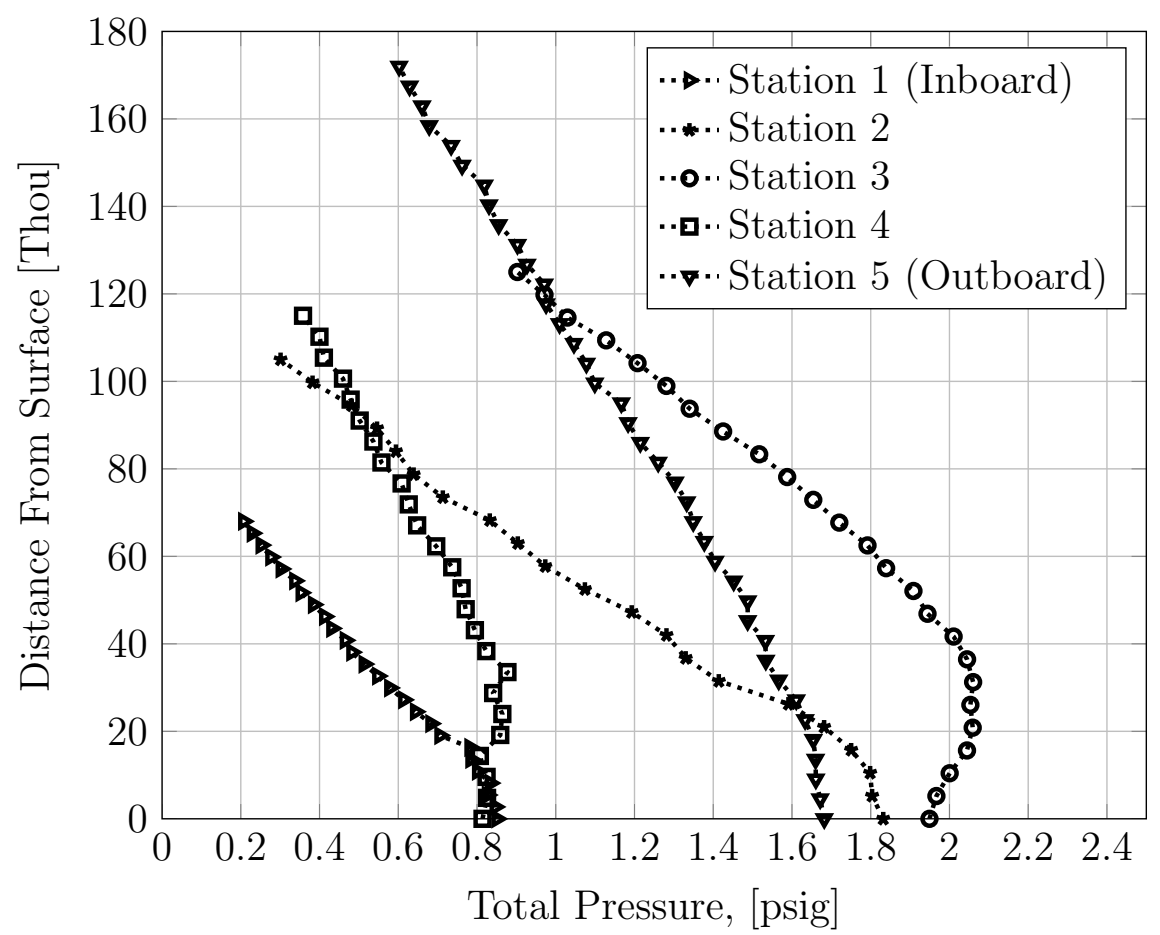

Figure 4.13: Left wing leading edge outboard total pressure profiles at $\frac{X}{c}=20 \%$.

The survey of the left wing's leading edge provided little useful information. Unlike it's counterpart from the right wing, the survey failed to capture the extent of the jet in the vertical direction (notice the maximum height reached is less than half that of Figure 4.12). Furthermore, pressures achieved at the various stations seem random and reflect few of the properties shown on the right wing. It's suspected by the test team that significant misalignment of the traverse occurred, in addition to possible supply condition inconsistency (i.e. flow supply or flow distribution adjustments made during the survey). Unfortunately the processing of this data and subsequent evaluation of its quality was delayed until the compressor was returned, thus eliminating the possibility of resurveying the left wing leading edge outboard plenum. 
Table 4.6: Station as percent plenum span (TEOB)

\begin{tabular}{cc}
\hline Station Number & Percent Along Plenum Span \\
\hline Station 1 & $1 \%$ \\
Station 2 & $14 \%$ \\
Station 3 & $28 \%$ \\
Station 4 & $57 \%$ \\
Station 5 & $86 \%$ \\
Station 6 & $101 \%$ \\
\hline
\end{tabular}

\subsection{Lessons Learned}

In completing the flow uniformity calibration and the system characterization many opportunities for improvement were recognized. A mass flow measurement device capable of more closely representing the conditions in the wind tunnel would have been preferred, however time constraints forced the use of the critical flow nozzle. Furthermore, better grid construction during the preparation for the total pressure surveys would have lead to a more complete dataset. The data would have also benefited from more precise alignment of the traverse system. More complete documentation of the internal total probe readings (especially during the flow uniformity survey during which they were not recorded) would have also benefited the dataset. 


\section{Chapter 5}

\section{Flow Visualization}

This chapter is devoted to the flow visualization effort conducted both during the calibration and during the wind tunnel test. While AMELIA's aerodynamic and performance results are thoroughly discussed in Reference [11](i.e. drag polars, lift curve slopes, etc.), the intention of the following is to provide a visual supplement that may also serve as a tool for comparison to results obtained via predictive codes. Herein, we may directly view evidence of the effect of circulation control on the flowfield.

\subsection{Oil Flow Visualization}

Perhaps no better application exists for flow visualization than in the diagnosis of a blowing or circulation control system. The flow visualization work outlined in Chapter 3 was vital to the success of overall wind tunnel test. Throughout the execution of the wind tunnel test, instances for investigation using oil flow visualization presented themselves. Beyond the periodic verification of flow uniformity, surface oil flow was used to capture aspects of the flowfield that remained yet 
unknown. Table 5.1 summarizes particular regions of interest and the reasoning behind their investigation.

Table 5.1: Regions of Interest

\begin{tabular}{l|l}
\hline \hline Region & Reasoning \\
\hline $\begin{array}{l}\text { Leading Edge Lower } \\
\text { Surface }\end{array}$ & $\begin{array}{l}\text { The presence of CC flow should cause both the leading } \\
\text { and trailing edge stagnation points to translate to the lower } \\
\text { surface. }^{*}\end{array}$ \\
\hline Wing Blend & $\begin{array}{l}\text { Based on early CFD results it is suspected that flow from the } \\
\text { leading edge inboard plenum turns outboard as it passes over } \\
\text { the wing blend. }\end{array}$ \\
\hline Fuselage & $\begin{array}{l}\text { Seperated flow on the aft end could indicate poor closeout } \\
\text { design. }\end{array}$ \\
\hline TPS Nacelle & $\begin{array}{l}\text { The nacelle was designed (with the aid of CFD) to minimize } \\
\text { separation, oil streamlines could provide a good comparison } \\
\text { to the prediction. }\end{array}$ \\
\hline
\end{tabular}

*The stagnation point should be more clearly visible at the leading edge due to the presence of the dual radius flap at the trailing edge.

The author would like to remind the reader that only visualization results for these regions are discussed herein. Parties with further interest in the flow near the surface of the model may also benefit from the static pressure data presented in Reference [11].

\subsubsection{Oil Preparation}

While conducting the flow uniformity calibration in the Fluid Mechanics Lab the Cal Poly research team was introduced to a simple method of preparing oil for flow visualization. The method requires only the following three ingredients: 
synthetic oil, pigment, and olive oil. The typical mixture found to provide good visualization by the Cal Poly team was approximately 0.5-cups of oil, 1-tsp of pigment, and only a few drops of olive oil. The components were combined until the desired consistency and color was reached, at which time the mixture was poured into a standard coffee filter. By collecting the sides of the filter and gently "blotting" the bottom of the filter onto the cleaned model surface, oil would be transferred to the surface with an even distribution. Figure 5.1 depicts the oil surface before and after flow is initiated. Beyond ensuring a clean model surface prior to oil application, the edges of each cover and all pressure port orifices were sealed with Kapton tape.
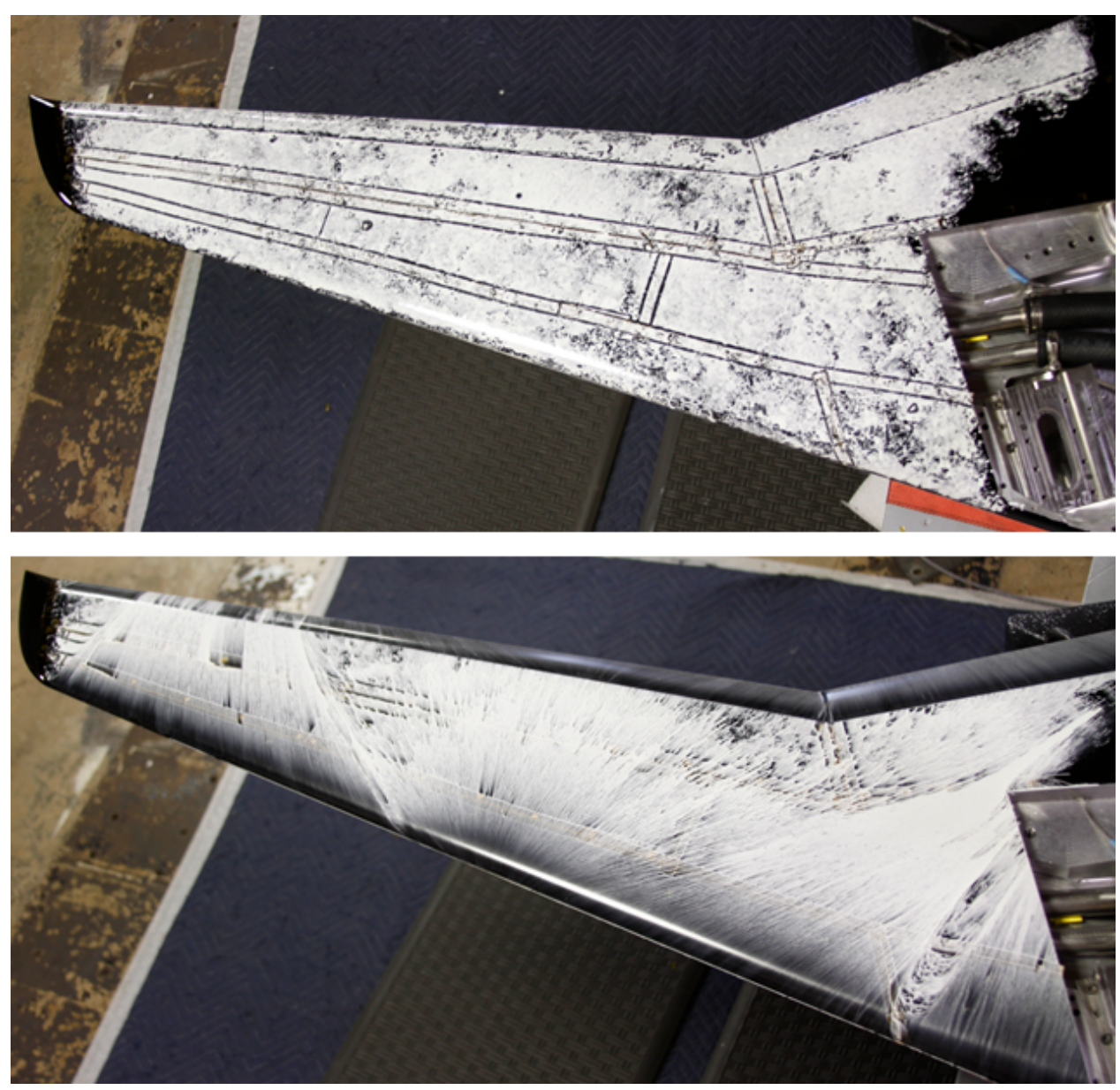

Figure 5.1: Oil application before(above) and after(below). 
The greatest challenge in successfully executing this type of flow visualization comes in selecting the appropriate oil viscosity for the given test condition. During the flow uniformity calibration, the jet issued from the circulation control system was expected to produce significant shear forces on the model surface. Thus a high viscosity gear oil was selected for this application (Amsoil's SAE 190 Off-Road and Drag Racing Gear Oil). A variety of oils were used in the subsequent oil flow visualization runs conducted in the wind tunnel and will be discussed on a case-by-case basis in the following sections.

Pigment was also carefully considered during the oil preparation. The flow uniformity calibration work utilized Titanium Dioxide, which (when combined with the oil) produces a light green pigment. A thin application of this mixture to the black model surface produces excellent contrast and leaves the oil looking more white than green. During the subsequent runs at the NFAC, other pigments were attempted which will be detailed in the following sections.

\subsubsection{Oil Flow Visualization Results}

The results of the visualization used for the flow uniformity calibration have previously been presented in Chapter 3, therefore the current section will be comprised of results from the flow visualization runs conducted at the NFAC. Surface oil flow visualization was attempted during four runs with varying degrees of success. In each case, executing the visualization in the NFAC's 40- by 80-ft test section proved significantly more difficult than during the flow uniformity calibration. Mounted to the sting, the model was elevated to approximately 23-ft and could be accessed via scissor-lift only(Figure 5.2 shows the test team applying oil to the model in the NFAC). Additionally the lengthy tunnel transients proved 


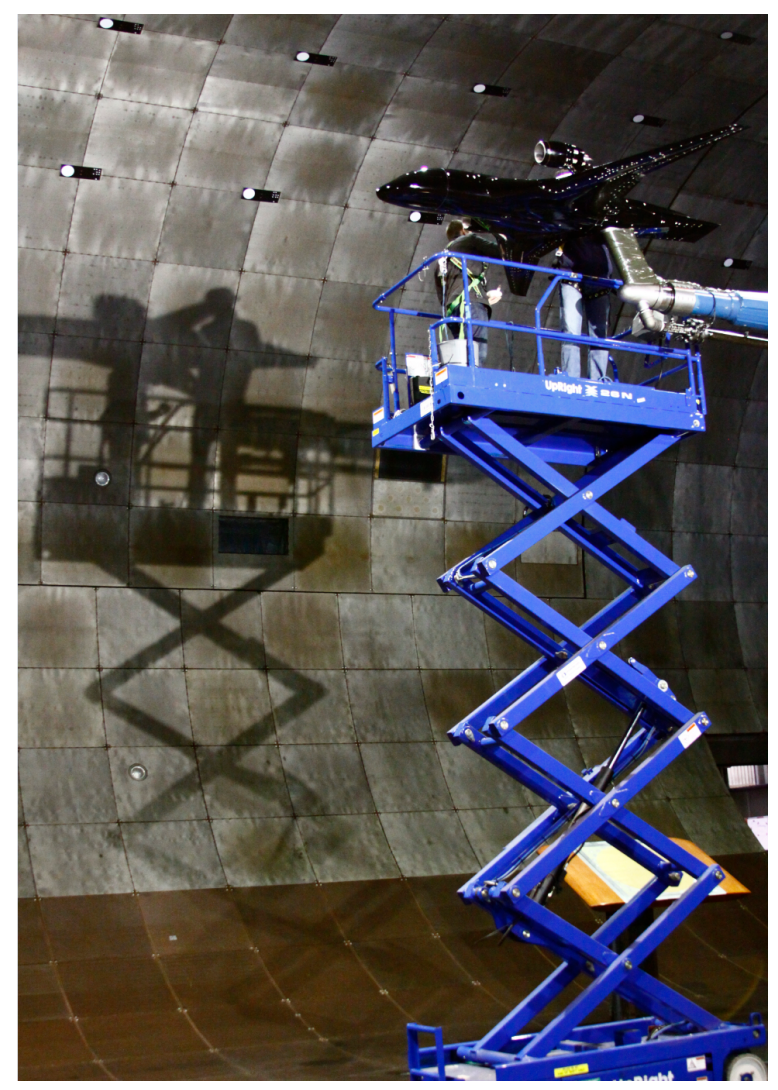

Figure 5.2: Oil Application in the NFAC.

to be problematic in some cases.

\section{Case 1}

The first flow visualization run was conducted in the second week of testing. The flow conditions are presented alongside a sample of the results in Figure 5.3.

Although acceptable results were obtained for the region under the influence of the circulation control jet, many of the unblown areas failed to develop streamlines. Upon reviewing the oil flow patterns, it was apparent that the oil viscosity used in the unblown regions (SAE 190) was much too high and failed to shear under the relatively weak force of the 30 knot freestream flow. No significant conclusions could be drawn from the streamlines on the TPS nacelle, or much of 

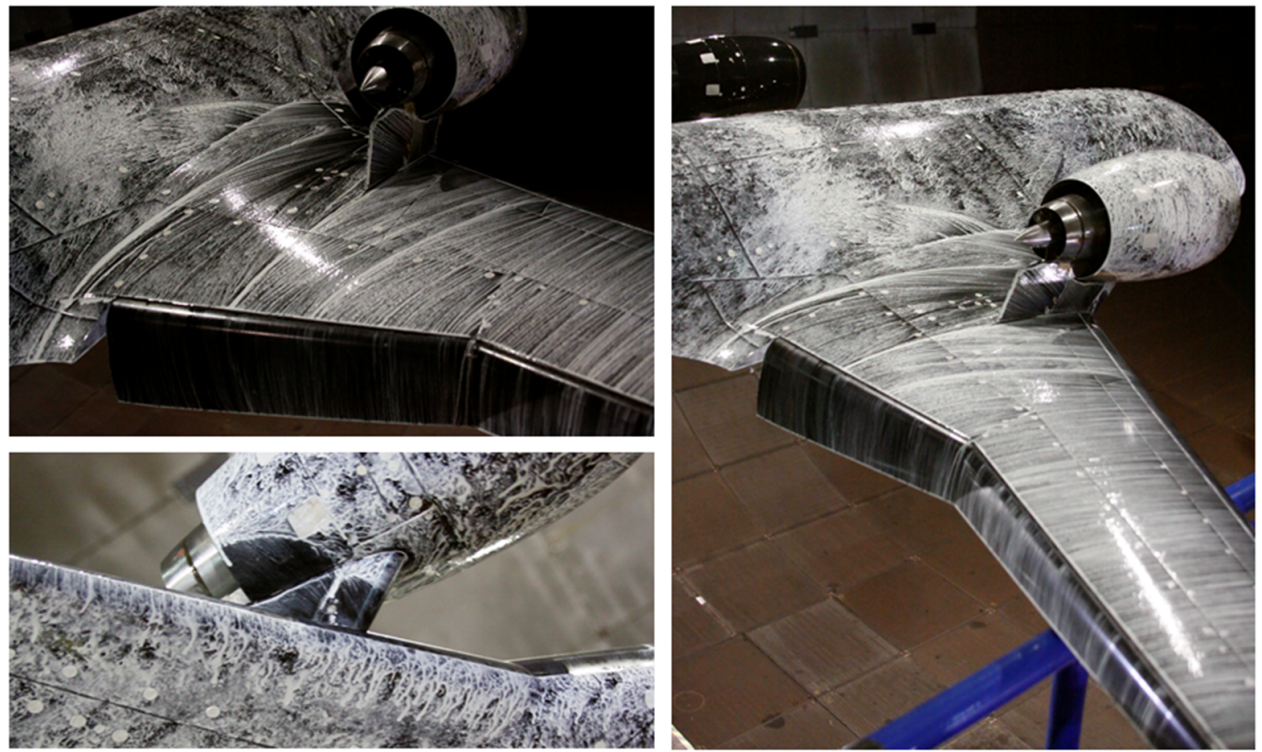

Run $45(01 / 10 / 2012)$ :

$q_{\infty}=3.12 p s f, \alpha=0^{\circ}, C_{\mu}=1.4, C_{T}=0$, Low Pylon, $60^{\circ}$ flap defl.

Figure 5.3: Oil Flow Visualization Case 1.

the fuselage. The image in the lower left of Figure 5.3 shows what appears to be some streamlines on the wing lower surface, however these are likely the result of gravity effects and thus meaningless. Some interesting flow patterns appear on the wing blend and near the TPS units. Although only partially captured in the oil, the streamlines across the wing blend seem to initially travel towards the model centerline as the CFD indicated. Near the TPS unit, streamlines indicate a slight misalignment of the pylon in the surface flow. This results in a minor lack of blowing on the inboard side of the pylon and may be a point of concern for designers wishing to implement an over-the-wing engine on a circulation control platform.

Unfortunately the test team was unable to repeat the run with an appropriate oil viscosity in the unblown regions. A few valuable conclusions could be drawn from the streamlines, but more importantly this run served to remind the test team of the significance of selecting the correct oil viscosity. 


\section{Case 2}

As the test progressed another opportunity for flow visualization presented itself-this instance provided for ample time to investigate proper oil viscosity in the unblown regions. In preparation for Case 2, the research team opted to modify the process of applying the oil to the model surface. In place of a uniform sheet of oil, the team applied droplets in an attempt to increase the visual contrast and allow for more detailed images. While the SAE 190 gear oil was applied to the blown area, a lower viscosity oil was prepared with red pigment and applied to the unblown area. The results are presented in Figure 5.4.

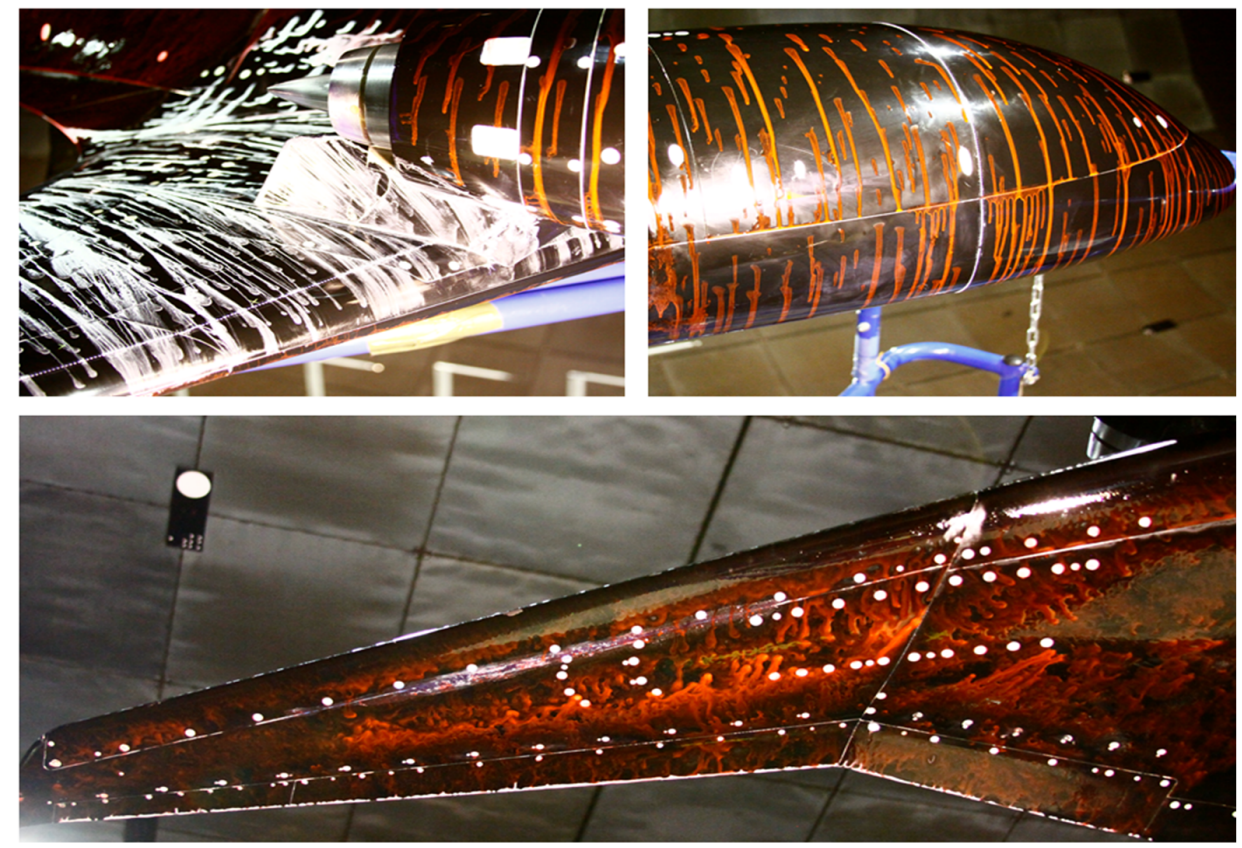

Run 114 (01/20/2012):

$q_{\infty}=3.4 p s f, \alpha=5^{\circ}, C_{\mu}=1.35, C_{T}=0$, Low Pylon, $0^{\circ}$ flap defl.

Figure 5.4: Oil Flow Visualization Case 2.

The results of this run were again unsatisfying. Despite a decrease in the oil viscosity for the unblown regions, the red colored oil failed to shear under the freestream flow. It did, however, shear under the force of gravity, which is 
particularly evident on the fuselage and TPS nacelle and in the "pooling" shown on the wing lower surface. Furthermore, the oil droplets appeared to hinder the visualization of the flow rather than help.

Although this case wasn't entirely successful in terms of investigating the regions outlined in Table 5.1, the test team was fortunate enough to have ample time to conduct another flow visualization case immediately following Case 2 . Throughout this series of runs (Case 2, 3, and 4) aerodynamic and performance data was continually collected, thus some conditions were subject to change depending on the test matrix (which held priority over the visualization data).

\section{Case 3}

Preparation for Case 3 immediately followed the model cleaning regiment conducted upon the conclusion of Case 2. Another oil (having lower viscosity than the red mixture used in Case 2) was selected for the unblown regions and prepared with titanium dioxide. The test team abandoned the application of oil droplets in favor of the uniform coat of oil-as it lead to more acceptable results. The outcome of Case 3 is provided in Figure 5.5.

As the test conditions show, during this case the TPS units were in operation at full mass flow rate (corresponding to an RPM near 34,000), and the tunnel freestream was 60 knots. With these conditions, safety regulations prevented the test team's presence in the test section during the run. Unfortunately the additional time required to image the model-tunnel transient time plus scissor lift setup time-allowed the streamlines to decay (due to gravity) on many of the vertical surfaces. Despite the gravity effects some new conclusions can be drawn from this unique dataset. For the first time the influence of the TPS exhaust 

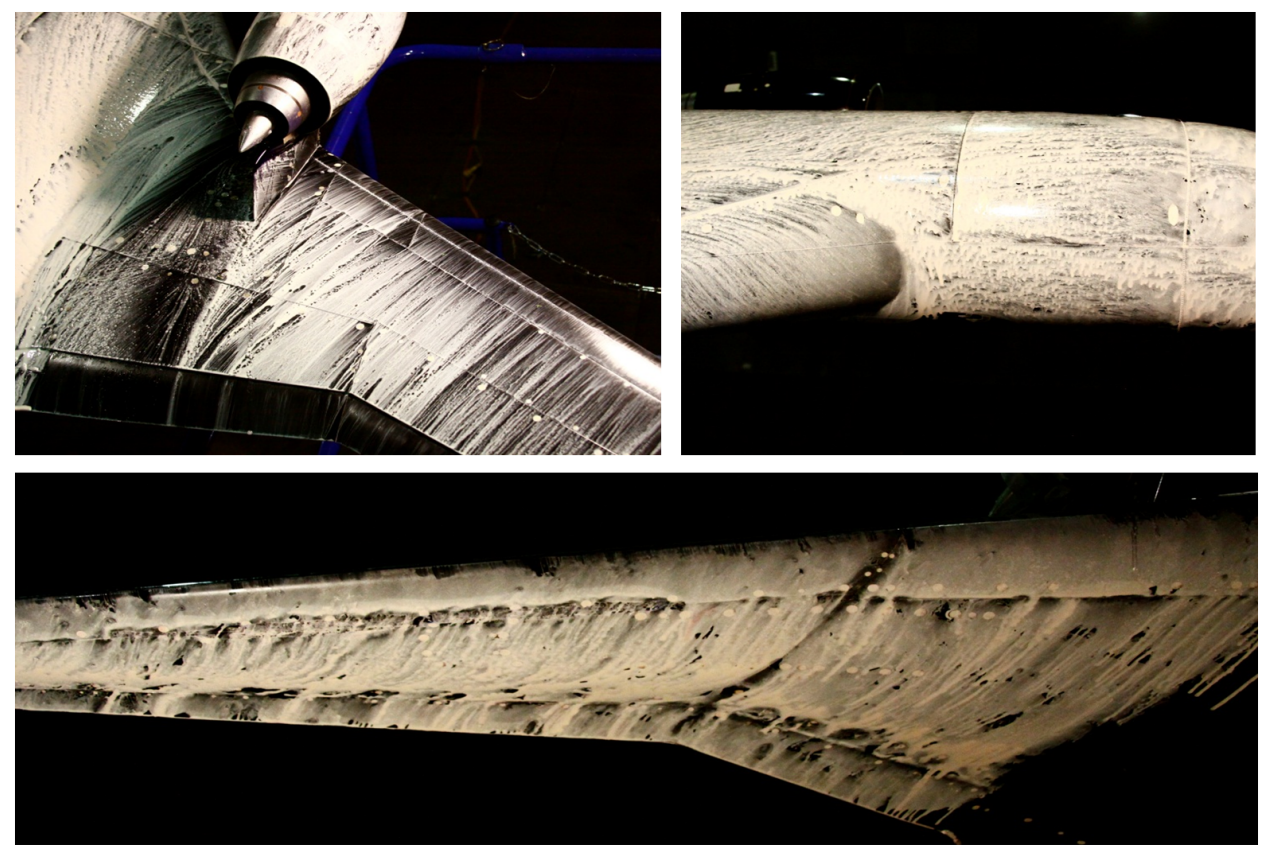

Run $115(01 / 20 / 2012)$ :

$q_{\infty}=12.2 p s f, \alpha=10^{\circ}, C_{\mu}=0.38, C_{T}=0.89$, Low Pylon, $O^{\circ}$ flap defl .

Figure 5.5: Oil Flow Visualization Case 3.

is captured by the visualization(shown in the upper left of Figure 5.5). The exposed black surface of AMELIA's wing just aft of the pylon indicates the jet impingement. In this region the TPS exhaust dominates the upper surface, and the circulation control flow is interrupted as indicated by the coalescing of surface streamlines just outboard of the exhaust impingement point. The image in the upper right of the figure displays some streamline turning at the wingroot, and shows no indication of separation on the fuselage. Some possible evidence for flow transition on the fuselage may be present in the blurred streamlines aft of the trip strip, however this may be gravity induced. Another possibly visible flow aspect is the leading edge stagnation point on the lower surface. The possibility for streamline manipulation due to gravity effects is particularly high in this region, but a separation point may be visible near the leading edge plenum cover junction (about 20\% chord aft of the leading edge). Additional images of the 
aft fuselage show no separation and indicate the LEIB flow turning outboard across the wingblend as indicated in the preliminary CFD cases (see appendix for additional images).

\section{Case 4}

A model change occurred between Case 3 and Case 4 during which the $0^{\circ}$ flap was exchanged for the $80^{\circ}$ flap. The run was conducted with a freestream velocity of only 30 knots and the TPS units were powered off which permitted the test teams presence in the tunnel. During this case, images were captured immediately following the run. The oil streamlines from Case 4 are presented in Figure 5.6.
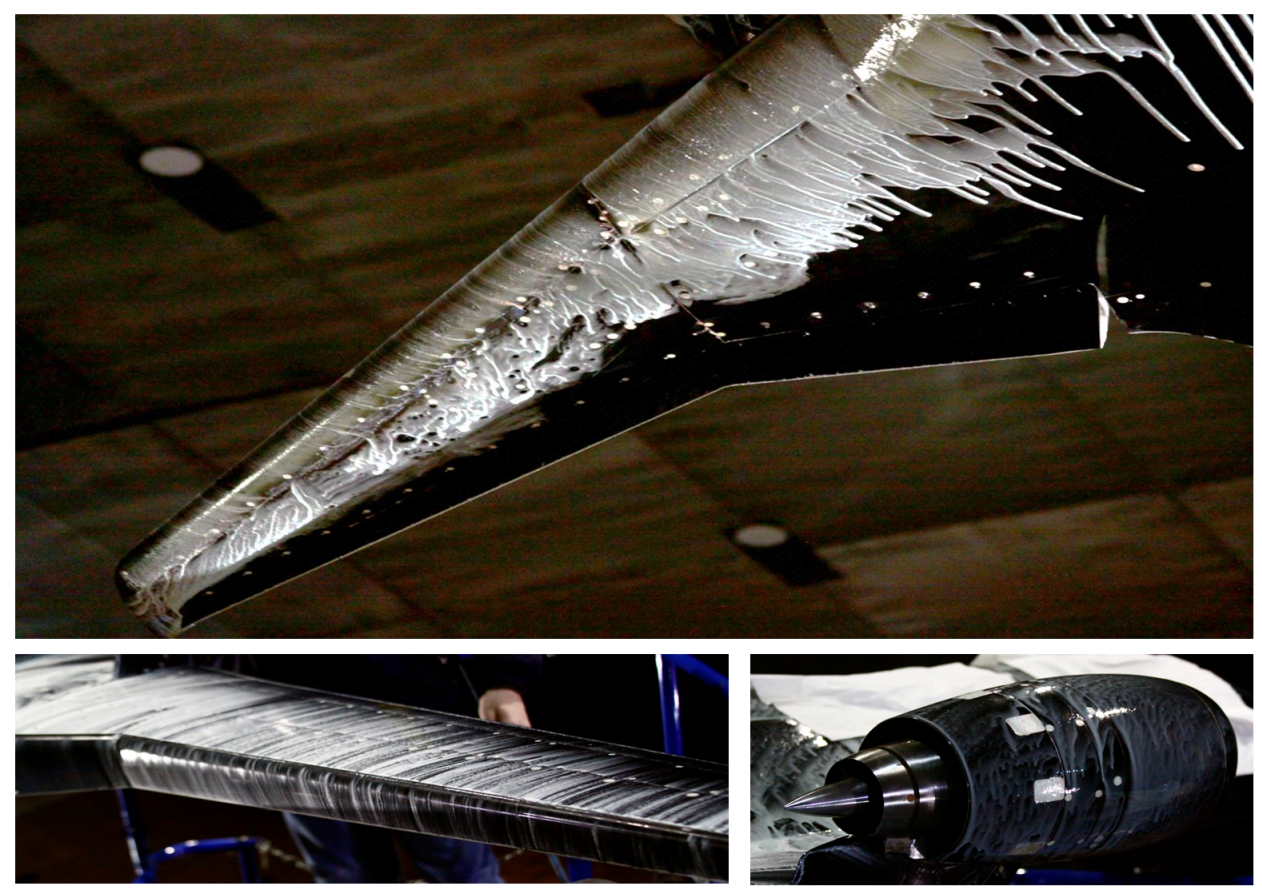

Run $116(01 / 20 / 2012)$ :

$q_{\infty}=3.24 p s f, \alpha=10^{\circ}, C_{\mu}=1.43, C_{T}=0$, Low Pylon, $80^{\circ}$ flap defl.

Figure 5.6: Oil Flow Visualization Case 4.

Despite the prompt image capturing at the close of the run, the low viscosity 
oil used on the unblown regions sheared under the force of gravity on most vertical surfaces. Traces of streamlines, however, were visible on the TPS nacelle and did not indicate any separation near the aft end. As expected, streamlines on the flap showed acceptable uniformity and flow attachment. Perhaps encouraged by the drastic flap deflection, the lower surface stagnation line seems to appear again near the $20 \%$ chord line, although its alignment with the plenum cover/model junction seems suspicious.

\section{Case 5}

Efficient test practices allowed the research team additional tunnel time to explore the "clean" AMELIA configuration-without the TPS units. It was thought that a CFD analyst attempting to simulate the test conditions might start with the clean configuration as it provides the most simplified flow. Fortunately enough time was allotted for a single oil flow case, the results of which are presented in Figure 5.7.

The clean configuration was subject to some extreme test conditions (note the $20^{\circ}$ angle of attack coupled with an $80^{\circ}$ flap deflection and a freestream velocity of 60 knots). Under these conditions, despite the leading edge blowing, the oil flow indicates the occurrence of separation at the wingtip. With no pylon to disrupt the flow, streamlines from the leading edge inboard plenum traverse the wing to the trailing edge as expected. Here we see again, the leading edge flow turning about the wingblend. Streamlines seem to collect at the trailing edge in the unblown region of the wingroot. Lower surface streamlines travel towards the upper surface, with only a few heading towards the trailing edge-an indicator that the oil was not placed aft enough to capture the full separation line. 


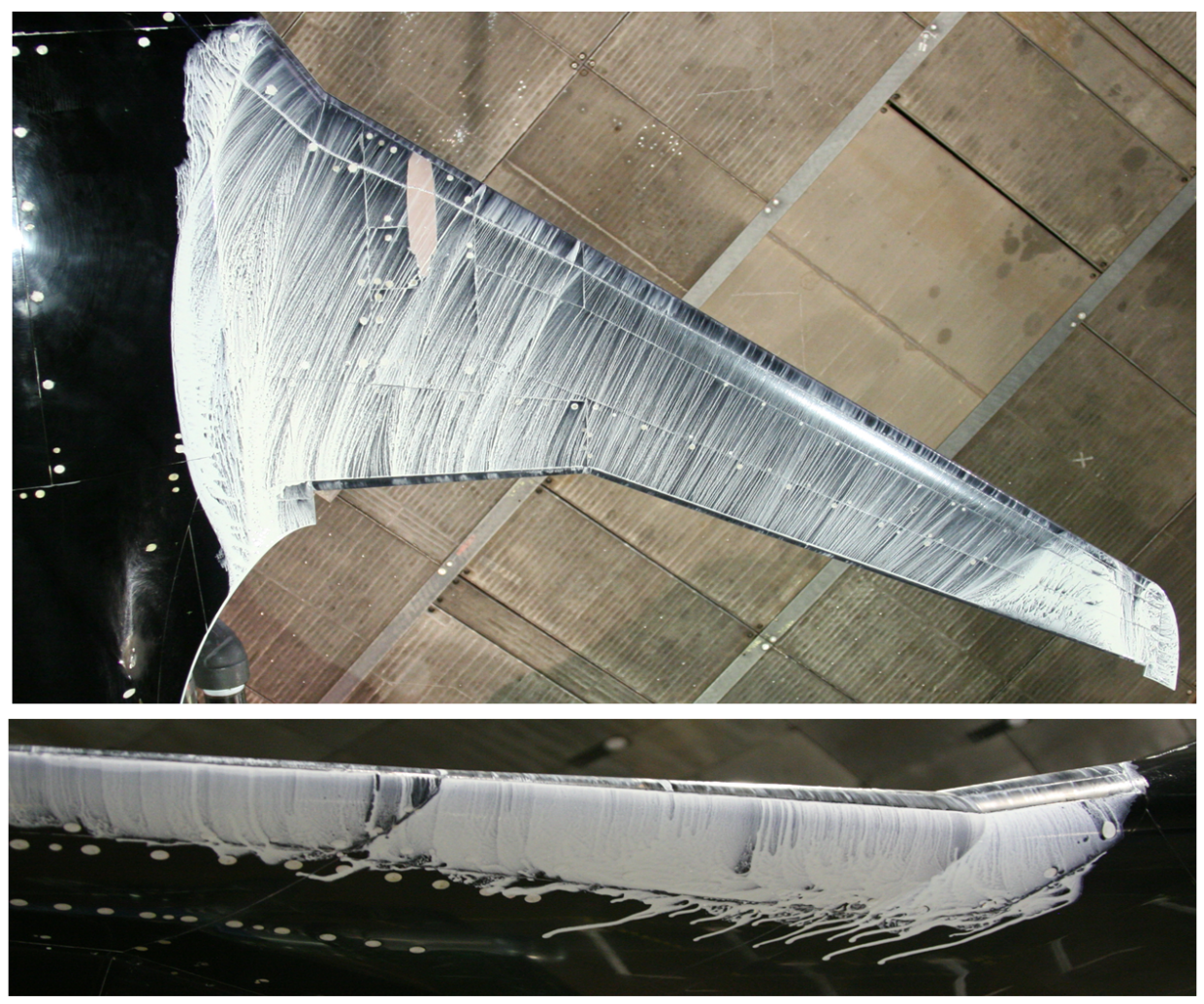

Run $231(02 / 08 / 2012)$ :

$q_{\infty}=11.85 p s f, \alpha=20^{\circ}, C_{\mu}=0.40$, Clean, $80^{\circ}$ flap defl.

Figure 5.7: Oil Flow Visualization Case 5.

\subsubsection{Oil Flow Conclusions}

The oil flow visualization provided valuable insight to AMELIA's surface flow, despite some difficulties with the execution. Images of the lower surface near the leading edge tend to suggest the leading edge stagnation point is augmented to approximately the $20 \%$ chord location. Although the evidence may be compromised by the gravity effects, a CFD analyst looking to make a comparison can easily do so based on the images and should not require exact location information. Flow issued by the leading edge circulation control plenum was seen to bend around the wing blend and travel slightly outboard as it reached the trailing edge. This is likely due to the opposing jet from the same plenum on the left 
wing acting to compress the flow in the plane of symmetry. No indications of fuselage separation or nacelle separation occur in the image sets.

\subsubsection{Oil Flow Lessons Learned}

The oil viscosity used for visualization is critical to quality of results. Although the test team was able to select an oil for the unblown regions that sheared under the relatively low freestream air, its low viscosity also made it difficult to image before gravity effects set in. It seems these results would have greatly benefited from better preparation in terms of selecting an oil viscosity that would permit shearing under the influence of the freestream flow, while resisting gravity effects. The dataset would have also benefited from the addition of runs with higher freestream flow, which could have provided more appropriate insight concerning flow about the fuselage and nacelle.

\subsection{Smoke Flow Visualization}

Oil flow proved useful in many instances, however it provided little insight to the extended flowfield around the model. In order to investigate the influence of the model on the surrounding flowfield, smoke flow visualization was employed. An invaluable addition the AMELIA dataset, this form of visualization allowed the research team to investigate aspects of the flow with "pin-point" accuracy. The smoke was used to highlight streamlines in a $\mathrm{C}_{\mu}$ sweep, along with a survey of the extended flowfield at multiple test conditions. 


\subsubsection{Smoke Flow Apparatus}

The equipment used to conduct smoke flow visualization was provided by the wind tunnel facility and included a smoke generator and control base unit, custom wand, and smoke fluid. Manufactured by Aerolab, the equipment is shown in Figure 5.8, however the large test section of the NFAC requires a significantly longer customized wand.

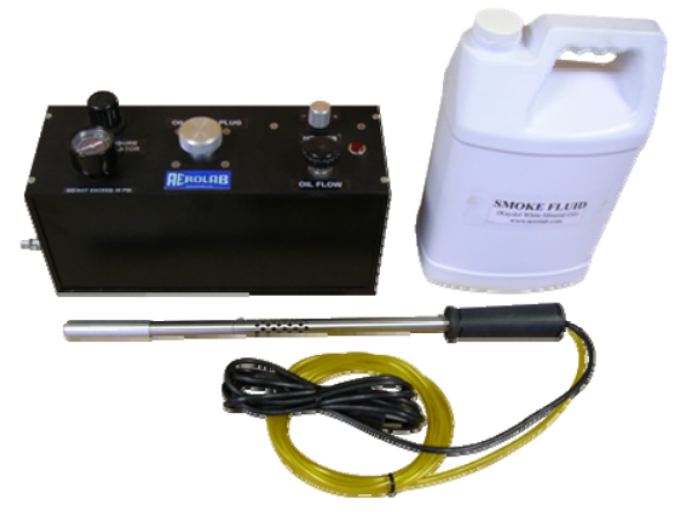

Figure 5.8: Smoke Flow Visualization Equipment[32].

The base unit is supplied with 115-volts and a source of compressed air and contains a reservoir of 16 fluid ounces. The smoke fluid-a simple white mineral oil sometimes called "Kaydol"-is pumped out of the base unit and up through the wand. A powerful heater at the tip of the wand heats the mineral oil causing a thick white vapor to form around the exposed tip. The dense vapor (or "smoke") creates a defined streamline which dissipates up to $20 \mathrm{ft}$ behind the tip of the wand (depending on flow conditions). The mineral oil leaves little residue on the model surface, however model surface pressure ports were taped over as a precaution.

The smoke system was operated from the scissors lift which was located approximately 10-ft upstream of the model's right wing for the majority of the 
smoke runs (one run was conducted upstream of the left wing). It was the intention of the test team to direct the streamline to the outboard section of the wing, as shown in Figure 5.9. This location was believed to be outside the region of TPS unit influence, and provide the most true indication of clean circulation control flow. Other regions were explored, however the streamlines depicted in the images within this chapter should be assumed to align with this location unless otherwise noted.
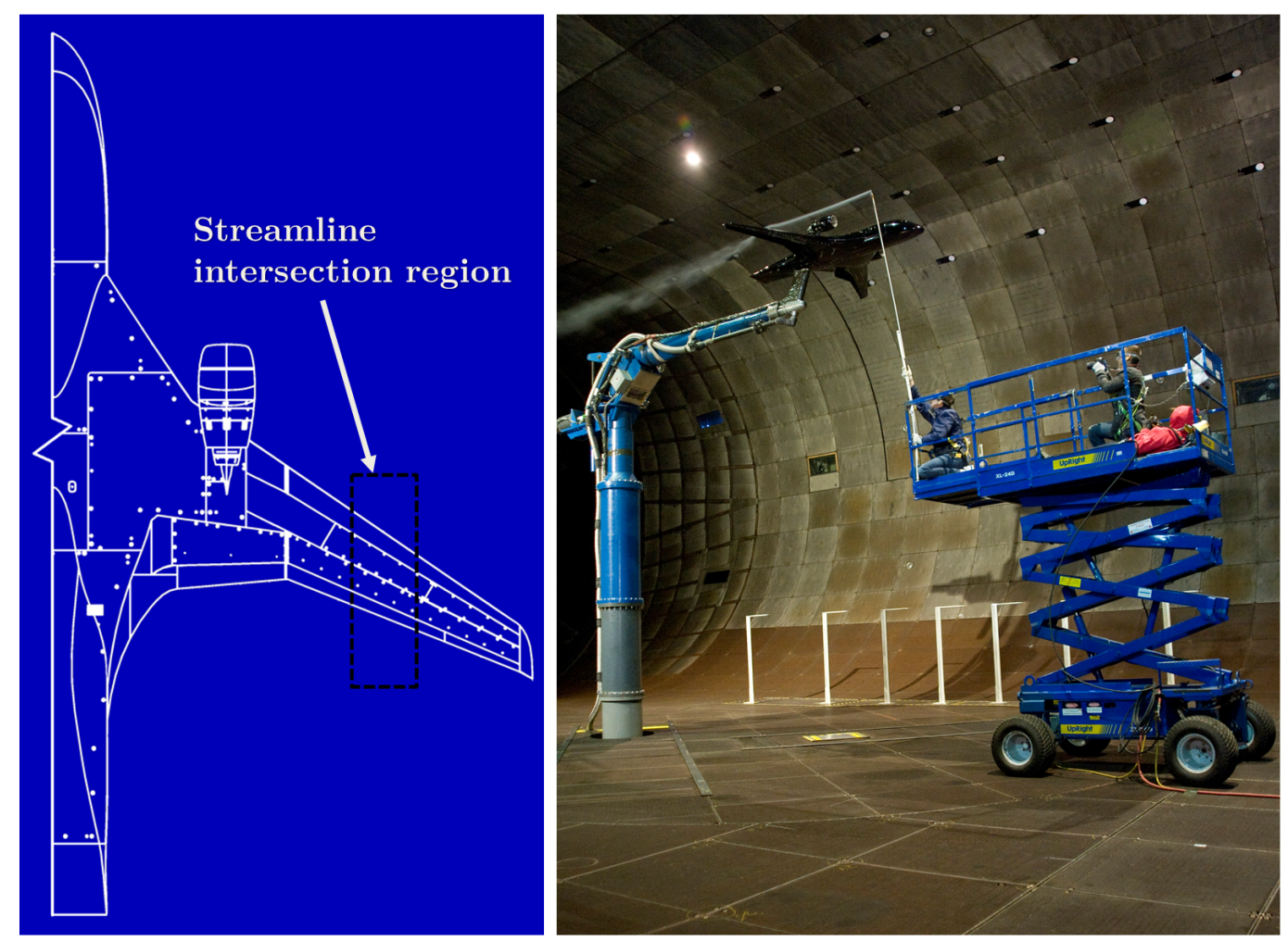

Figure 5.9: Target Location for Smoke Streamline.

\subsubsection{Smoke Flow Visualization Results}

The smoke system enabled the test team to visualize the fascinating flowfield surrounding the AMELIA model. The visualization was conducted over many cases, the first of which was an informal probing of many regions around the model 
(i.e. wingtips, fuselage, TPS nacelle, and mounting hardware). Subsequent runs applied a more scientific approach and include the investigation of the effect of a $\mathrm{C}_{\mu}$ sweep on a single streamline, as well as a series of runs that explored the extended flowfield of the model at $\alpha=10^{\circ}$ for various values of $\mathrm{C}_{\mu}$.

\section{Case 1}

A series of runs-some taking place during the oil flow visualization-served to acquaint the test team with the smoke flow visualization equipment. Despite differing conditions these runs will be grouped together to comprise Case 1 of the smoke flow visualization. A sample of the images recorded will be presented and discussed herein, however additional photographs from this series are included in the appendix. (As an informal investigation, images from this case should not be assumed to align at the outboard location shown in Figure 5.9). Selected results of Case 1 are presented in Figure 5.10 through 5.12 .

Flow around the fuselage behaved as expected for run 114, however under the conditions of run $117\left(\alpha=10^{\circ}\right)$ the streamline separated from the fuselage surface and reattached near the aft end. The flowfield around the TPS unit nacelle varied drastically as the streamline approached the model surface. A streamline near the top of the nacelle (left image of Figure 5.11) is relatively unperturbed by the circulation control flow. The image on the right of Figure 5.11 shows a streamline near the nacelle/pylon junction, which appears to be entrained into the circulation control flow, causing it to turn drastically at the Coanda surface. The left image of Figure 5.12 shows the tight wingtip vortex formed from the unblown/blown junction at the wingtip, while the image on the right depicts the rapid dissipation of a streamline in close proximity to the vortex. 

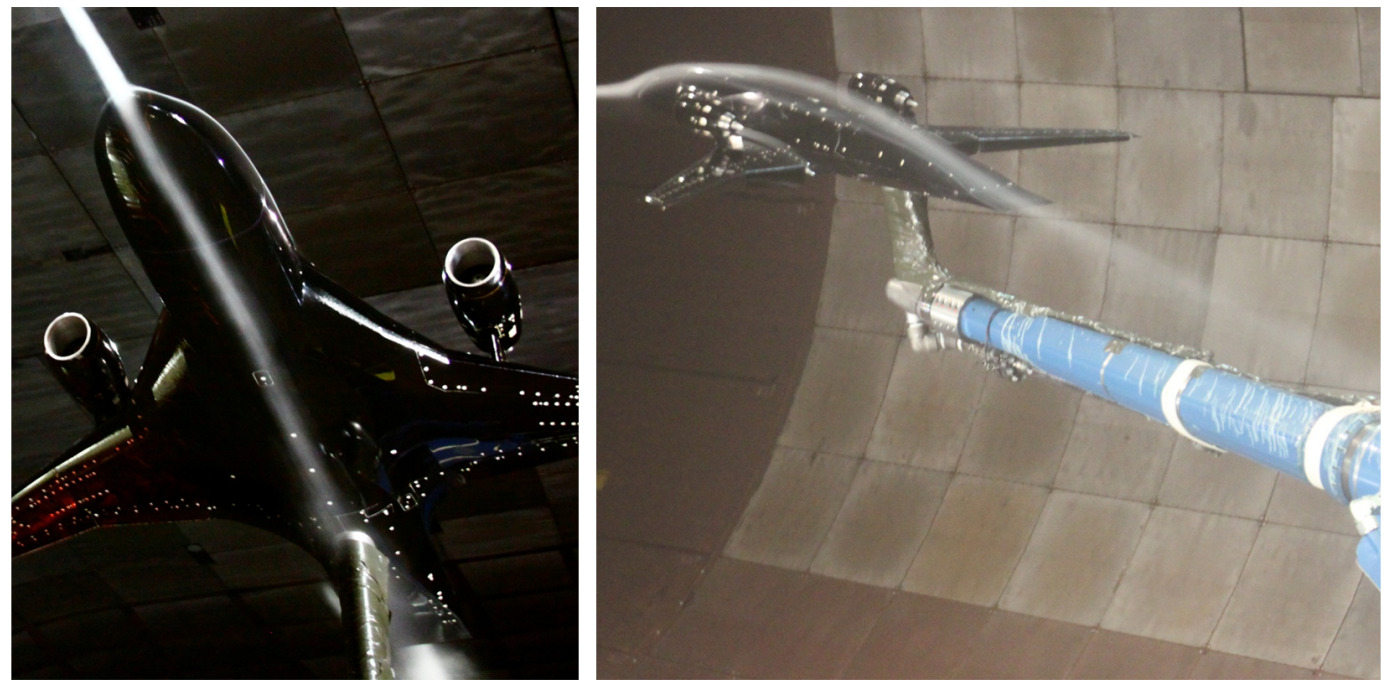

Run 114 (01/20/2012) (Left):

$q_{\infty}=3.4 p s f, \alpha=5^{\circ}, C_{\mu}=1.35, C_{T}=0$, Low Pylon, $0^{\circ}$ flap defl. Run 117 (01/20/2012) (Right):

$q_{\infty}=2.94 p s f, \alpha=10^{\circ}, C_{\mu}=1.62, C_{T}=0$, Low Pylon, $80^{\circ}$ flap defl.

Figure 5.10: Smoke Flow Visualization Case 1a. 

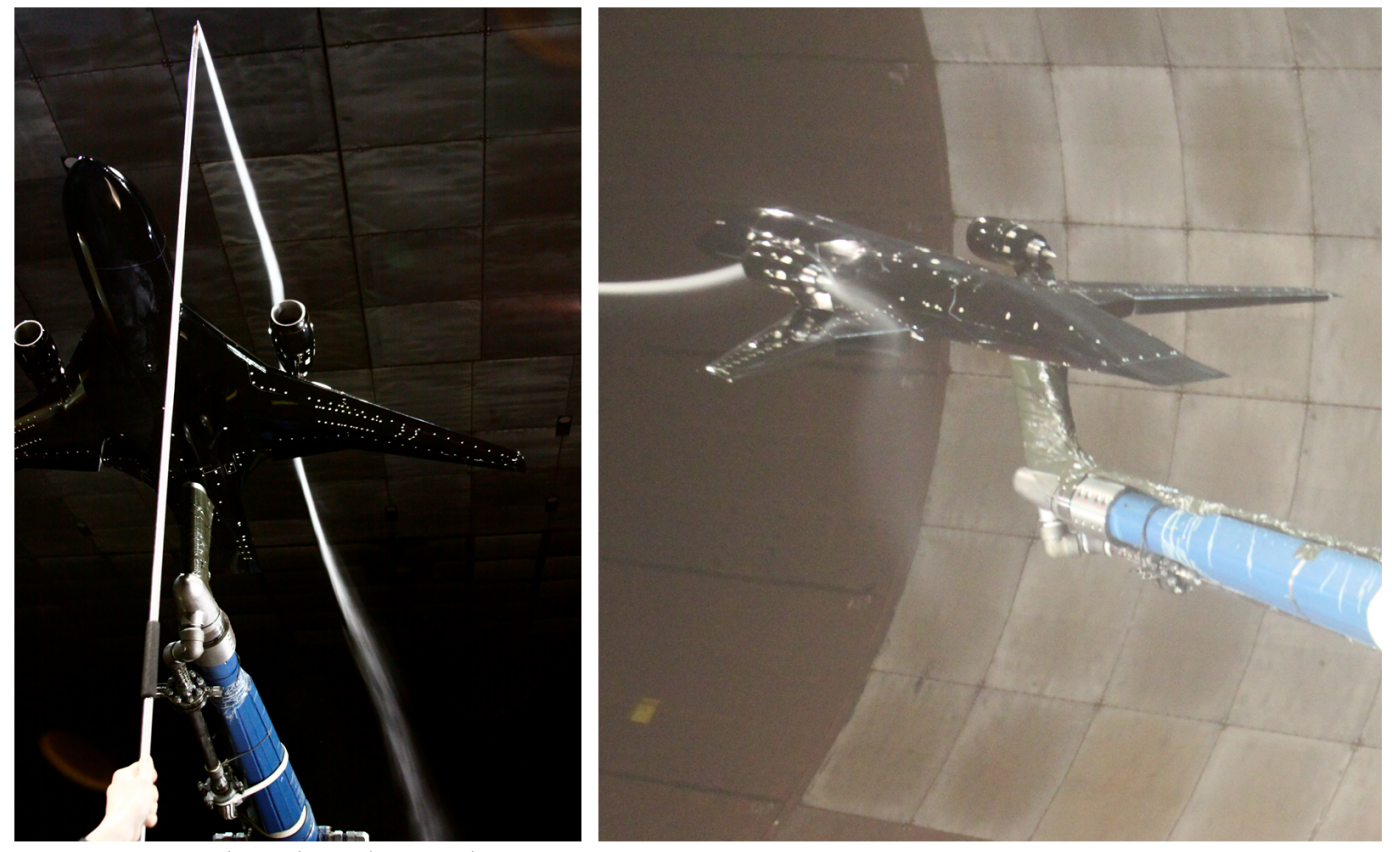

Run 117 (01/20/2012) :

$q_{\infty}=2.94 p s f, \alpha=10^{\circ}, C_{\mu}=1.62, C_{T}=0$, Low Pylon, $80^{\circ}$ flap defl.

Figure 5.11: Smoke Flow Visualization Case 1b.
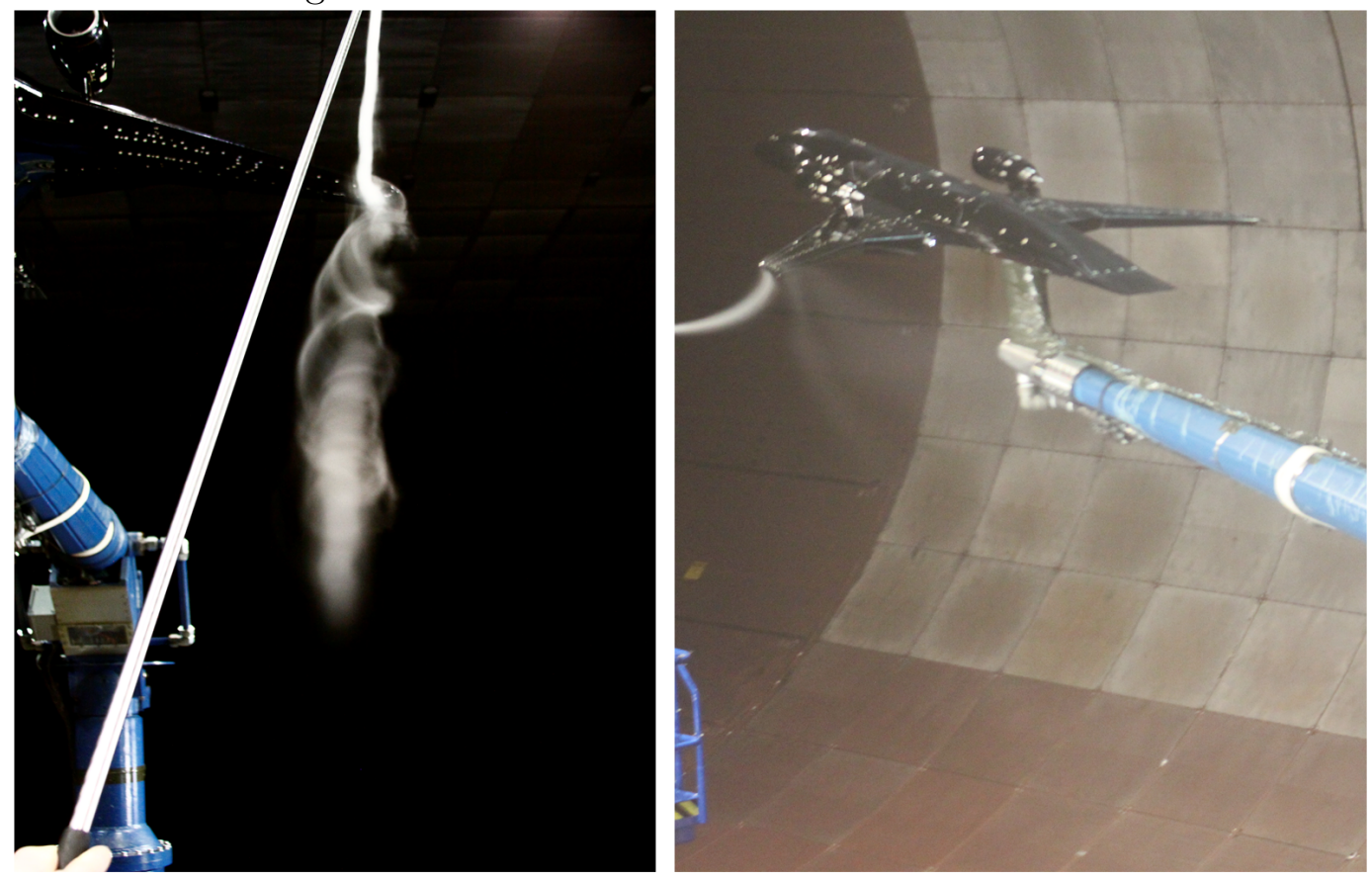

Run $117(01 / 20 / 2012)$ :

$q_{\infty}=2.94 p s f, \alpha=10^{\circ}, C_{\mu}=1.62, C_{T}=0$, Low Pylon, $80^{\circ}$ flap defl.

Figure 5.12: Smoke Flow Visualization Case 1c. 


\section{Case 2}

A more formal survey of the effect of circulation control on a single streamline was desired. During Case 2 the test team attempted to hold a steady streamline while engineers in the control room gradually increased circulation control flow from $\mathrm{C}_{\mu}=0\left(\dot{m}_{\text {slot }}=0 \frac{l b_{m}}{\mathrm{~s}}\right)$ to the "full" condition of $\mathrm{C}_{\mu}=0.87\left(\dot{m}_{\text {slot }}=2.80 \frac{l b_{m}}{\mathrm{~s}}\right)$. The freestream flow was held constant at 40 knots, while the images were captured from a second scissor lift located approximately 4-ft from the right wingtip. The results of Case 2 are shown in Figure 5.13.

The streamline appears to be unperturbed until a $\mathrm{C}_{\mu}$ of 0.07 is achieved. From this condition each increment of additional mass flow to the circulation control plenums produces a greater deflection of the streamline until the final condition is reached. At the "full" condition the streamline is dramatically influenced by the circulation control flow and is significantly deflected towards the tunnel floor. Images from other angles indicate a flow deflection of approximately 8-ft vertically (see appendix). 

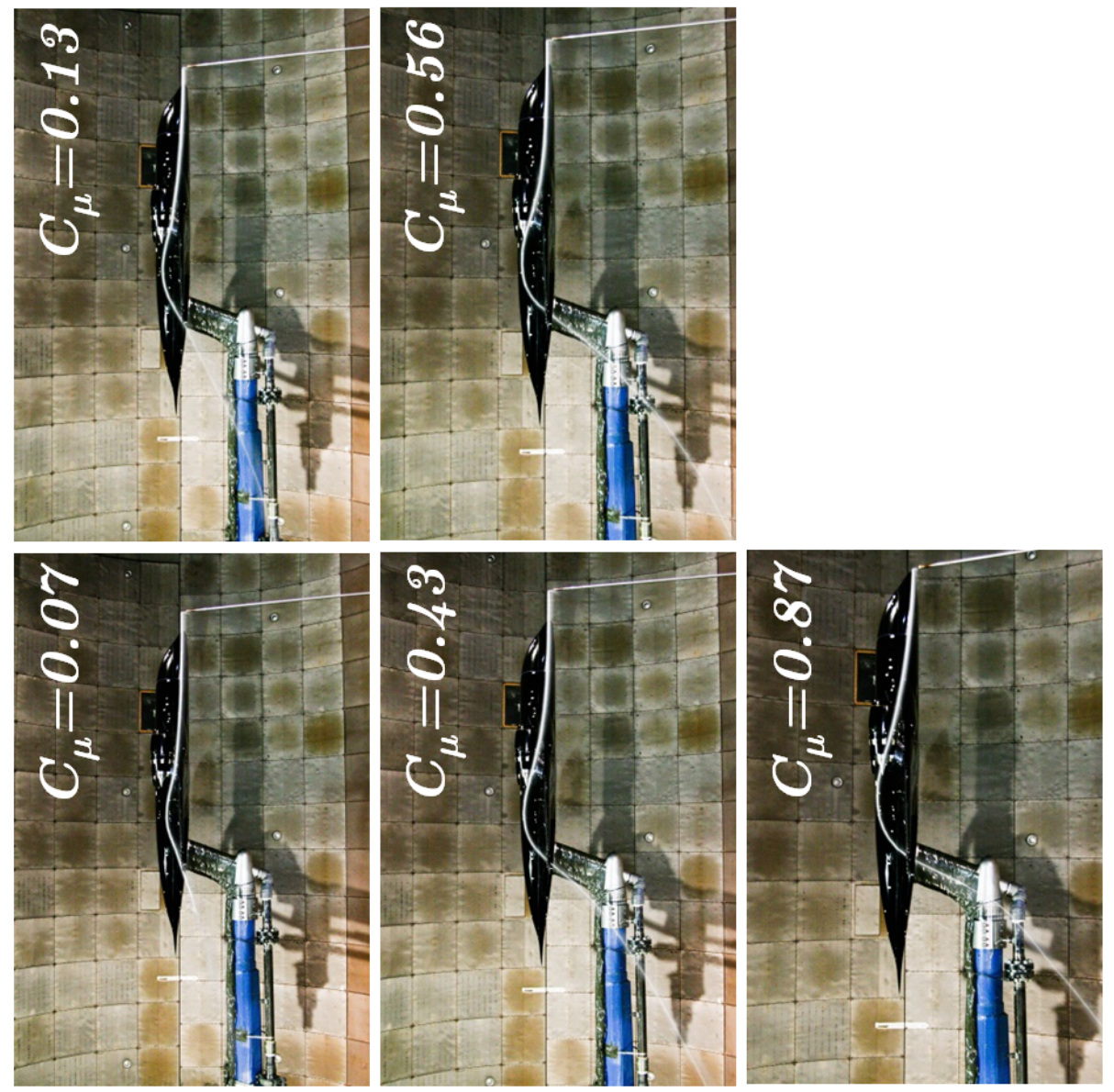

$\frac{\pi}{0}$
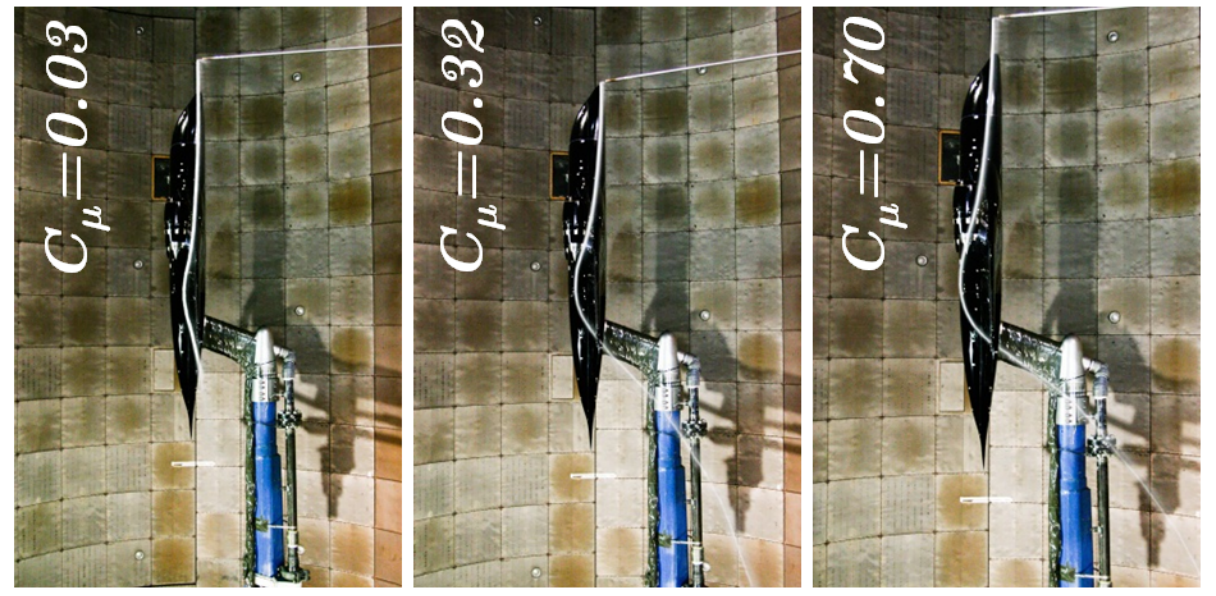

$\frac{8}{5}$

$\infty$
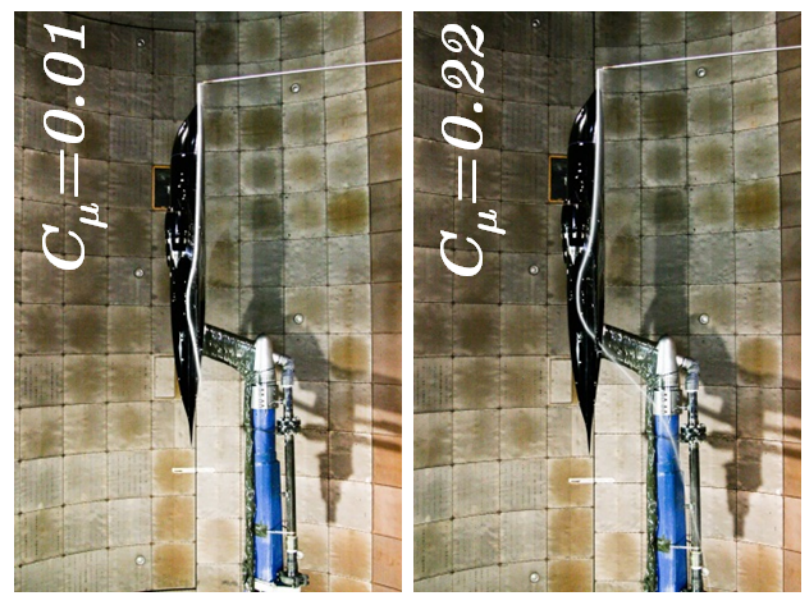

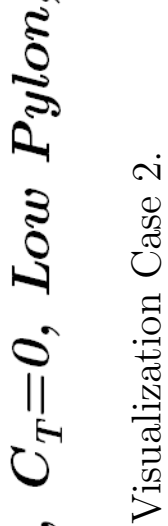

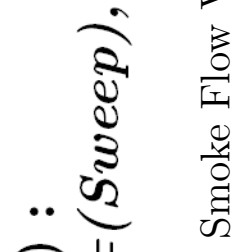

ลิ

กิ

N०

ำ

$>0$

帛

요

न

$\exists \quad 11$ 


\section{Case 3}

Without stopping the tunnel, the angle of attack of the model was increased to $\alpha=10^{\circ}$, the circulation control flow was terminated and Case 3 began. This case served to investigate the extended flowfield about the model. The wand was positioned at nine vertical stations allowing each streamline to be imaged. The nine images were then compiled (using post-processing image software) to create an array of streamlines mimicking the effect of a smoke rake. The results of Case 3 are presented in Figure 5.14.

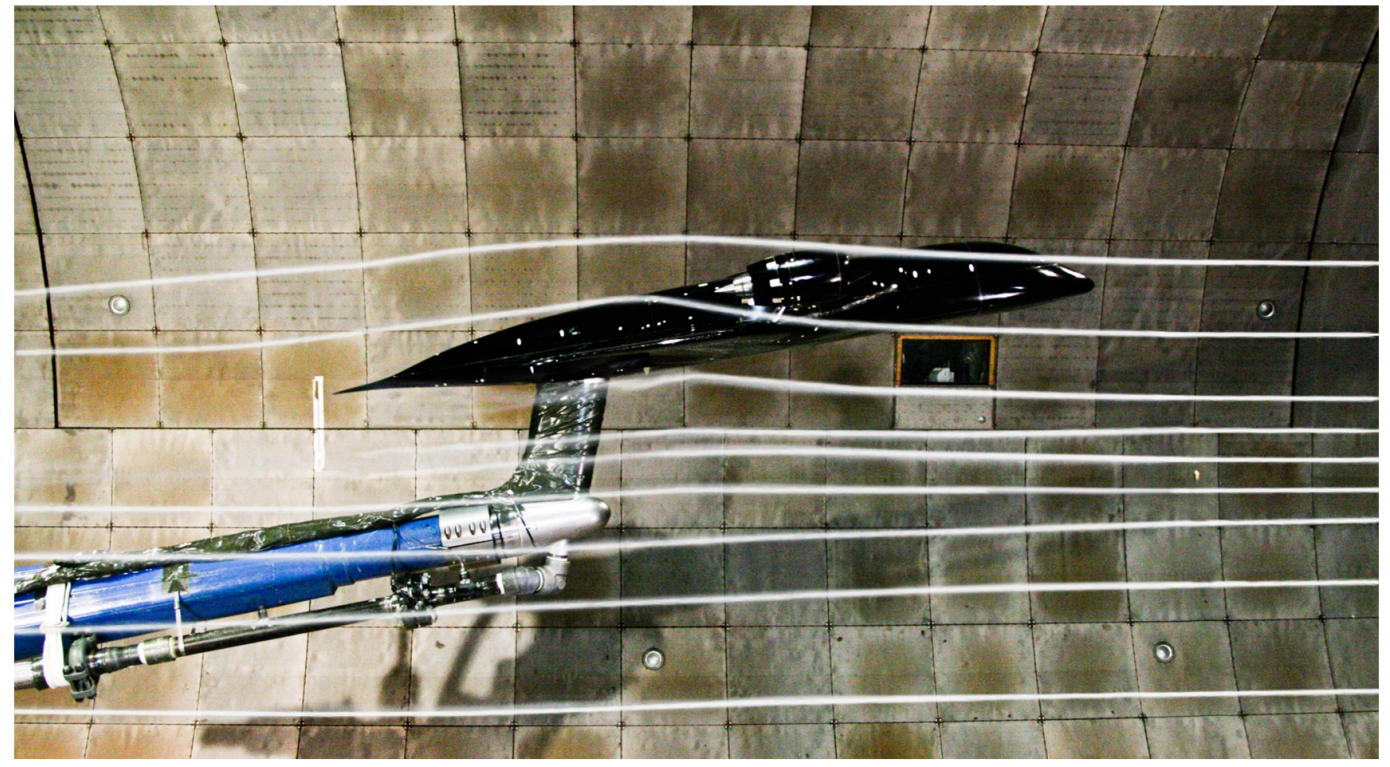

\section{Run $170(01 / 27 / 2012)$ : \\ $q_{\infty}=5.4 p s f, \alpha=10^{\circ}, C_{\mu}=0, C_{T}=0$, Low Pylon, $80^{\circ}$ flap defl.}

Figure 5.14: Smoke Flow Visualization Case 3.

With no additional mass flow exiting the model's circulation control system, the effect on the surrounding flowfield is minimum. The two streamlines above the wing are slightly influenced by the model's presence as they gently curve around the wing. The presence of the $80^{\circ}$ flap has the most drastic effect on the flow in that streamlines in close proximity to the flap are dissipated quickly. This 
is an indication of the tremendous drag and resulting turbulent flow created by the deflected flap.

\section{Case 4}

Immediately following Case 3, the circulation control flow system was powered up to create a $\mathrm{C}_{\mu}$ of 0.29 , or $\frac{1}{3}$ of the "full" condition. All other conditions remained constant. The resulting flow survey is provided in Figure 5.15.
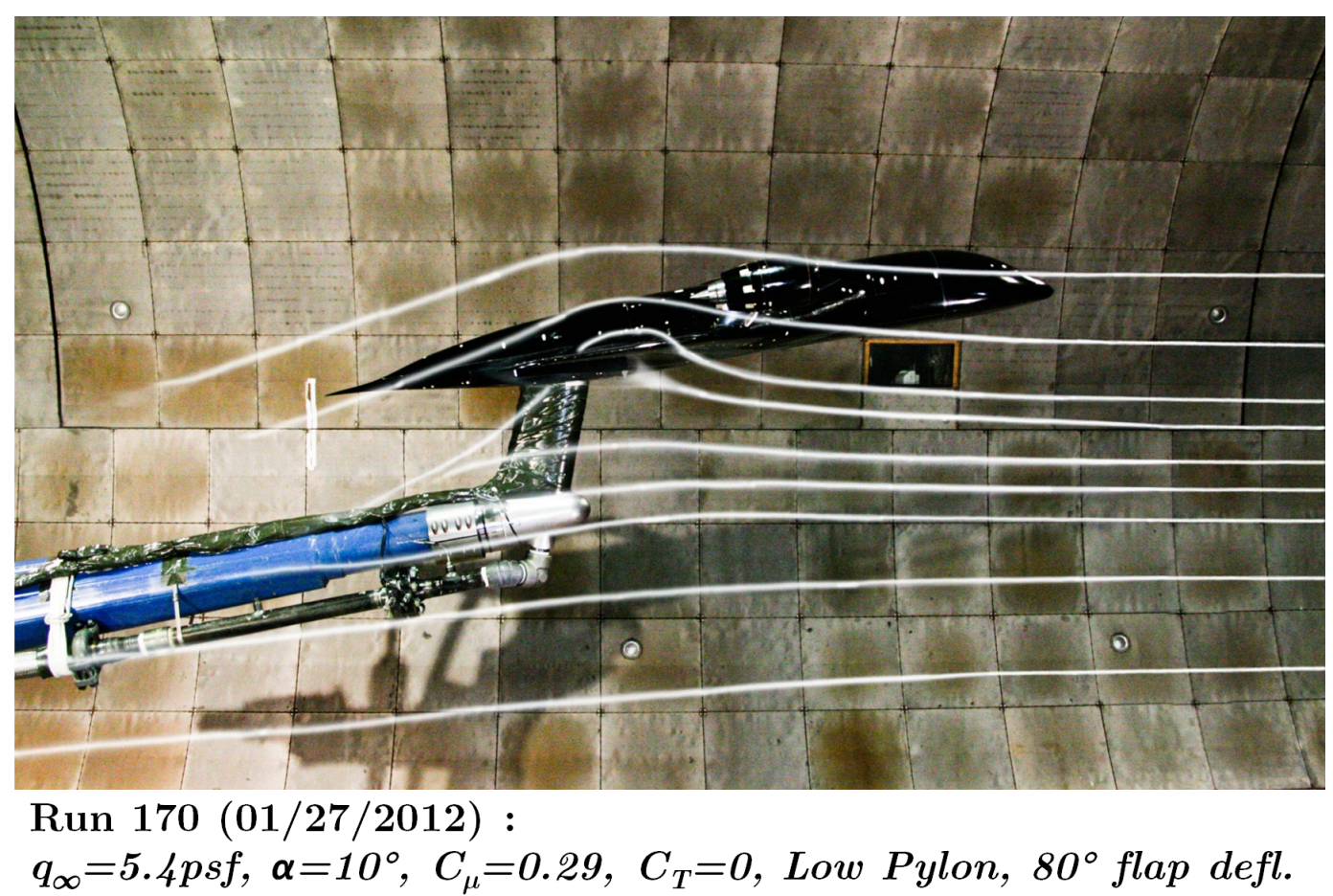

Figure 5.15: Smoke Flow Visualization Case 4.

For relatively little mass flow addition $\left(\dot{m}_{\text {slot }} \approx 0.90 \frac{l b_{m}}{s}\right)$ the effect on the flowfield is significant; the components of the circulation control system are beginning to augment the flowfield. At the leading edge, streamlines which previously traveled below the wing are now traversing the upper surface due to the suction created by the leading edge blowing. One streamline in particular is caught in what appears to be the leading edge stagnation point, where it dissipates above 
and below the wing. At the trailing edge, the upper surface streamlines are deflected along the Coanda surface, but detach relatively quickly due to the low blowing rate. Streamlines further above the wing are beginning to be deflected but unfortunately dissipate prior to leveling off.

\section{Case 5}

The discharge coefficient was increased to the condition $C_{\mu}=0.58$ and the survey was repeated. The results of Case 5 are presented in Figure 5.16.

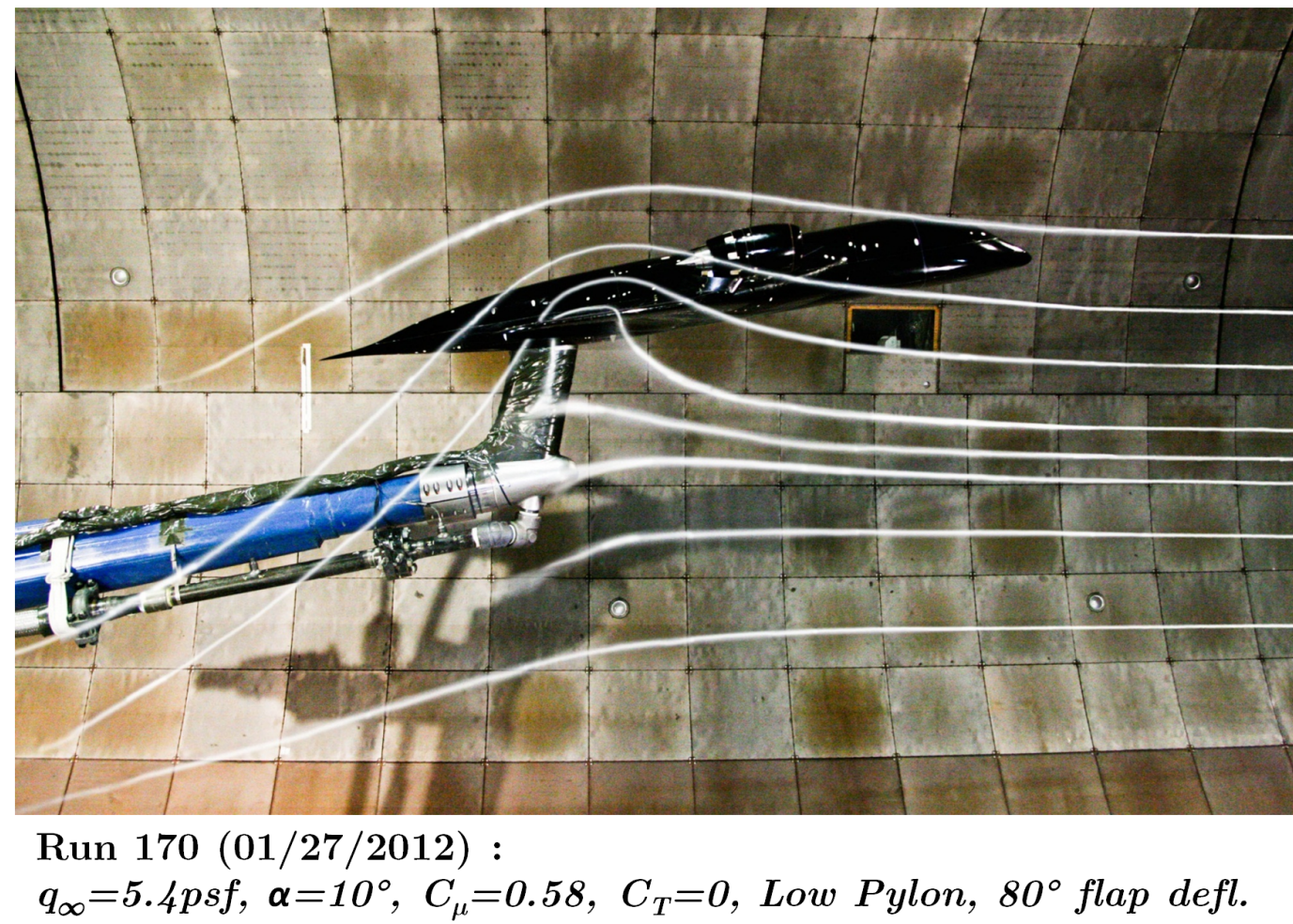

Figure 5.16: Smoke Flow Visualization Case 5.

Here the potential of the leading edge device is beginning to come into fruition. A streamline originating 1-ft below the model is brought over the upper surface. Additionally it seems to follow the entire Coanda surface through the $80^{\circ}$ deflection. Streamlines above the wing are significantly deflected by the trailing edge 
blowing-traveling many feet below the model. Streamlines well below the wing are deflected by the jet sheet issued from the trailing edge.

\section{Case 6}

Finally, the discharge coefficient was increased to the "full" condition of $\mathrm{C}_{\mu}=0.87$. The compilation of images from Case 6 are provided in Figure 5.17.

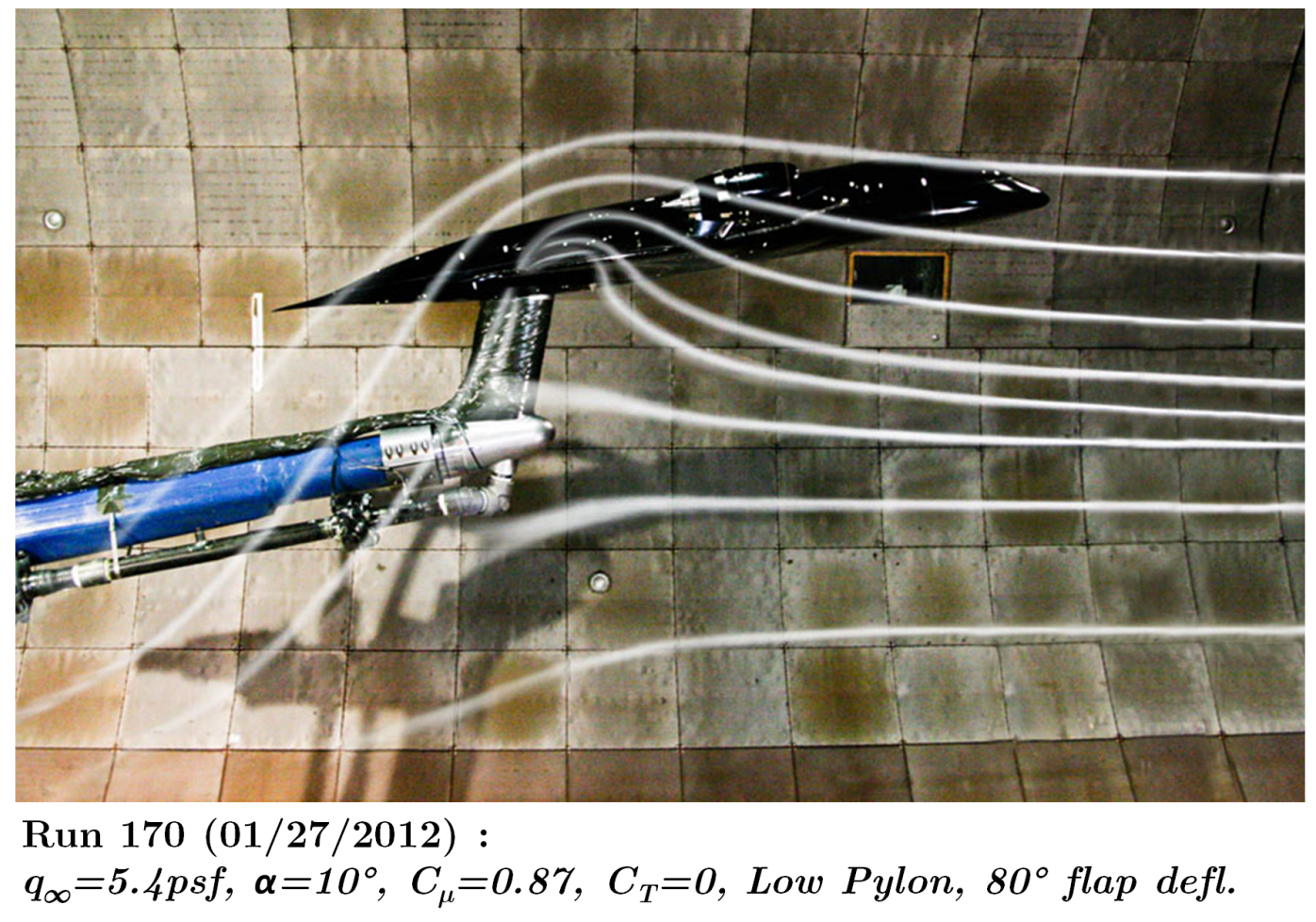

Figure 5.17: Smoke Flow Visualization Case 6.

The full discharge coefficient augments the flowfield around the AMELIA model significantly. The leading edge blowing system further influences the stagnation point, causing additional streamlines to travel across the upper surface despite their low origins. More flow turning at the trailing edge also occurs with 
little premature separation from the flap. Many of the lower streamlines dissipate in the presence of the trailing edge jet sheet.

\subsubsection{Smoke Flow Conclusions}

The smoke flow visualization was an effective means of exploring the flowfield. It brought to life many of the circulation control flow features that had yet only existed in CFD images. While some of more mundane aspects of the flowfield were investigated, such as the fuselage and TPS flow, many exciting images were also recorded depicting the intensity of the wingtip vortex, the incredible effect of the leading edge blowing on low streamlines, and the power of the jet sheet from the trailing edge. Many additional smoke flow visualization images are included in the appendix.

\subsubsection{Smoke Flow Lessons Learned}

While the smoke flow cases were fruitful, there were opportunities for improvement in the process. Better coordination between the test team and the control room could have lead to more accurate knowledge of the correlation between images captured and test conditions. Furthermore, the image capturing equipment (five CCD cameras) should have been synced in time to allow for coupled images from the same instant (an attempt to sync images in post processing was somewhat successful but very labor intensive). Additionally, lowering the lighting at the aft end of the model may have helped to provide improved contrast between the background and smoke. 


\subsection{Flow Visualization Conclusions}

The visualization effort provided considerable insight concerning the flow surrounding AMELIA. The cases discussed previously resulted in hundreds of images capturing various test conditions and model configurations-each of which can be used for a comparison to results garnished from CFD analysis. More importantly, much of the interesting and unique flow behavior of the circulation control model was explored and imaged which may have otherwise left CFD analysts puzzled and questioning the validity of their results. 


\section{Chapter 6}

\section{Conclusions}

The preceding discussion has served to detail many of the aspects of AMELIA's circulation control system that are required for accurate representation within CFD software. Additionally, flow visualization images are presented for comparison with CFD results. As a whole, this thesis should be considered a supplement to the many documents that detail the AMELIA wind tunnel test and Cal Poly, GTRI, and NASA's effort to develop a next-generation, regional, CESTOL airliner that abides by the $\mathrm{N}+2$ metrics(see References [33, 11, 34]).

The pre-test effort to achieve uniform streamlines from the circulation control slots by manipulating plenum treatment proved to provide a permanent fix. Circulation control flow quality investigation through flow visualization and other means proved that the plenum treatment applied at the FML functioned throughout the test. Ensuring uniform flow directionality provides the CFD analyst with confidence that AMELIA's flow conditions can be accurately represented in computer simulation.

The characterization of the slot flow will also aid in giving the CFD ana- 
lyst the best opportunity to simulate this boundary condition. The slot height measurements are easily incorporated into the CAD geometry, and can be relied upon in both pressurized and static cases as the data showed no significant difference. The effort expended in creating symmetric slot flow (and documenting instances of asymmetry) will provide the CFD analyst with the knowledge required to determine the appropriateness of a plane-of-symmetry type of domain. Additionally, the total slot exit area of the right and left wing was found to differ by only $1.10 \%$ with the majority of difference coming from the leading edge. Furthermore, the total pressure surveys of the circulation control jet can be used as a boundary condition in the simulation.

Finally the results of the flow visualization conducted at the NFAC should prove to be a valuable resource to CFD analysts and circulation control researchers alike. The oil streamlines provided valuable insight to the surface flow and permitted the investigation of the leading edge stagnation point, TPS nacelle, wingblend, and fuselage. Flow behaved as expected on the nacelle and fuselage, however flow about the wingblend exhibited some interesting characteristics. The stagnation point of the leading edge proved to be more difficult to capture with the oil flow due to gravity effects on the low viscosity oil which was required for the low freestream velocity. The stagnation point was, however, captured well during the smoke flow visualization. The single streamline sweep of $\mathrm{C}_{\mu}$ shows the degree of influence a circulation control wing can assert on a streamline at zero angle of attack. The subsequent surveys of the extended flowfield provide proof of the potential for flowfield augmentation due a circulation control system at a positive angle of attack. The visualization results are all valid information for comparison to CFD based predictions.

Throughout this effort, the focus and overall goal has been to generate a 
dataset of high enough quality to be relied upon for CFD validation, Reference [11] gives precisely that. This thesis has, however, provided the supporting material required to generate predictions for that comparison, along with a series of images that depict the flowfield. The characterization data provides enough information to make the CFD simulation as accurate as possible, while the flow visualization allows the analyst to quickly verify trends in the flowfield. 


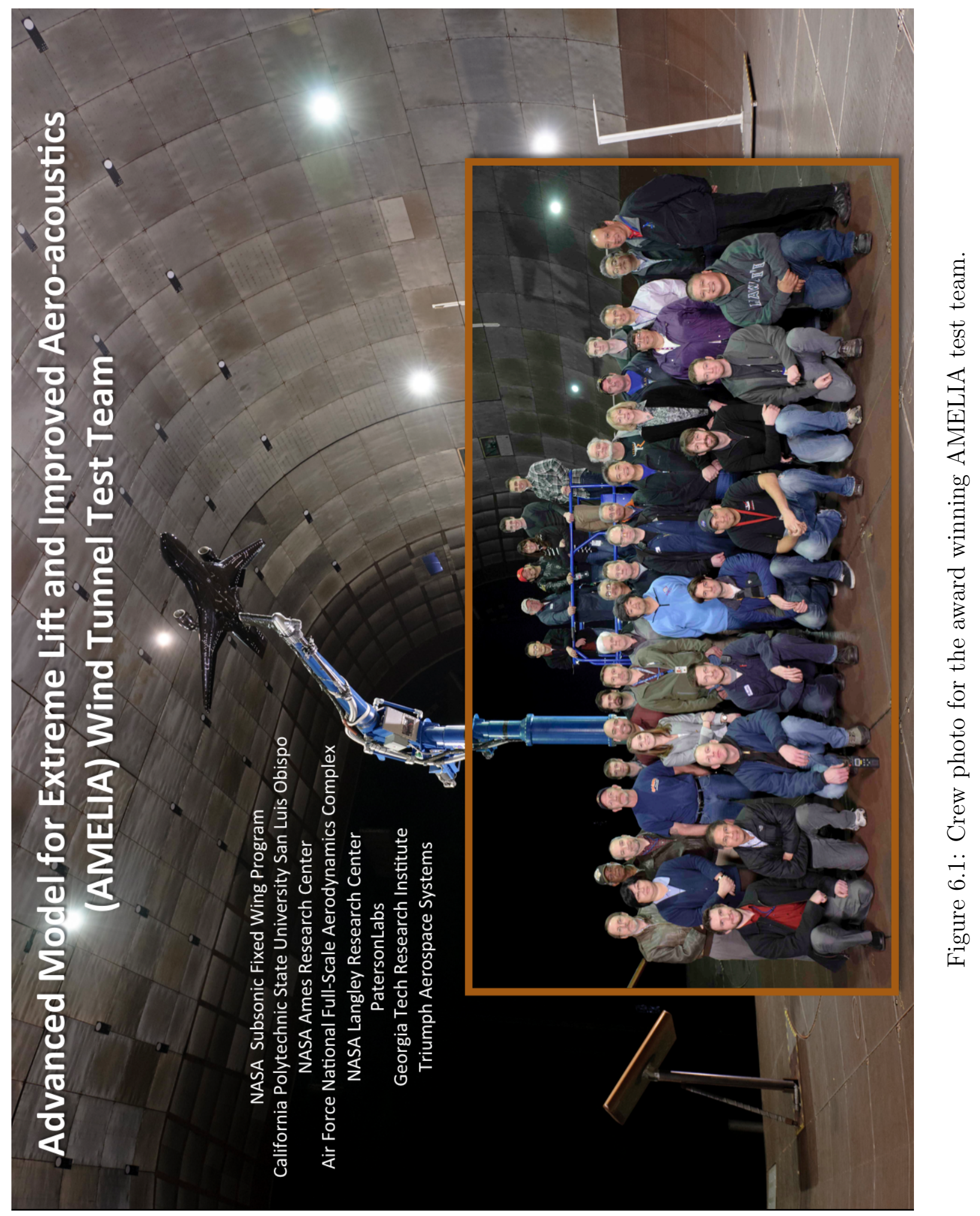




\section{Bibliography}

[1] R. Del Rosario, J. Koudelka, R. Wahls, and N. Madavan. "NASA Subsonic Fixed Wing Project Overview". NASA Fundemental Aeronautics Program Technical Conference, Cleveland, OH, March 2012.

[2] Capacitec Inc. "Gap Measurement Systems-Thin Gap Sensors", August 2013.

[3] N. R. Alley, J. Steele, J. C. Neidhoefer, R. J. Englar, and G. Blaylock. "Development of a Cruise-Efficient Extreme-STOL-Capable Demonstrator UAV". AIAA 2010-3450, April 2010.

[4] D. Marshall, et al. "NASA NRA End of Year One Progress Report". Technical report, NASA, 2008.

[5] J. Bonet. "Boeing ERA N+2 Advanced Vehicle Concept Results". 50 ${ }^{\text {th }}$ AIAA Aerospace Sciences Meeting, Nashville, TN, January 2012.

[6] R. J. Englar, R. J. Gaeta, L. W. Lee, and V. Leone. "Development of Pneumatic Over-the-Wing Powered-Lift Technology; Part I: Aerodynamic/Propulsive". 27 ${ }^{\text {th }}$ AIAA Applied Aerodynamics Conference, San Antonio, TX, AIAA 2009-3942, June 2009. 
[7] R. J. Englar., G. M. Blaylock., R. J. Gaeta., G. S. Jones., and W. E. Milholen. "Recent Experimental Development of Circulation Control Airfoil and Pneumatic Powered-Lift Systems". 48 ${ }^{\text {th }}$ AIAA Aerospace Sciences Meeting, Orlando, FL, AIAA 2010-345, January 2010.

[8] K. K. Jameson, D. D. Marshall, R. S. Ehrmann, E. N. Paciano, R. Golden, and D. Mason. "Design and Wind Tunnel Testing of Cal Poly's AMELIA 10 Foot Span Hybrid Wing-Body Low Noise CESTOL Aircraft". $27^{\text {th }}$ International Congress of the Aeronautical Sciences, Nice, FR, September 2010.

[9] D. Booth and N. Ulbrich. "Calibration and Data Analysis of the MC-130 Air Balance". 51 ${ }^{\text {st }}$ AIAA Aerospace Sciences Meeting, Grapevine, TX, AIAA 2013-0545, May 2012.

[10] R. J. Englar. "TPS/Nacelle/Pylon Characterization Testing Final Data Report" (Unpublished). Georgia Tech Research Institute, September 2011.

[11] J. A. Lichtwardt. "An Experimental Investigation of the STOL Performance of Cal Poly's AMELIA in the NFAC". Master's thesis, California Polytechnic State University, April 2013.

[12] N. Wood and J. Nielsen. "Circulation Control Airfoils Past, Present, Future". 23 ${ }^{\text {rd }}$ AIAA Aerospace Sciences Meeting, Reno, NV, AIAA 85-0203, January 1985.

[13] D. G. Kirkpatrick and D. R. Barnes. "Development and Evolution of the Circulation Control Rotor". 36 ${ }^{\text {th }}$ Annual Forum of the American Helicopter Society, Washington D.C., Preprint 80-13, May 1980.

[14] G. D. Shrewsbury. "Evaluation of a Research Circulation Control Airfoil 
Using Navier-Stokes Methods". Advanced Flight Sciences Department Lockheed Mariett-Georgia, May 1986.

[15] C. J. Novak, K. C. Conrnelius, and R. K. Roads. "Experimental Investigation of the Circular Wall Jet on a Circulation Control Airfoil". 25 $5^{\text {th }}$ AIAA Aerospace Sciences Meeting, Reno, NV, AIAA-87-0155, January 1987.

[16] R. J. Englar. "Overview of Circulation Control Pneumatic Aerodynamics: Blown Force and Moment Augmentation and Modification as Applied Primarily to Fixed-Wing Aircraft". Proceedings of the 2004 NASA/ONR Circulation Control Workshop, 2005.

[17] Nielson J. N, editor. "Proceedings of the Circulation Control Workshop", number NASA Conference Publication 2432, NASA Ames Research Center, Moffett Field, February 1986.

[18] R. J. Englar. "Investigation into and Application of the High Velocity Circulation Control Wall Jet for High Lift and Drag Generation on STOL Aircraft". $7^{\text {th }}$ AIAA Fluid and Plasma Dynamics Conference, Palo Alto, CA, June 1974.

[19] R. J. Englar. "Subsonic Two-Dimensional Wind Tunnel Investigation of the High Lift Capability of Circulation Control Wing Sections". Naval Air Systems Command, Washington DC, DTNSRDC-ASED-274, April 1975.

[20] R. J. Englar. "Circulation Control for High Lift and Drag Generation on STOL Aircraft". Journal of Aircraft, 12(5):457-463, May 1975.

[21] R. J. Englar. "Circulation Control Technology for Powered-Lift STOL Aircraft". Lockheed Horizons, No. 24, September 1987. 
[22] J. L. Loth, J. D. Fanucci, and S. C. Roberts. "Flight Performance of a Circulation Control STOL Aircraft". Journal of Aircraft, 13(3):169-173, 1976.

[23] S. C. Roberts. "West Virginia University Circulation Control STOL Aircraft Flight Test". WVU Aerospace, Technical Report No. 42, July 1974.

[24] J. C. Eppel, M. D. Shovlin, D. N. Jaynes, R. J. Englar, and J. H. Nichols. "Static Investigation of the Circulation-Control-Wing/UpperSurface-Blowing Concept Applied to the Quiet Short-Haul Research Aircraft". Technical Report 84232, NASA TM, July 1982.

[25] R. D. Joslin and G. S. Jones, editors. Applications of Circulation Control Technology, volume 214. AIAA, 2006.

[26] R. J. Englar, G. S. Jones, B. G. Allan, and J. C. Lin. "2-D Circulation Control Airfoil Benchmark Experiments Intended for CFD Code Validation". $47^{\text {th }}$ AIAA Aerospace Sciences Meeting, Orlando, FL, AIAA 2009-902, January 2009 .

[27] D. Wetzel, J. Griffin, F. Liu, and L. Cattafesta. "An Experimental Study of a Circulation Control Airfoil Trailing Edge Flow Field". $5^{\text {th }}$ AIAA Flow Control Conference, Chicago, IL, AIAA 2010-4576, June 2010.

[28] Cagle C. M. Milholen W. E., Jones G. S. "NASA High-Reynolds Number Circulation Contorl Research Overview of CFD and Planned Experiments (Invited)". $48^{\text {th }}$ AIAA Aerospace Sciences Meeting, Orlando, FL, AIAA 2010-3923, January 2010.

[29] C. M. Cagle and G. S. Jones. "A Wind Tunnel Model to Explore Unsteady Circulation Control for General Aviation Applications". $22^{\text {nd }}$ AIAA Aerody- 
namics Measurement Technology and Ground Testing Conference, St. Louis, MO, AIAA 2002-3240, June 2002.

[30] ERG Aerospace Corporation. "What is Duocel Foam?", 2011. [http://www.ergaerospace.com/Descriptors.html].

[31] Pall Corporation. "Rigimesh Filter Elements-Rigimesh Elements and Their Characteristics", 2012. [http://www.pall.com/main/oem-mediamembranes-and-materials/product.page?id=41251].

[32] AeroLab LLC. "Smoke Generator System", August 2012. [http://www.aerolab.com/downloadabledocuments/smokegenbrochure.pdf].

[33] D. D. Marshall, K. K. Jameson, R. K. Fong, J. A. Lichtwardt, and E. N. Paciano. "Advanced Model for Extreme Lift and Improved Aeroacoustics (AMELIA) Technical Memorandum". In accordance with the requirements outlined by NASA Aeronautics Subsonic Fixed Wing Program Contract \#NNL07AA55C fulfilled by California Polytechnic State University in collaboration with Georgia Tech Research Institute. (Under review at time of publication), March 2013.

[34] D. D. Marshall and K. K. Jameson. "Overview of Recent Circulation Control Modeling Activities at Cal Poly". 48 $8^{\text {th }}$ AIAA Aerospace Sciences Meeting, Orlando, FL, AIAA 2010-348, January 2010. 


\section{Appendix A}

\section{Additional Oil Flow Images}

Oil Case 1

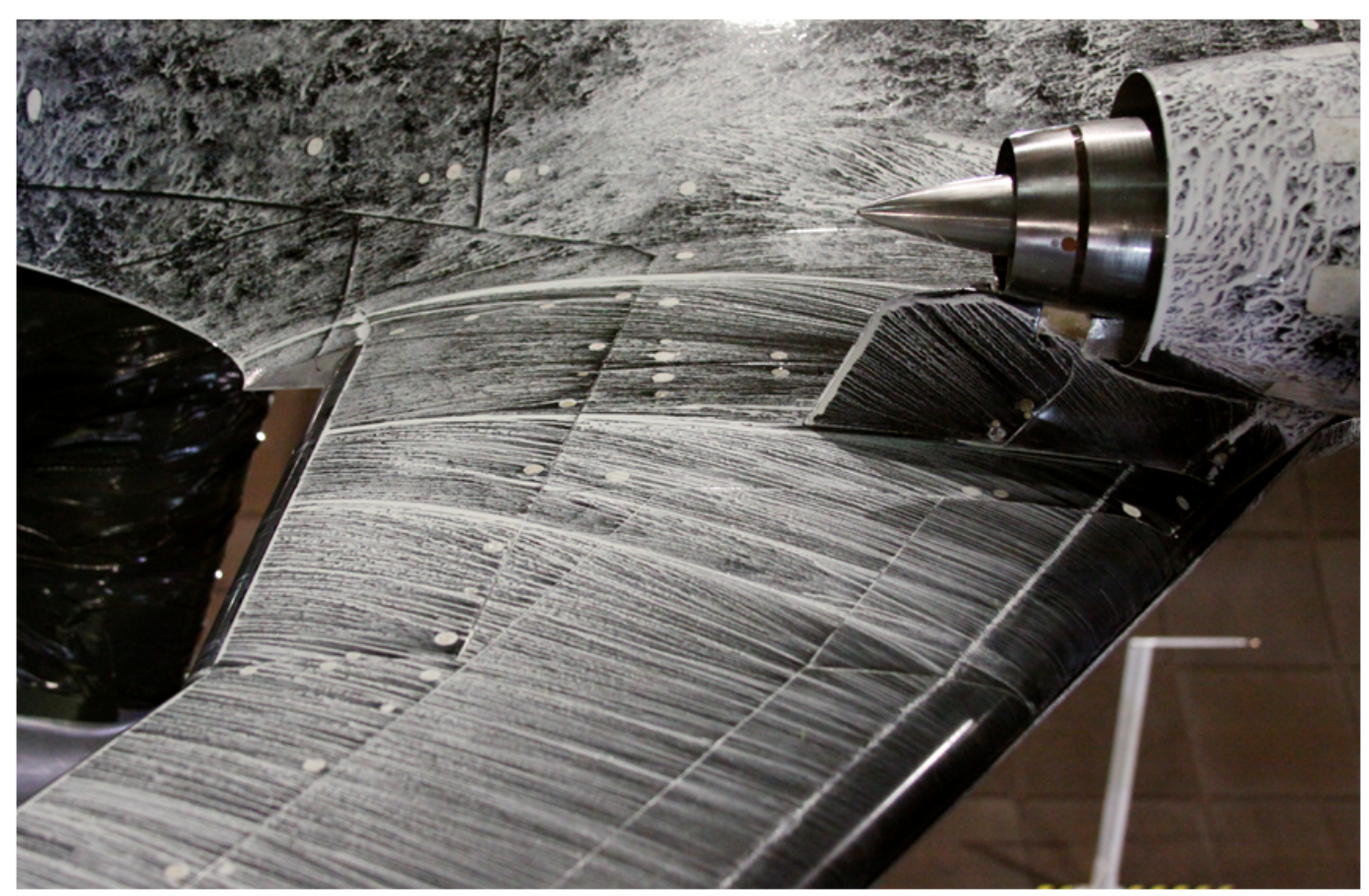

Run 45 (01/10/2012):

$q_{\infty}=3.12 p s f, \alpha=0^{\circ}, C_{\mu}=1.4, C_{T}=0$, Low Pylon, $60^{\circ}$ flap defl . 


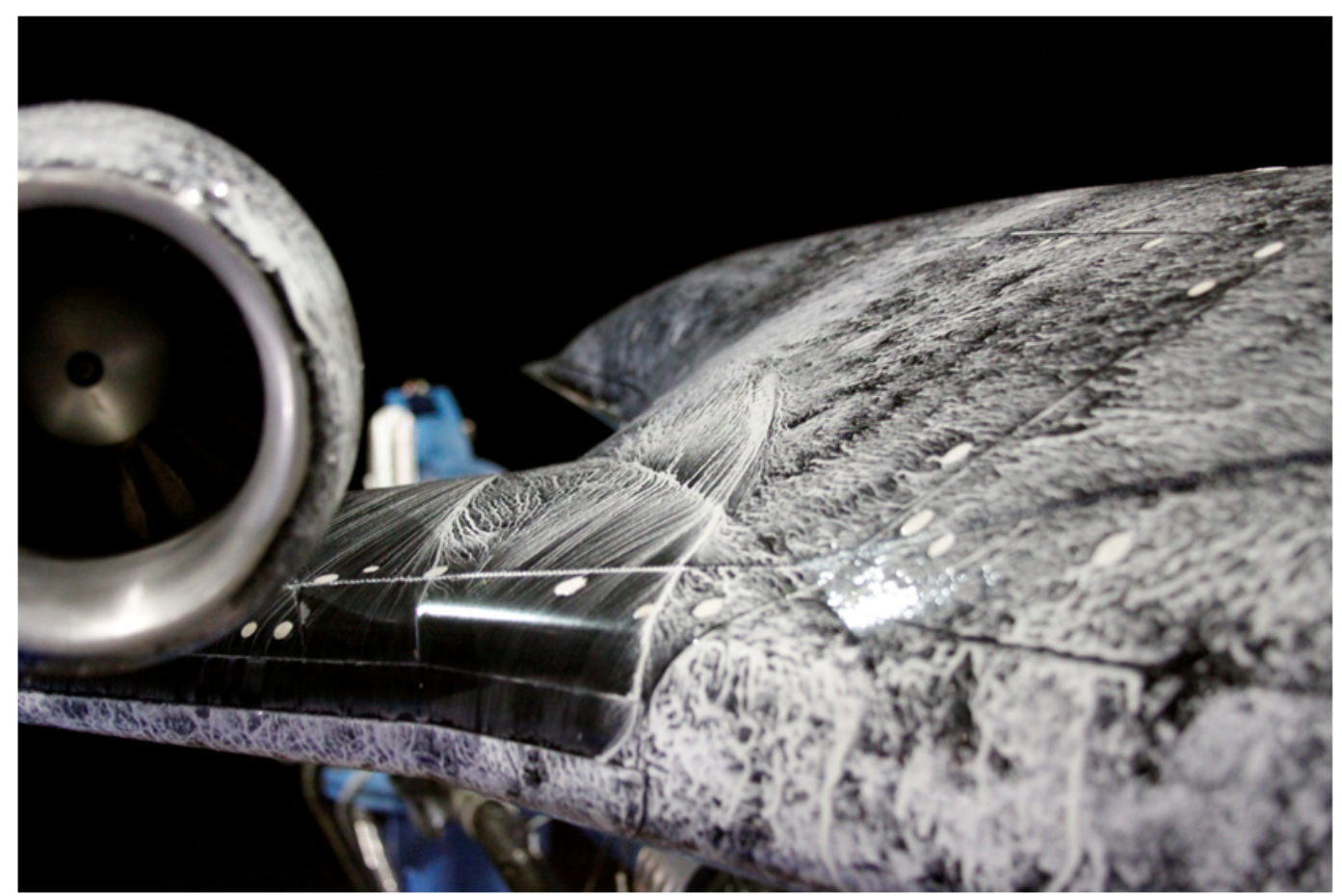

Run 45 (01/10/2012):

$q_{\infty}=3.12 p s f, \alpha=0^{\circ}, C_{\mu}=1.4, C_{T}=0$, Low Pylon, $60^{\circ}$ flap defl.

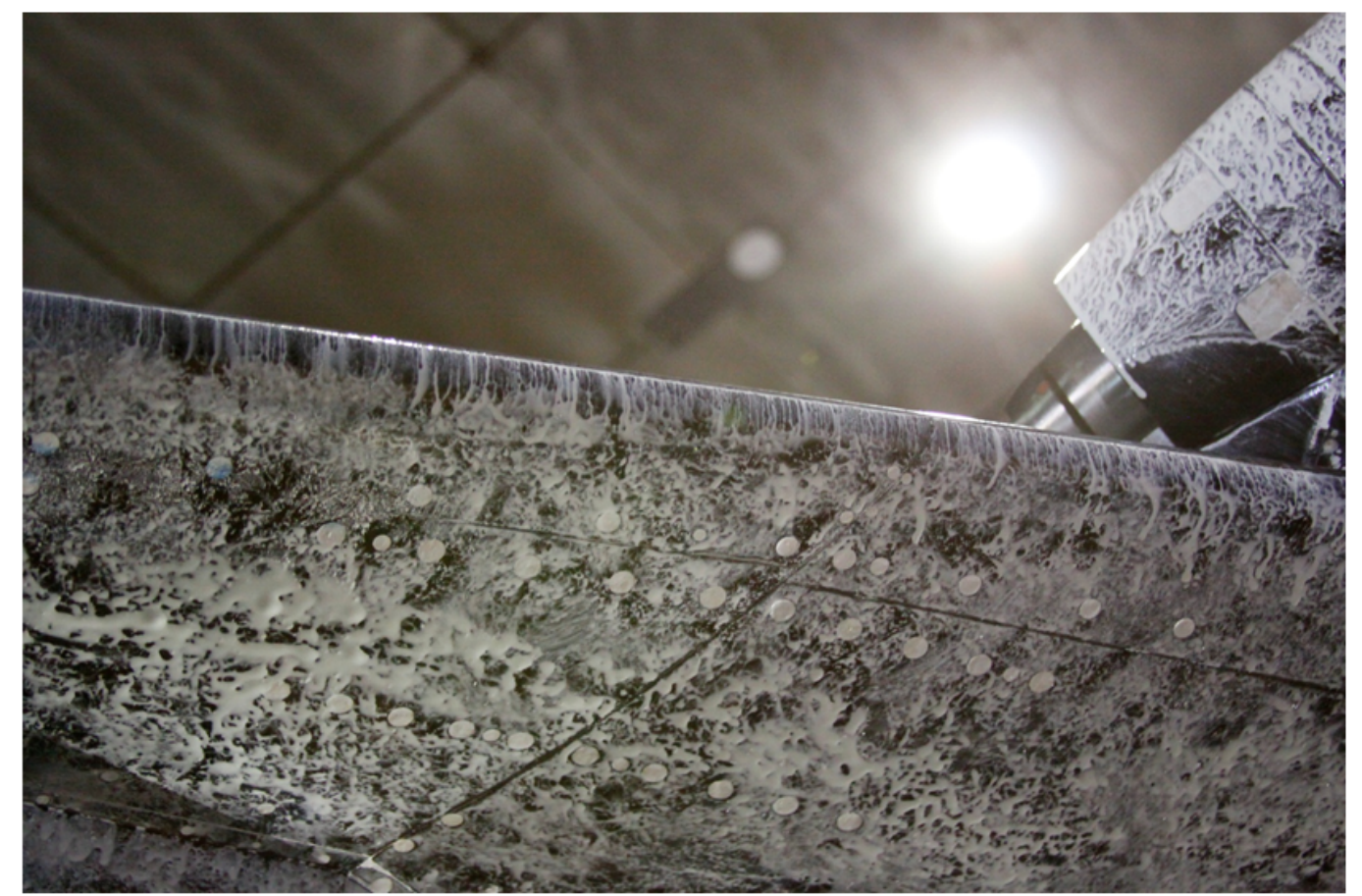

Run $45(01 / 10 / 2012)$ :

$q_{\infty}=3.12 p s f, \alpha=0^{\circ}, C_{\mu}=1.4, C_{T}=0$, Low Pylon, $60^{\circ}$ flap defl. 

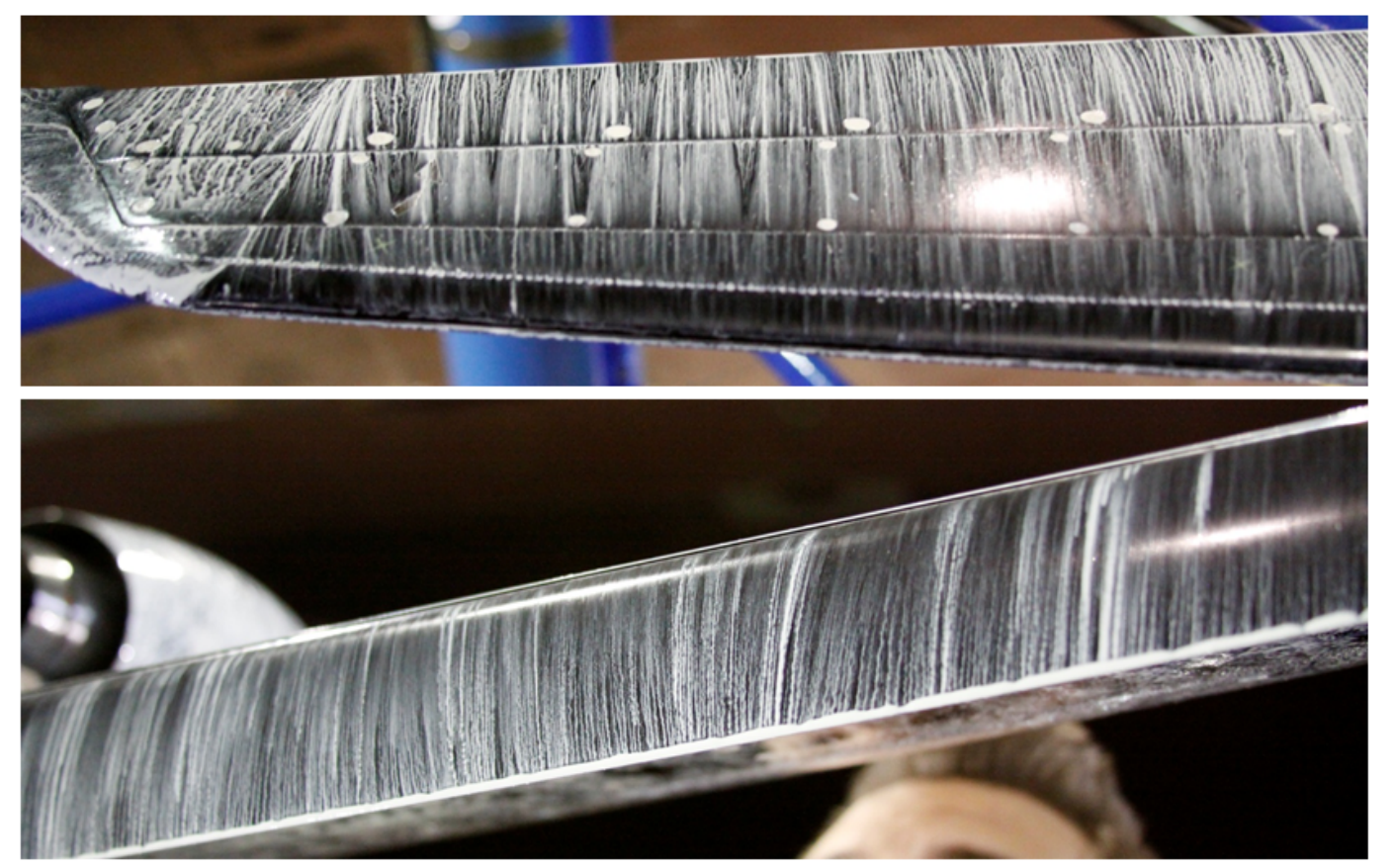

Run $45(01 / 10 / 2012)$ :

$q_{\infty}=3.12 p s f, \alpha=0^{\circ}, C_{\mu}=1.4, C_{T}=0$, Low Pylon, $60^{\circ}$ flap defl. 
Oil Case 2

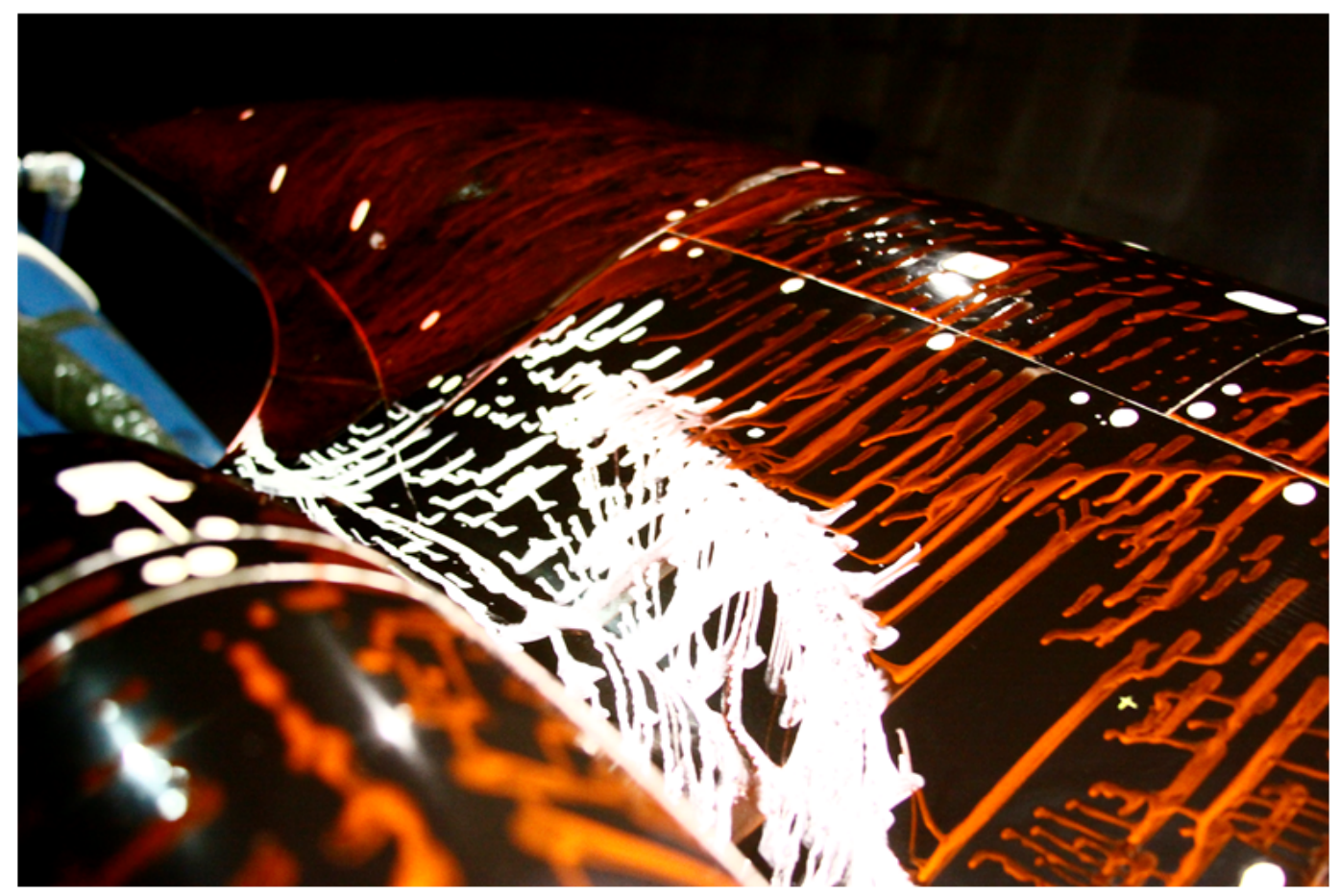

Run $114(01 / 20 / 2012)$ :

$q_{\infty}=3.4 p s f, \alpha=5^{\circ}, C_{\mu}=1.35, C_{T}=0$, Low Pylon, $0^{\circ}$ flap defl. 


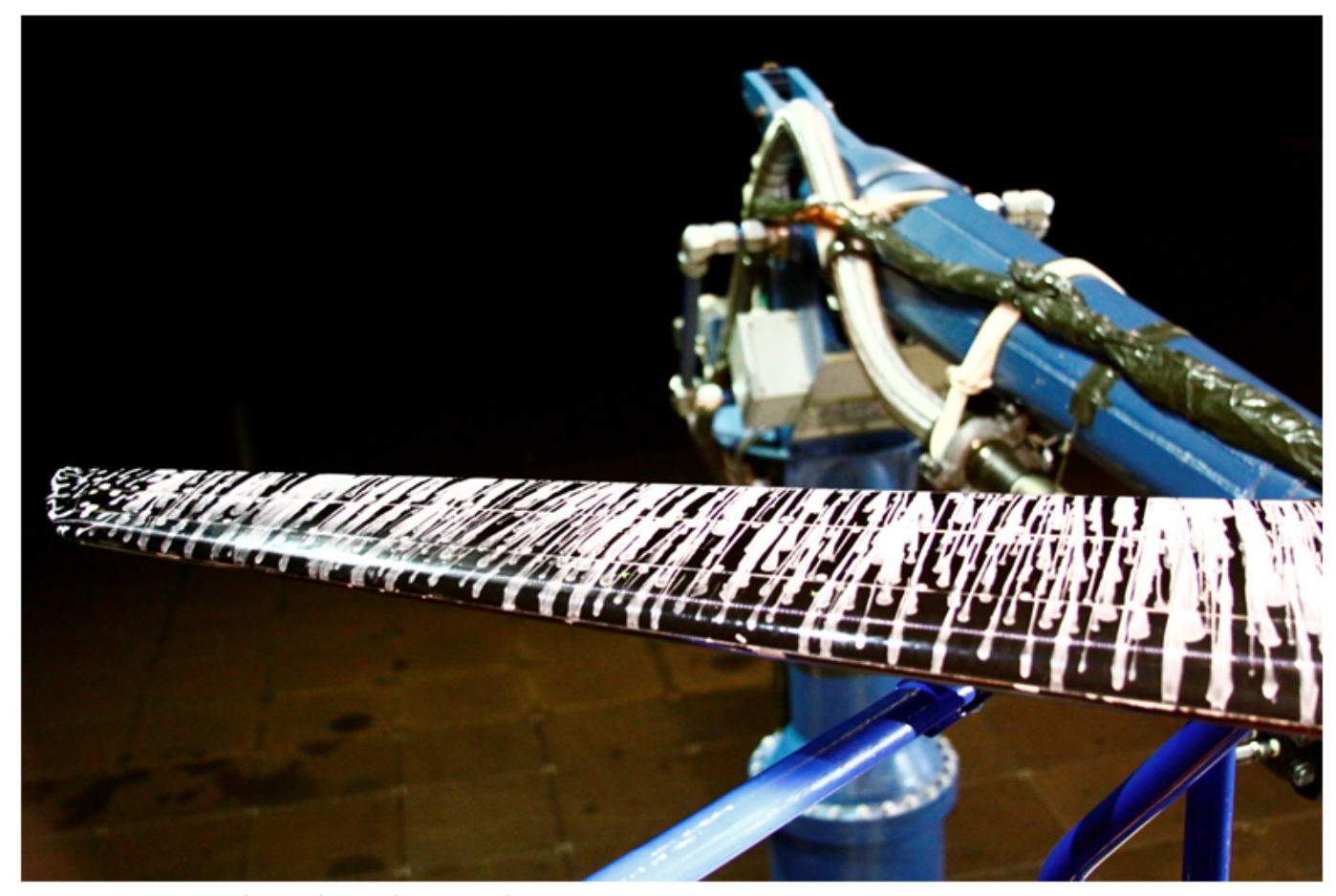

Run $114(01 / 20 / 2012)$ :

$q_{\infty}=3.4 p s f, \alpha=5^{\circ}, C_{\mu}=1.35, C_{T}=0$, Low Pylon, $0^{\circ}$ flap defl.

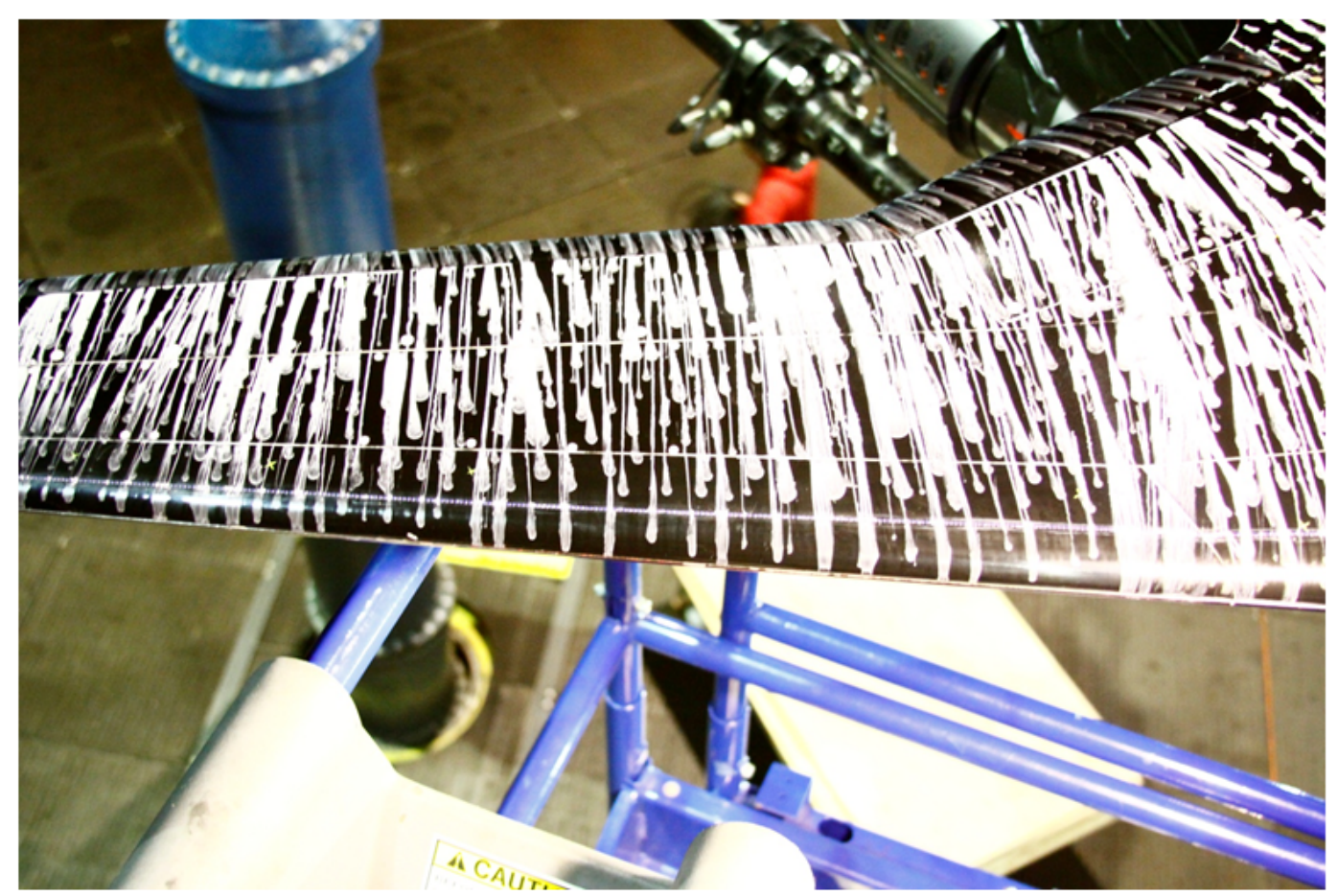

Run $114(01 / 20 / 2012)$ :

$q_{\infty}=3.4 p s f, \alpha=5^{\circ}, C_{\mu}=1.35, C_{T}=0$, Low Pylon, $0^{\circ}$ flap defl. 


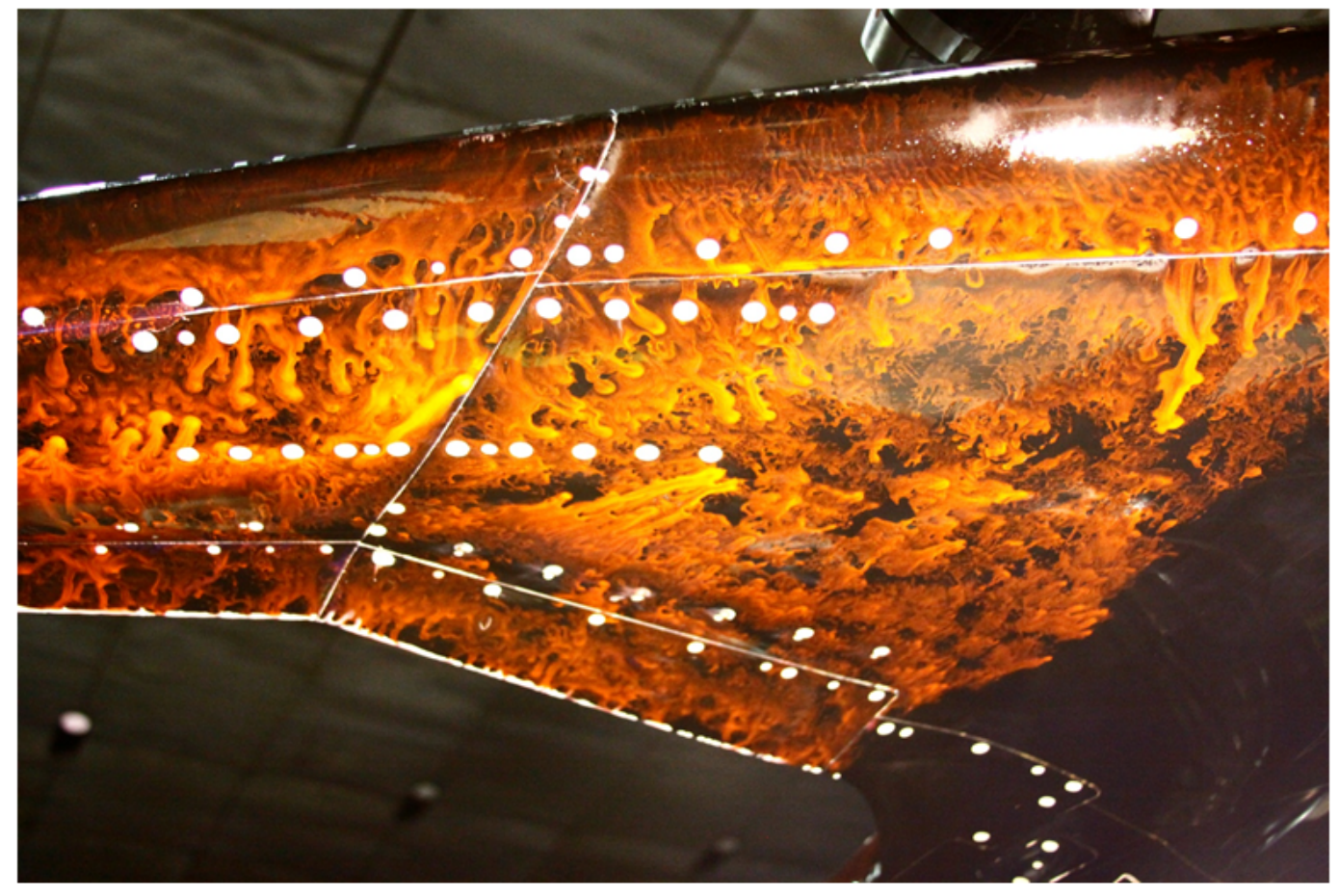

Run 114 (01/20/2012):

$q_{\infty}=3.4 p s f, \alpha=5^{\circ}, C_{\mu}=1.35, C_{T}=0$, Low Pylon, $0^{\circ}$ flap defl. 


\section{Oil Case 3}

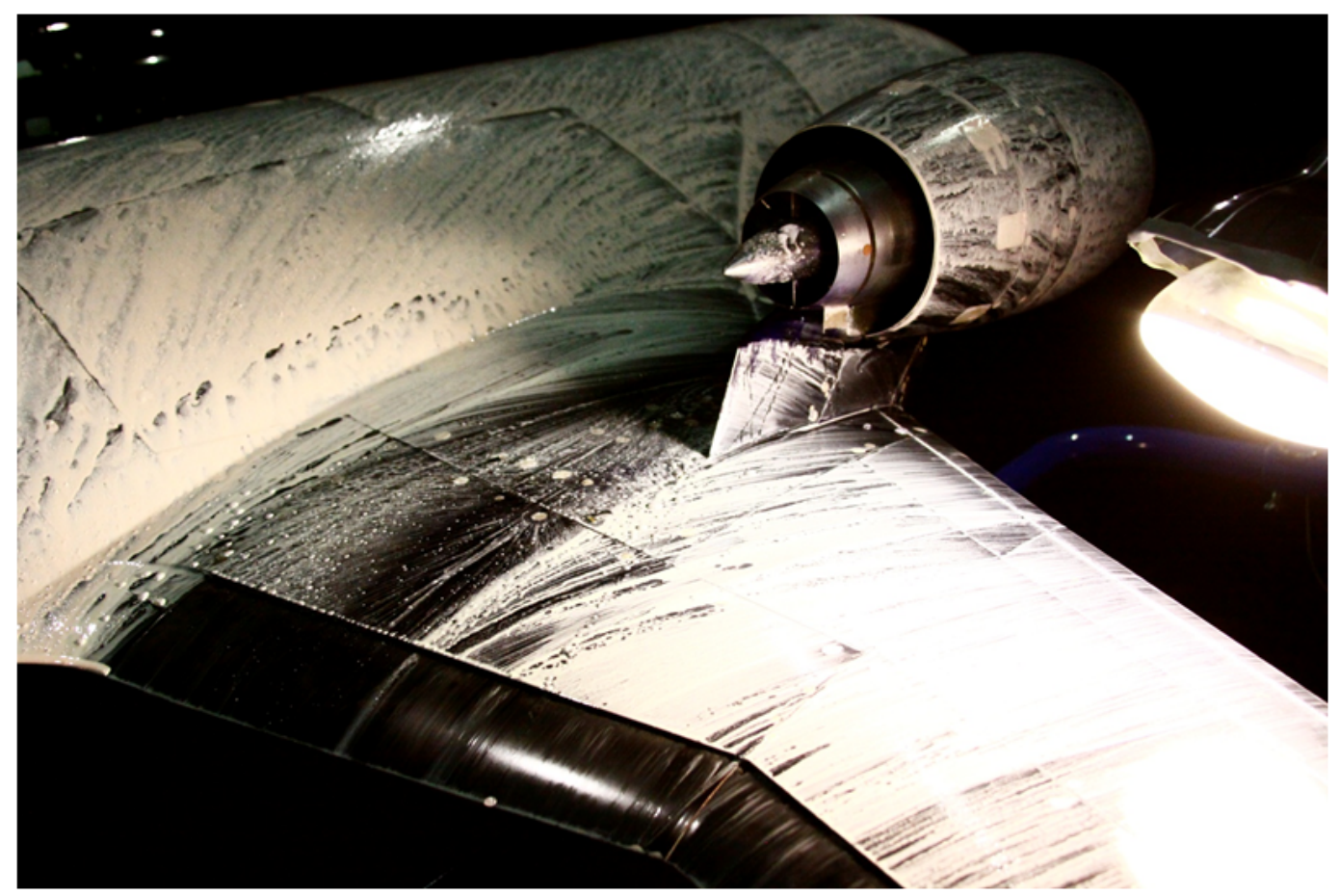

Run $115(01 / 20 / 2012)$ :

$q_{\infty}=12.2 p s f, \alpha=10^{\circ}, C_{\mu}=0.38, C_{T}=0.89$, Low Pylon, $0^{\circ}$ flap defl . 


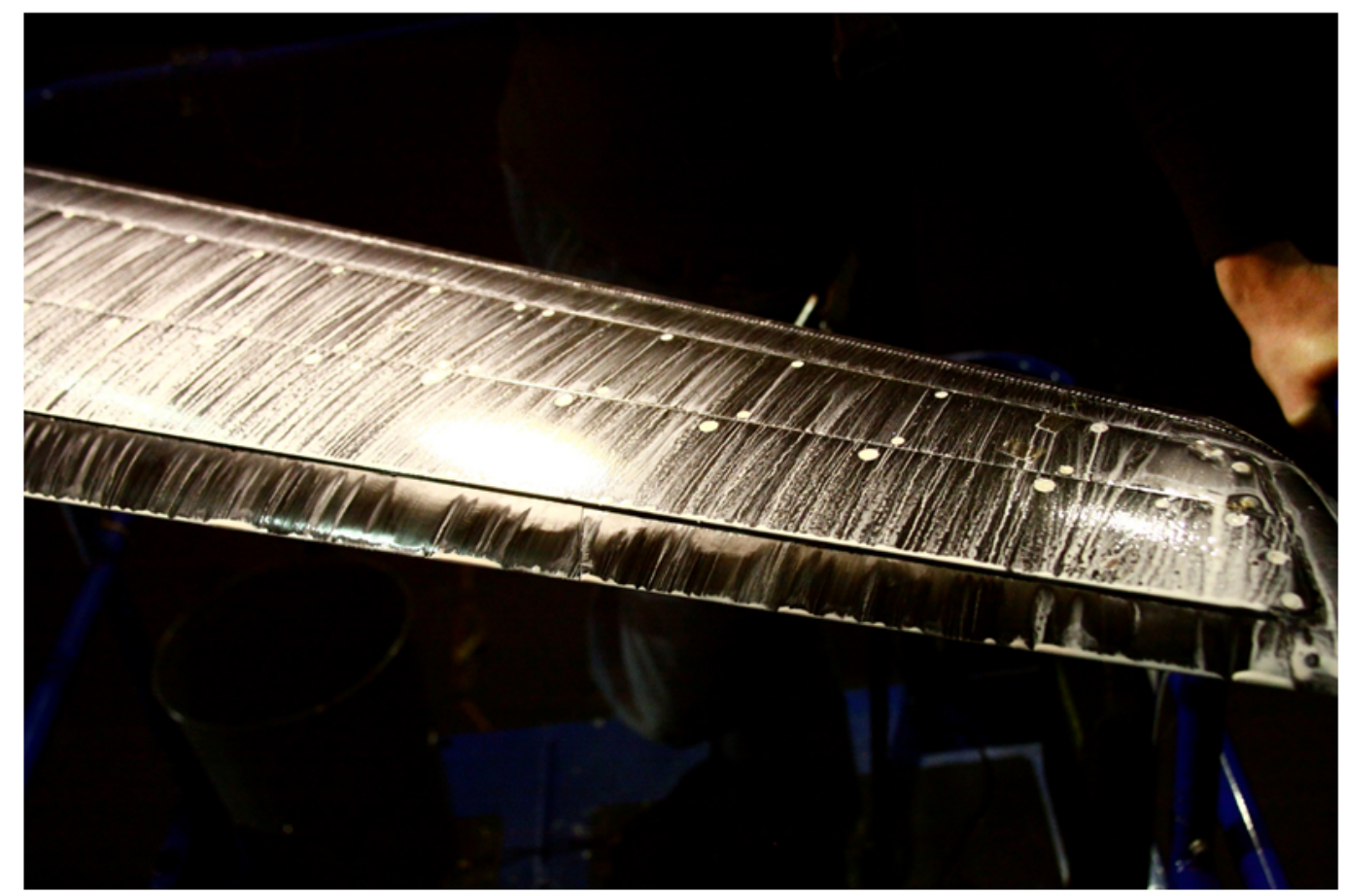

Run $115(01 / 20 / 2012)$ :

$q_{\infty}=12.2 p s f, \alpha=10^{\circ}, C_{\mu}=0.38, C_{T}=0.89$, Low Pylon, $0^{\circ}$ flap defl.

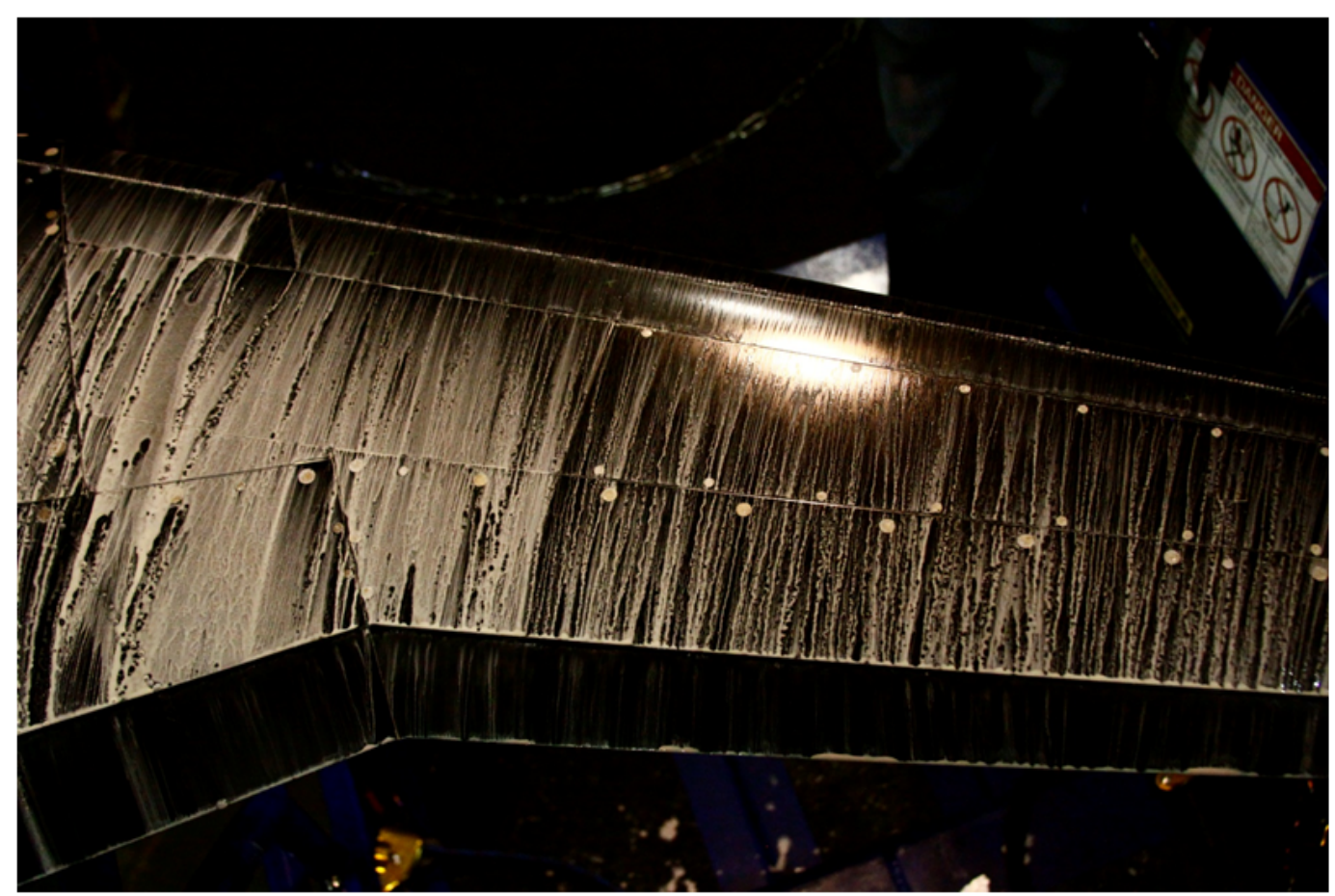

Run 115 (01/20/2012):

$q_{\infty}=12.2 p s f, \alpha=10^{\circ}, C_{\mu}=0.38, C_{T}=0.89$, Low Pylon, $0^{\circ}$ flap defl. 


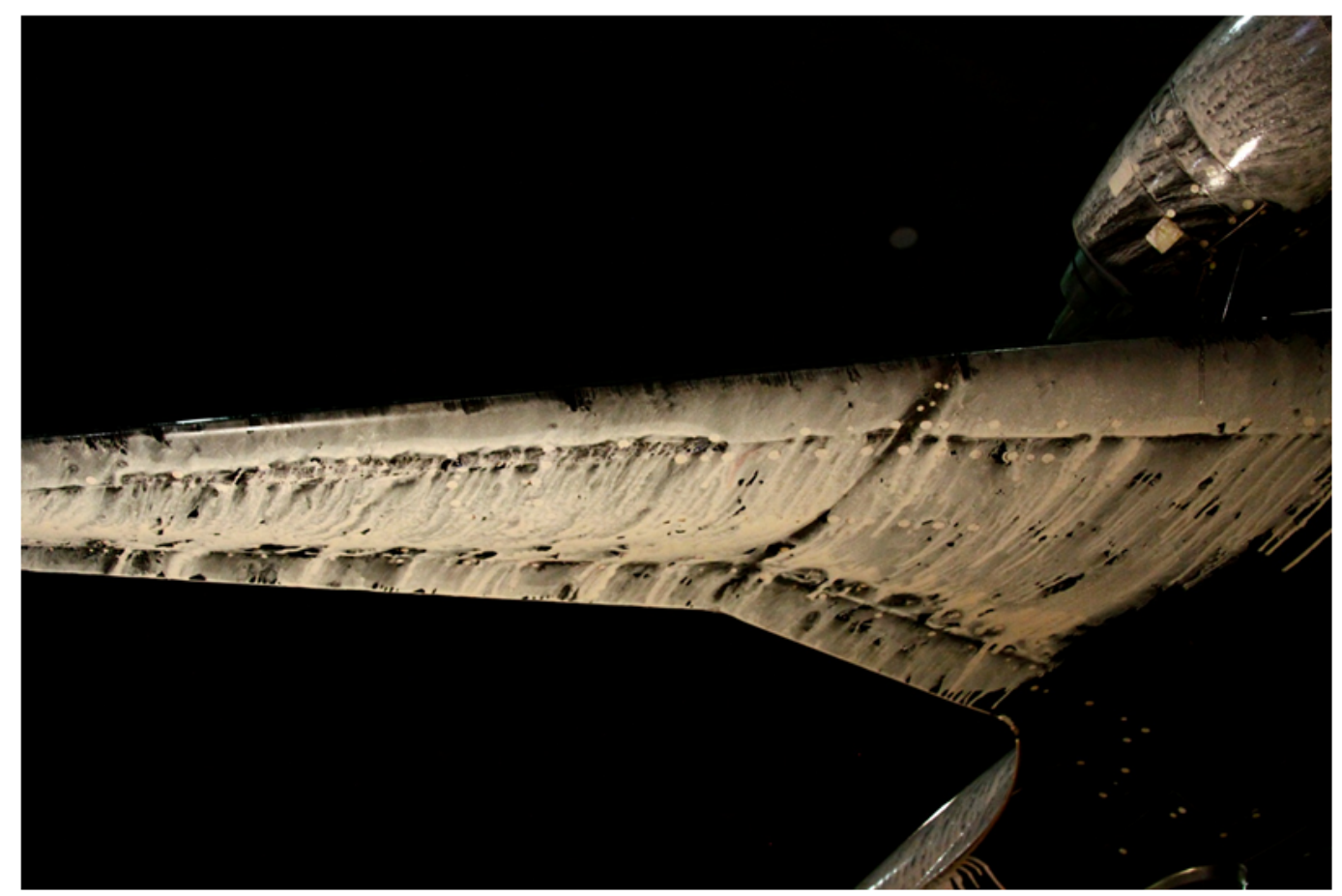

Run 115 (01/20/2012):

$q_{\infty}=12.2 p s f, \alpha=10^{\circ}, C_{\mu}=0.38, C_{T}=0.89$, Low Pylon, $0^{\circ}$ flap defl . 


\section{Oil Case 4}

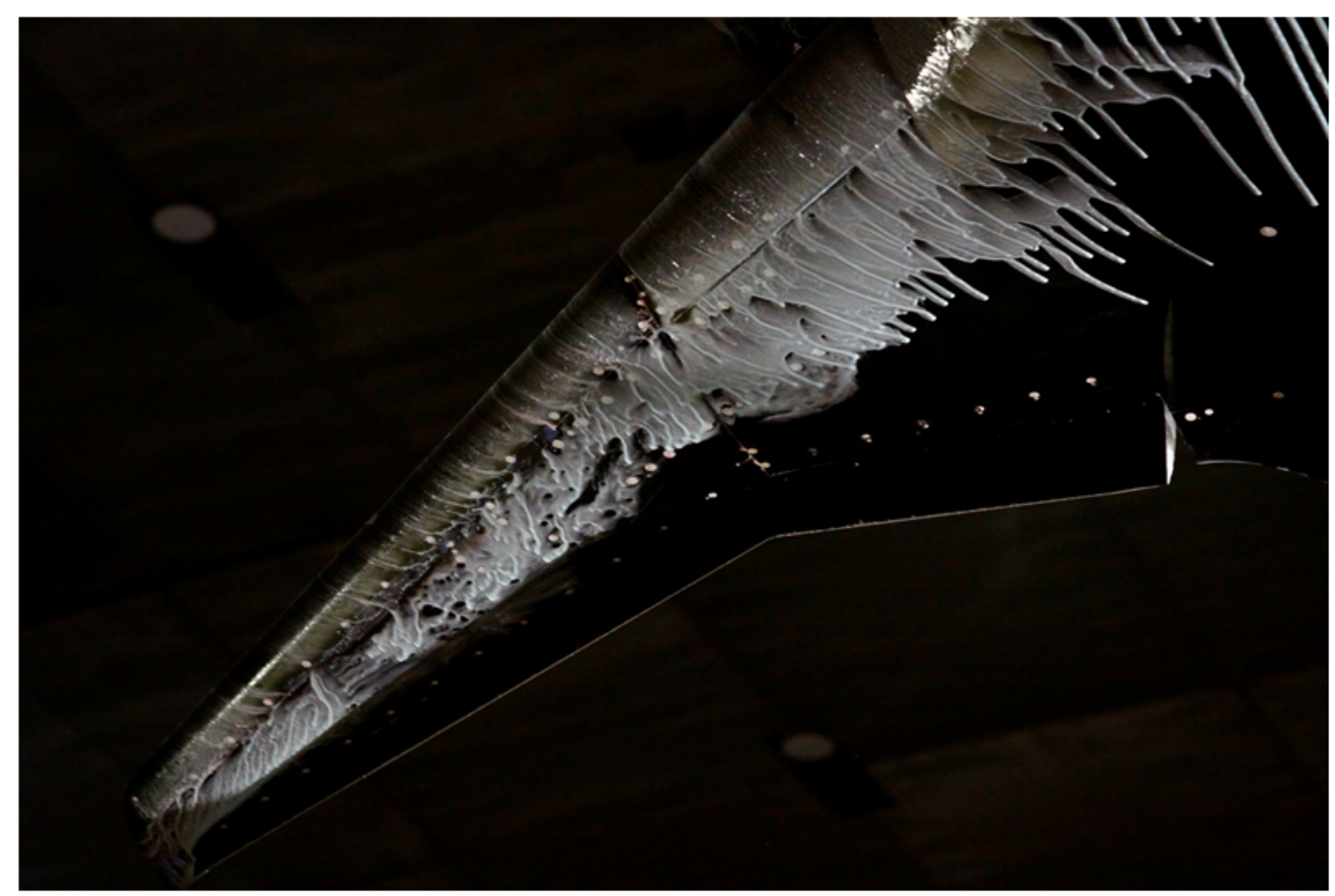

Run $116(01 / 20 / 2012)$ :

$q_{\infty}=3.24 p s f, \alpha=10^{\circ}, C_{\mu}=1.43, C_{T}=0$, Low Pylon, $80^{\circ}$ flap defl. 


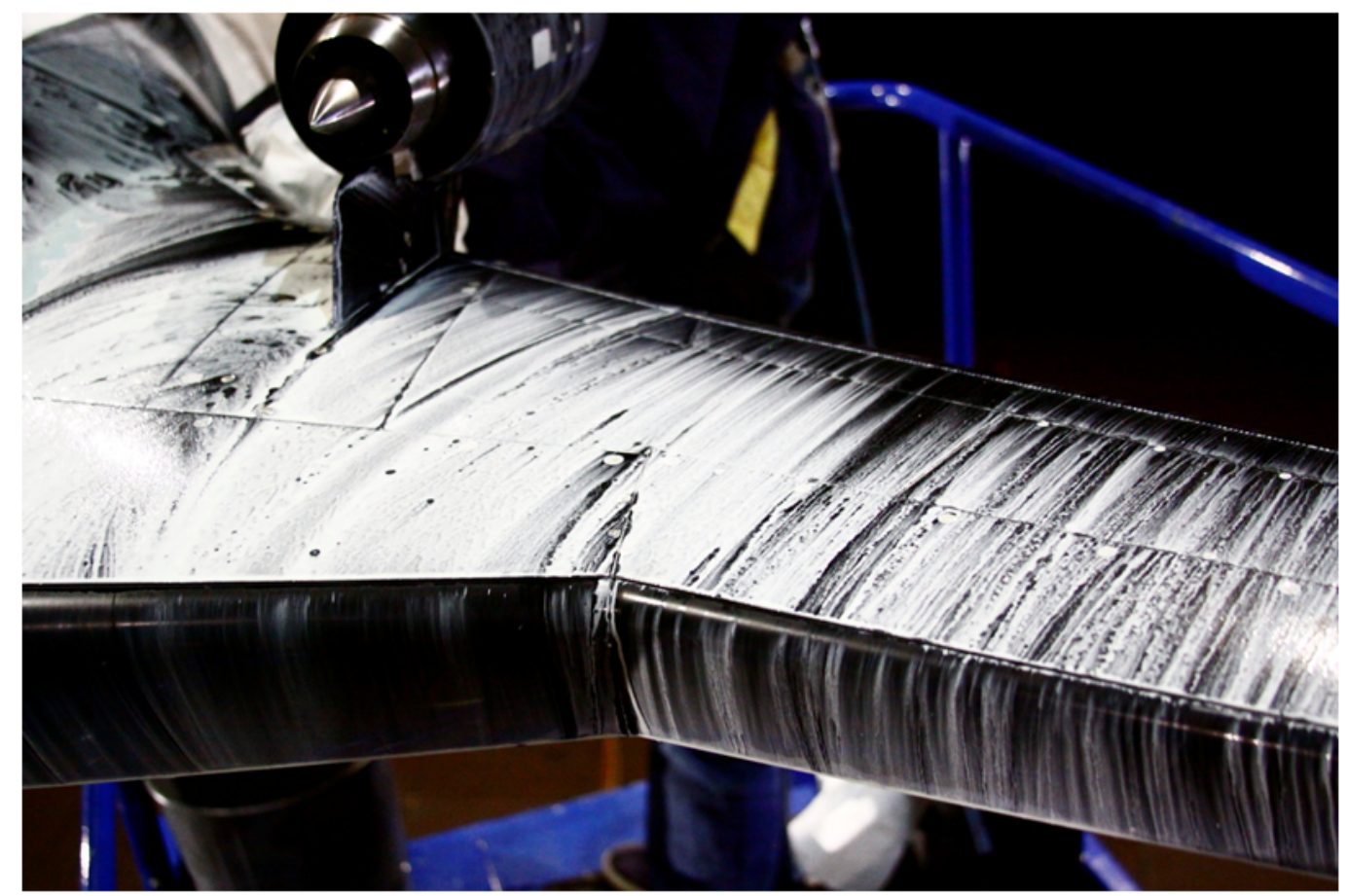

Run 116 (01/20/2012):

$q_{\infty}=3.24 p s f, \alpha=10^{\circ}, C_{\mu}=1.43, C_{T}=0$, Low Pylon, $80^{\circ}$ flap defl .

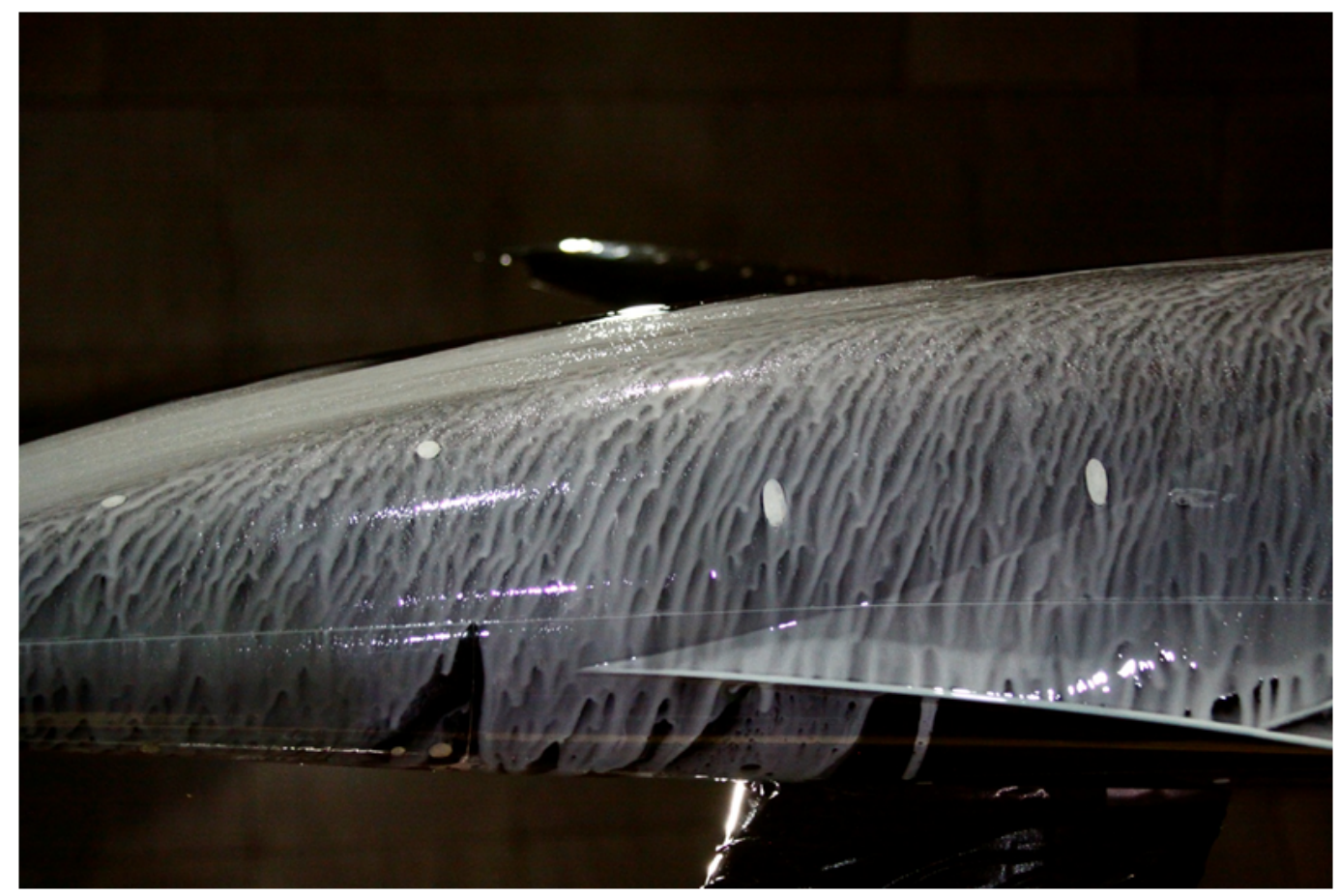

Run $116(01 / 20 / 2012)$ :

$q_{\infty}=3.24 p s f, \alpha=10^{\circ}, C_{\mu}=1.43, C_{T}=0$, Low Pylon, $80^{\circ}$ flap defl . 


\section{Oil Case 5}

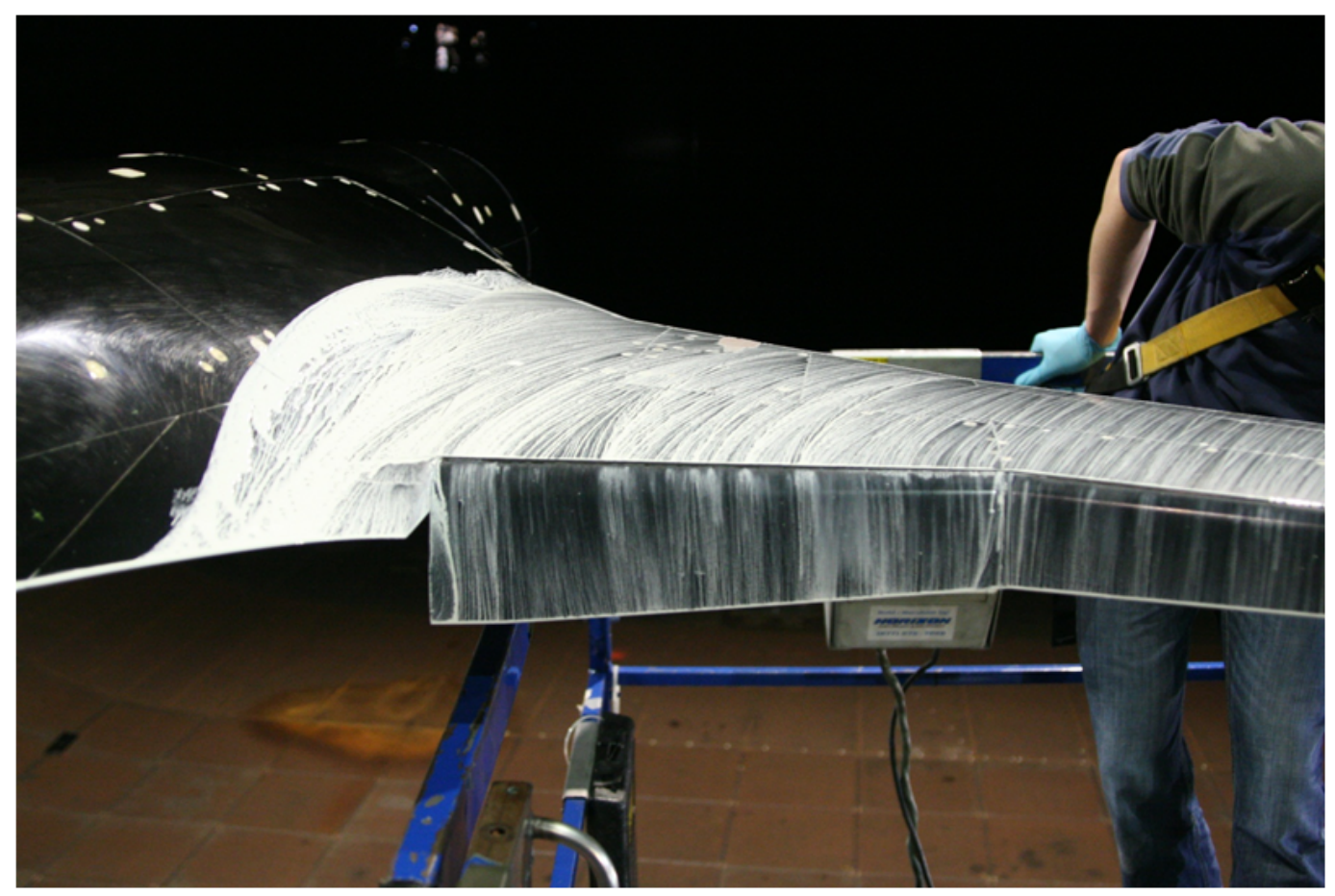

Run $231(02 / 08 / 2012)$ :

$q_{\infty}=11.85 \mathrm{psf}, \alpha=20^{\circ}, C_{\mu}=0.40$, Clean, $80^{\circ}$ flap defl. 


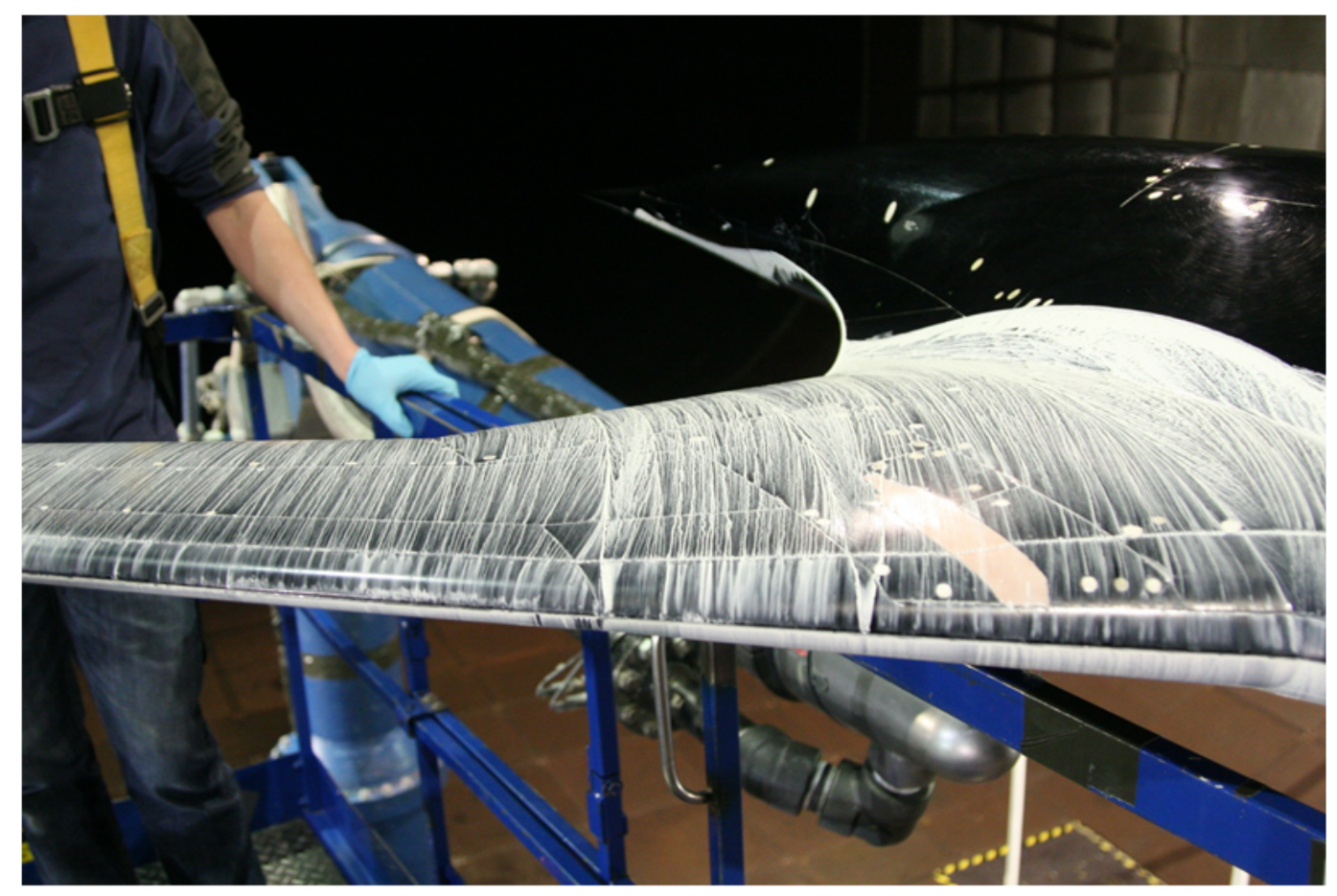

Run 231 (02/08/2012):

$q_{\infty}=11.85 \mathrm{psf}, \alpha=20^{\circ}, C_{\mu}=0.40$, Clean, $80^{\circ}$ flap defl.

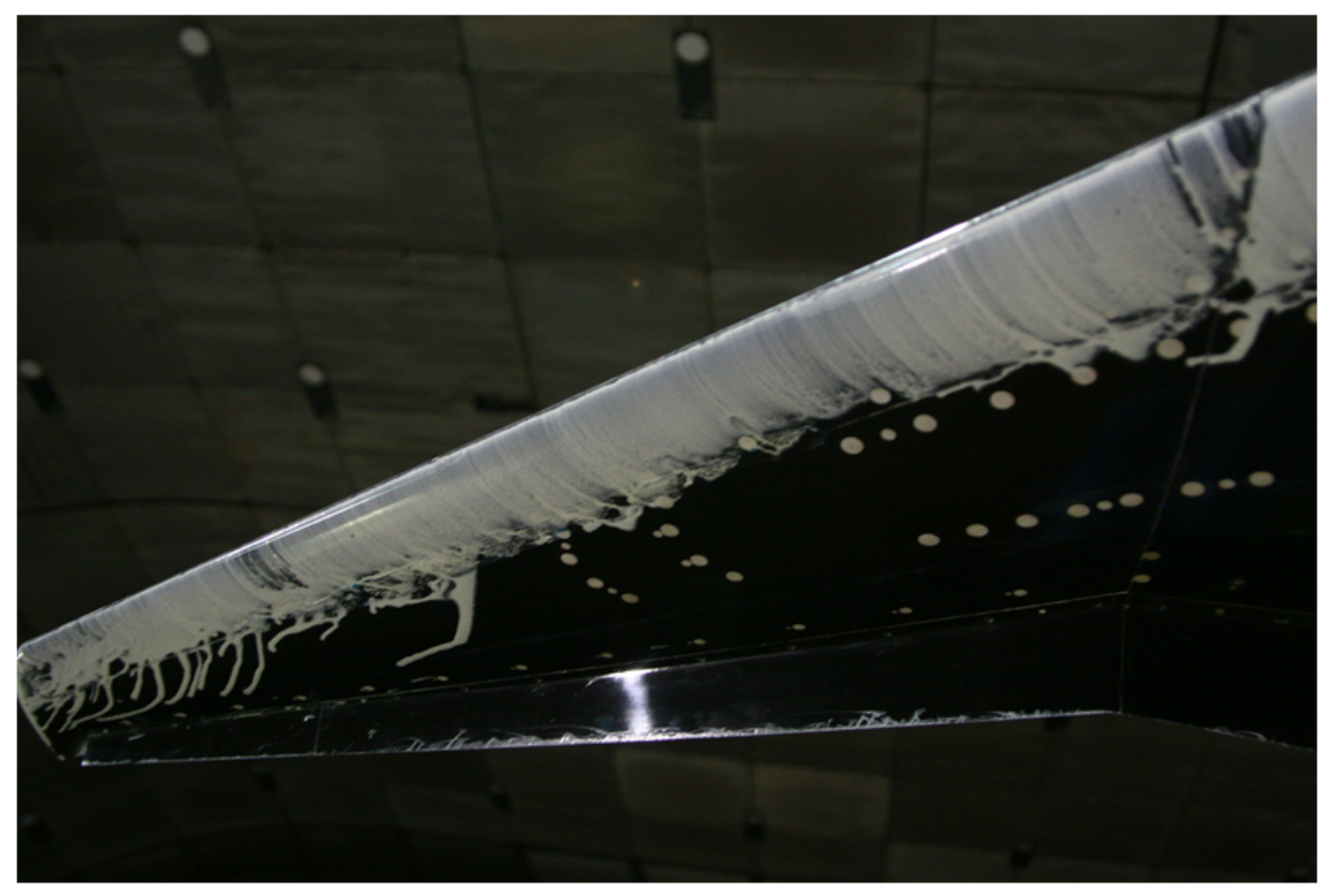

Run $231(02 / 08 / 2012)$ :

$q_{\infty}=11.85 \mathrm{psf}, \alpha=20^{\circ}, C_{\mu}=0.40$, Clean, $80^{\circ}$ flap defl . 


\title{
Appendix B
}

\section{Additional Smoke Flow Images}

\author{
Smoke Case 1
}
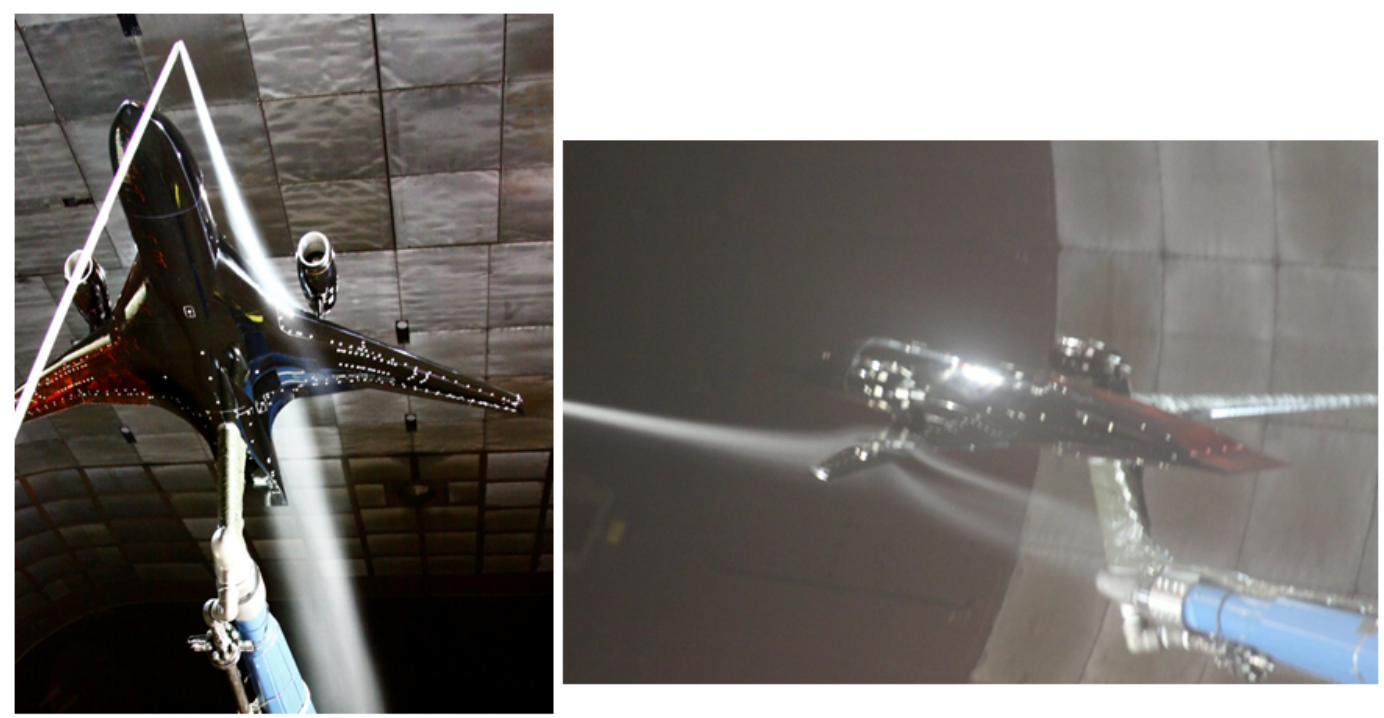

Run $114(01 / 20 / 2012)$ :

$q_{\infty}=3.4 p s f, \alpha=5^{\circ}, C_{\mu}=1.35, C_{T}=0$, Low Pylon, $0^{\circ}$ flap defl. 

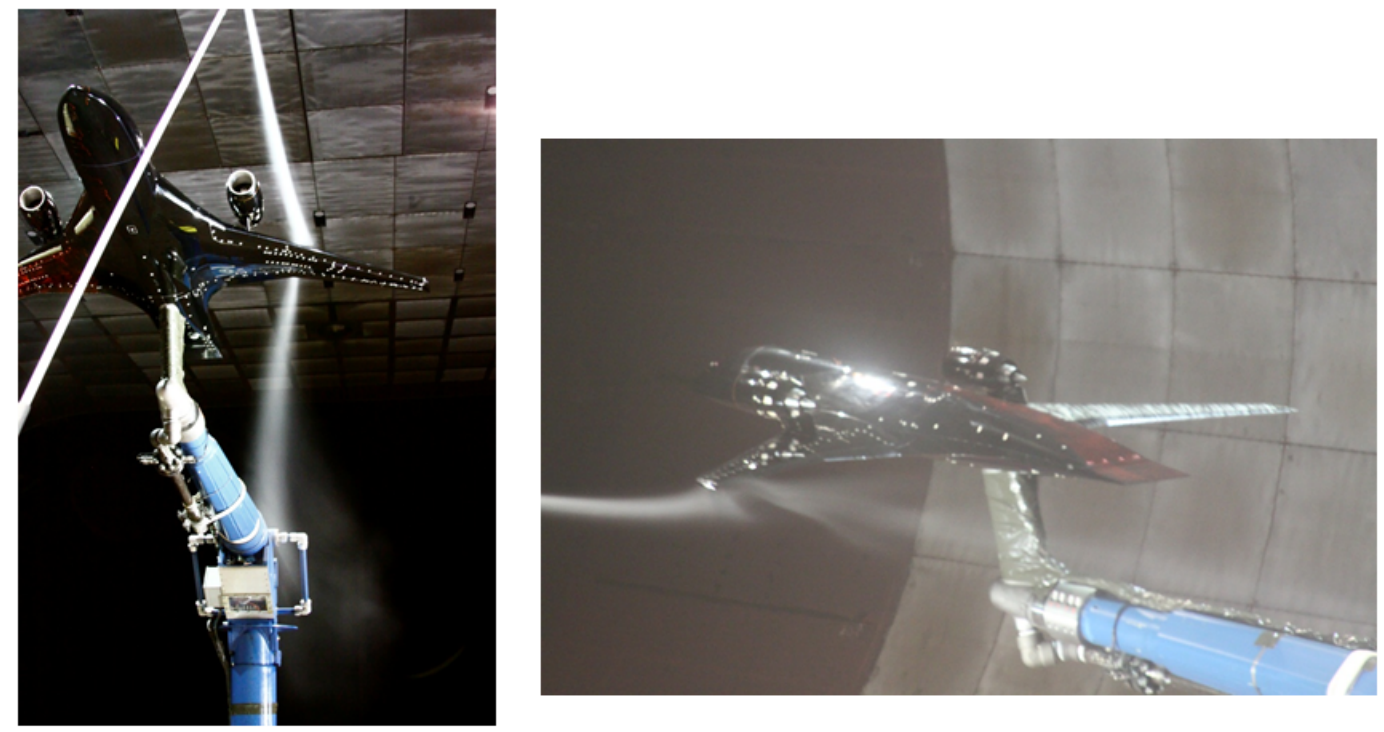

Run $114(01 / 20 / 2012)$ :

$q_{\infty}=3.4 p s f, \alpha=5^{\circ}, C_{\mu}=1.35, C_{T}=0$, Low Pylon, $0^{\circ}$ flap defl .
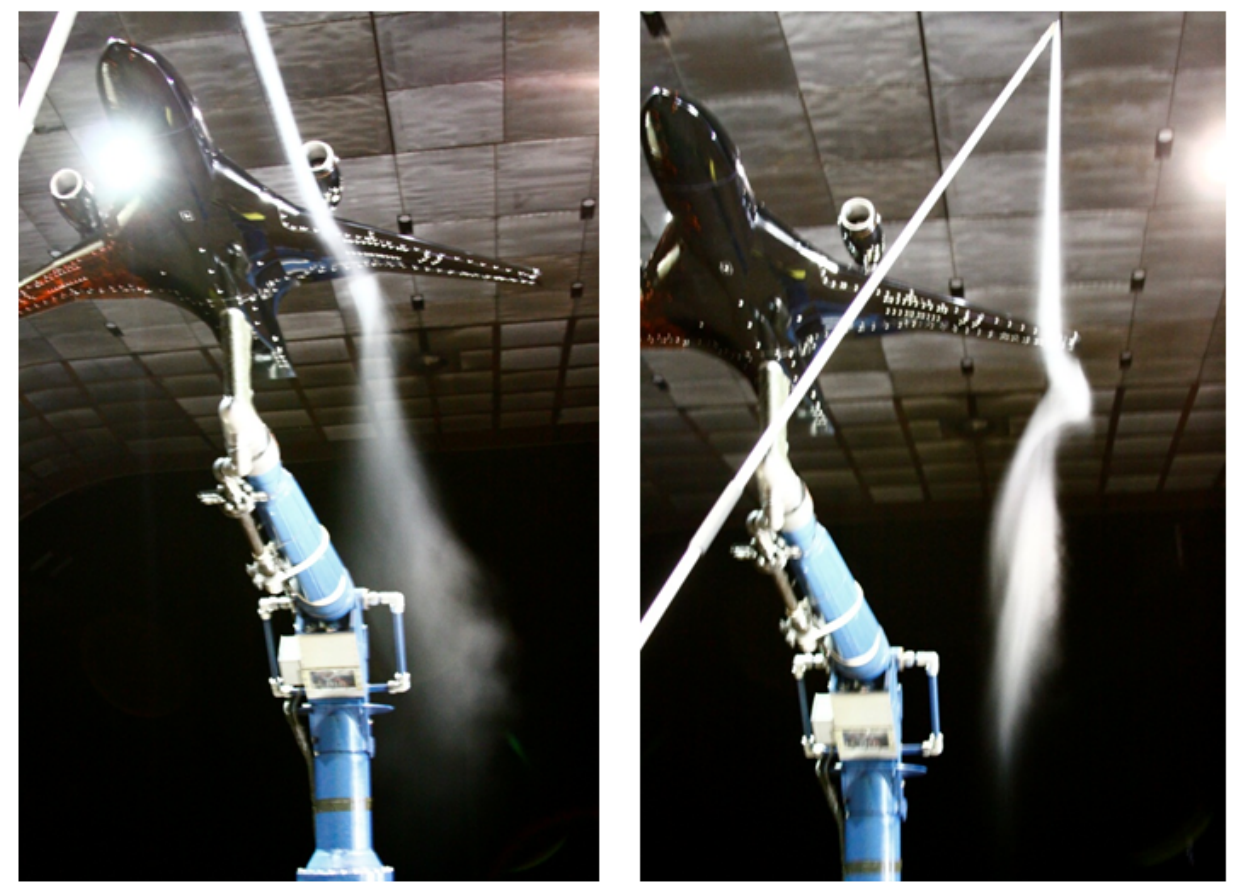

Run $114(01 / 20 / 2012)$

$q_{\infty}=3.4 p s f, \alpha=5^{\circ}, C_{\mu}=1.35, C_{T}=0$, Low Pylon, $0^{\circ}$ flap defl. 

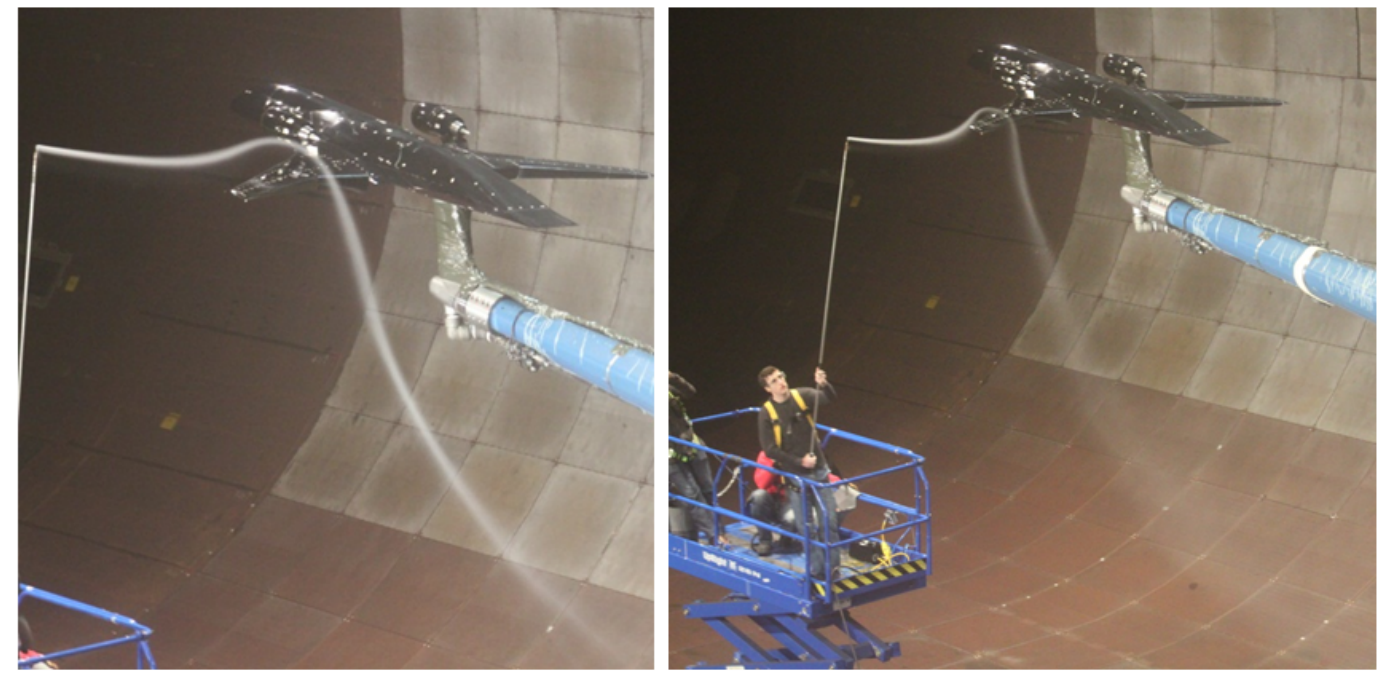

Run $117(01 / 20 / 2012)$ :

$q_{\infty}=2.94 \mathrm{psf}, \boldsymbol{\alpha}=10^{\circ}, C_{\mu}=1.62, C_{T}=0$, Low Pylon, $80^{\circ}$ flap defl .
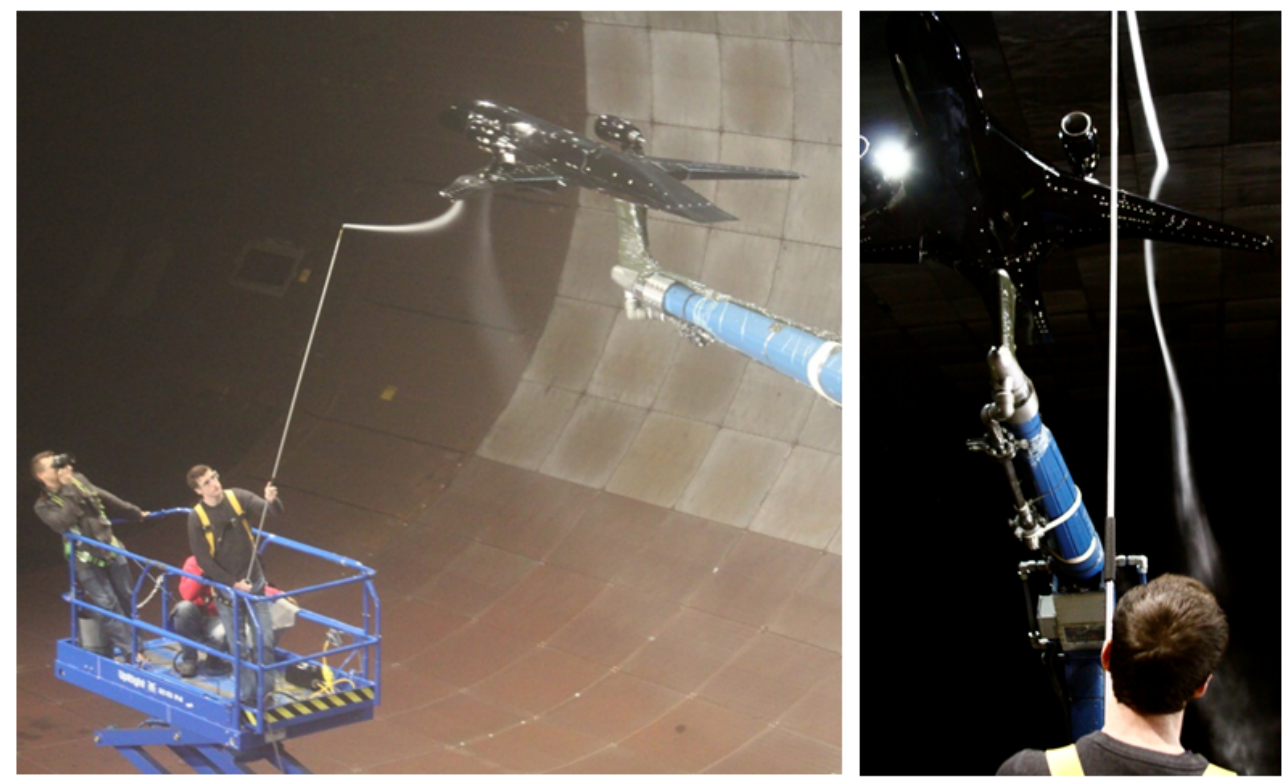

Run $117(01 / 20 / 2012)$ :

$q_{\infty}=2.94 \mathrm{psf}, \boldsymbol{\alpha}=10^{\circ}, C_{\mu}=1.62, C_{T}=0$, Low Pylon, $80^{\circ}$ flap defl. 


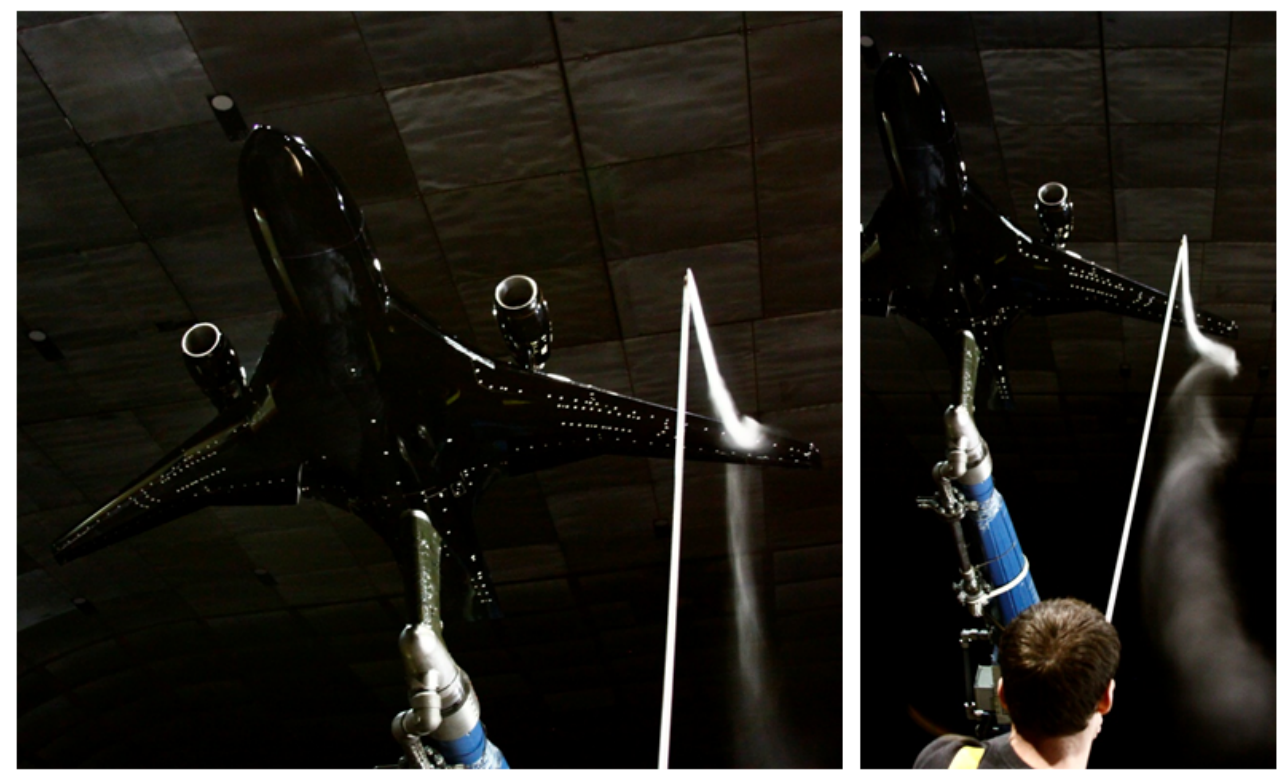

Run 117 (01/20/2012):

$q_{\infty}=2.94 p s f, \alpha=10^{\circ}, C_{\mu}=1.62, C_{T}=0$, Low Pylon, $80^{\circ}$ flap defl.
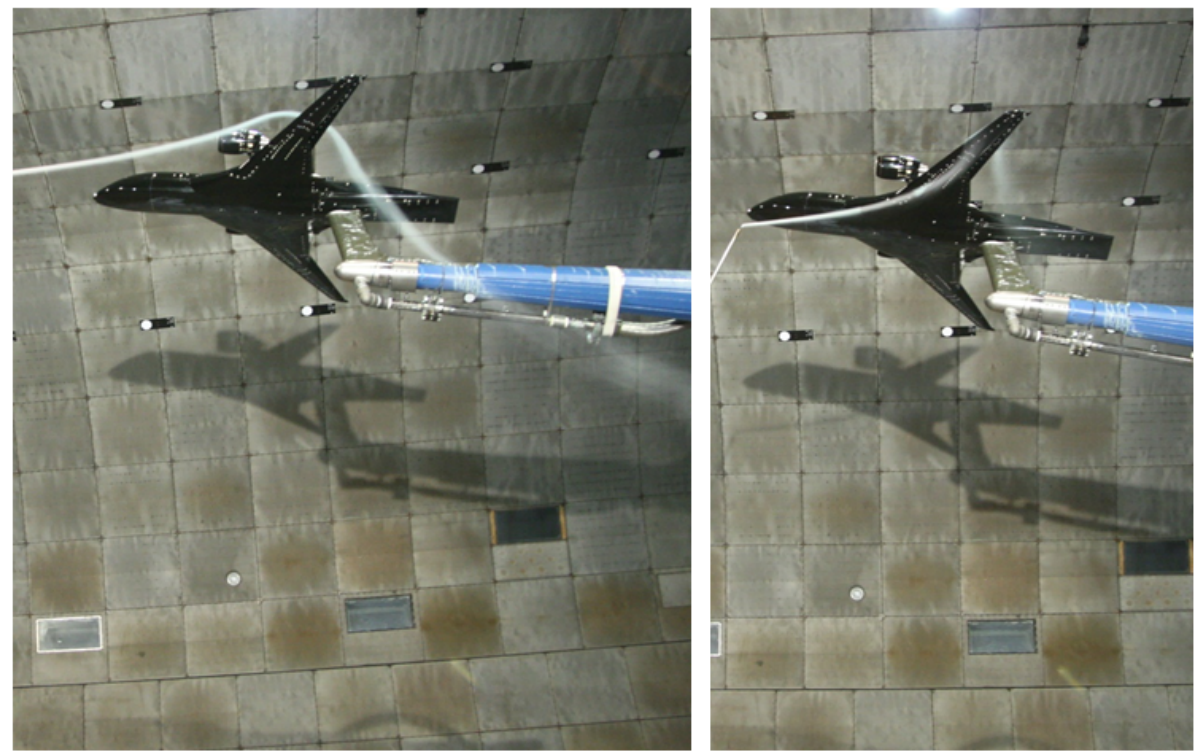

Run $117(01 / 20 / 2012)$ :

$q_{\infty}=2.94 p s f, \alpha=10^{\circ}, C_{\mu}=1.62, C_{T}=0$, Low Pylon, $80^{\circ}$ flap defl . 

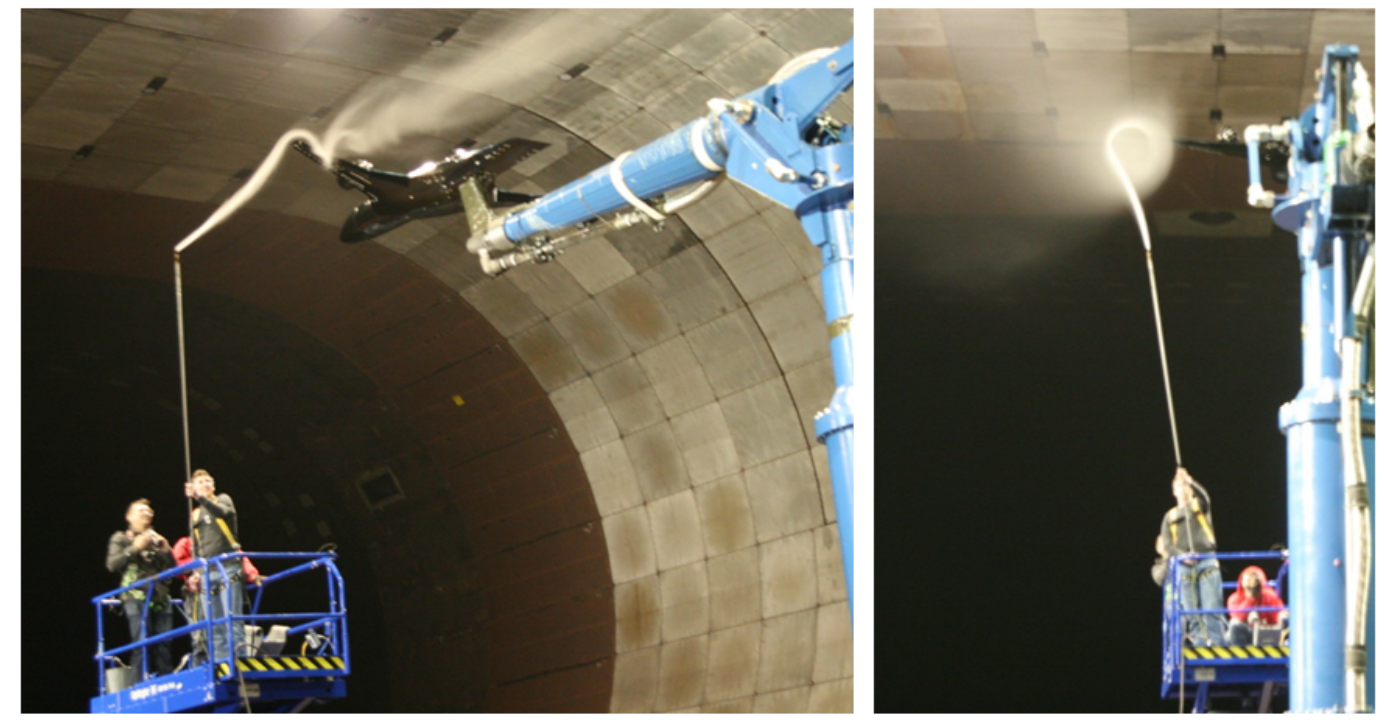

Run 117 (01/20/2012):

$q_{\infty}=2.94 p s f, \alpha=10^{\circ}, C_{\mu}=1.62, C_{T}=0$, Low Pylon, $80^{\circ}$ flap defl.
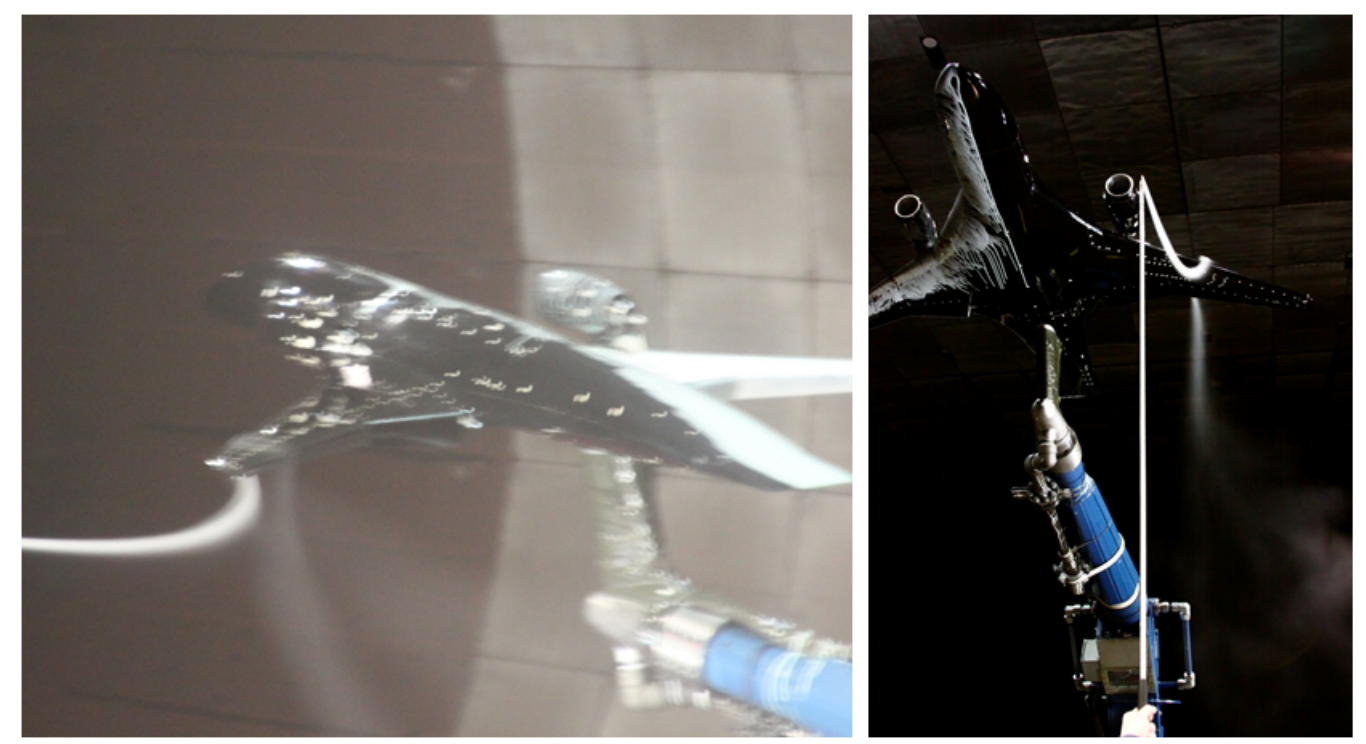

Run $116(01 / 20 / 2012)$ (Left):

$q_{\infty}=3.24 p s f, \alpha=10^{\circ}, C_{\mu}=1.43, C_{T}=0$, Low Pylon, $80^{\circ}$ flap defl . 

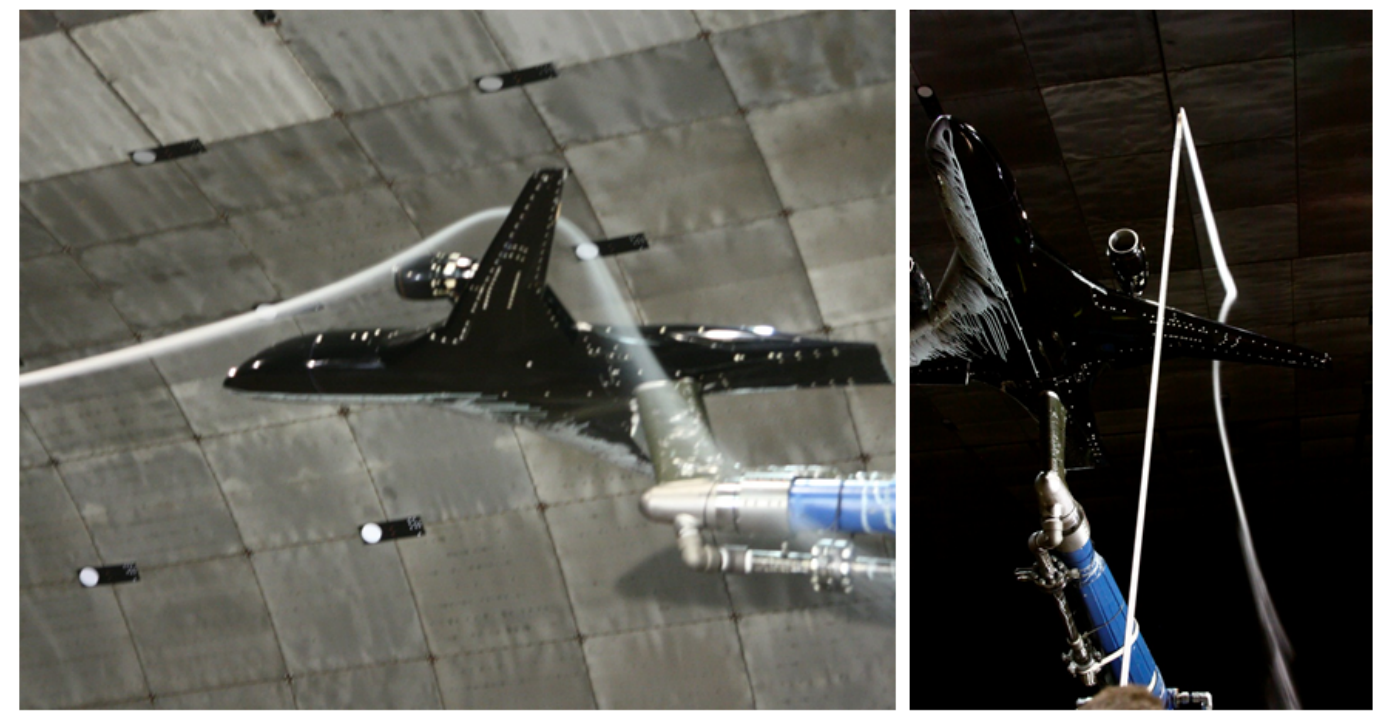

Run $116(01 / 20 / 2012)$ (Left):

$q_{\infty}=3.24 p s f, \alpha=10^{\circ}, C_{\mu}=1.43, C_{T}=0$, Low Pylon, $80^{\circ}$ flap defl. 


\section{Smoke Case 2}

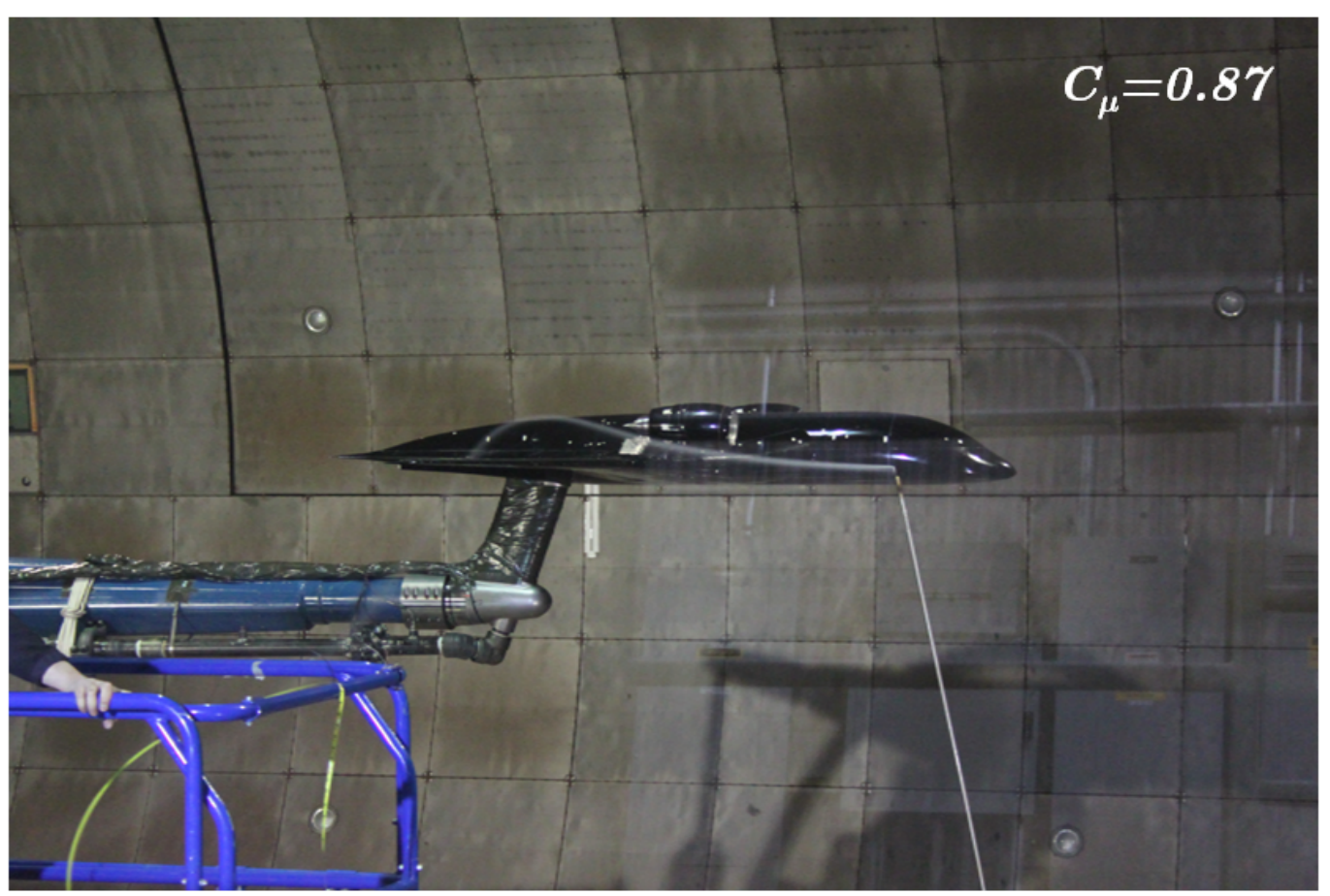

Run $170(01 / 27 / 2012)$ :

$q_{\infty}=5.4 p s f, \alpha=0^{\circ}, C_{\mu}=($ Sweep $), C_{T}=0$, Low Pylon, $80^{\circ}$ flap defl . 


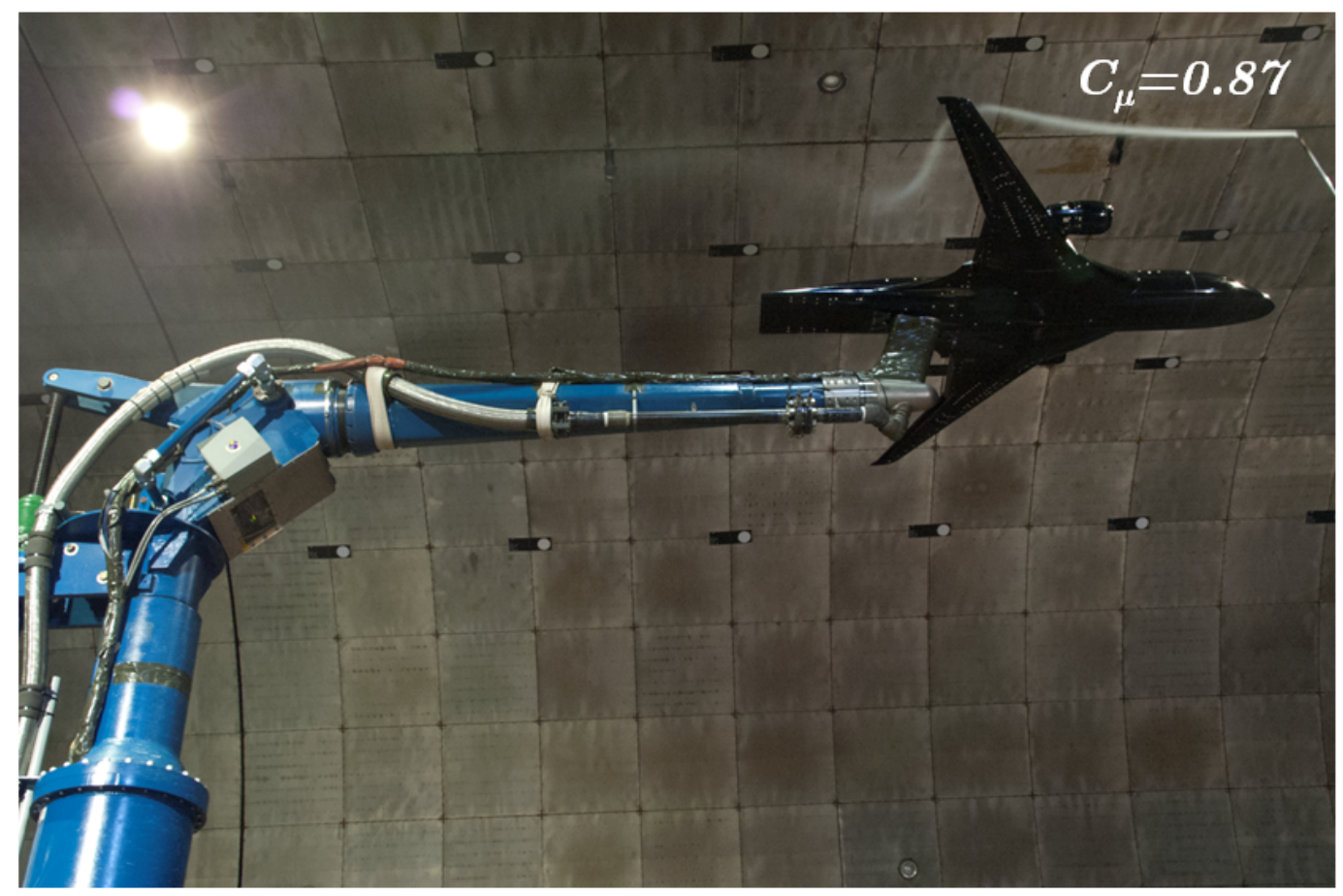

Run $170(01 / 27 / 2012)$ :

$q_{\infty}=5.4 p s f, \alpha=0^{\circ}, C_{\mu}=($ Sweep $), C_{T}=0$, Low Pylon, $80^{\circ}$ flap defl .

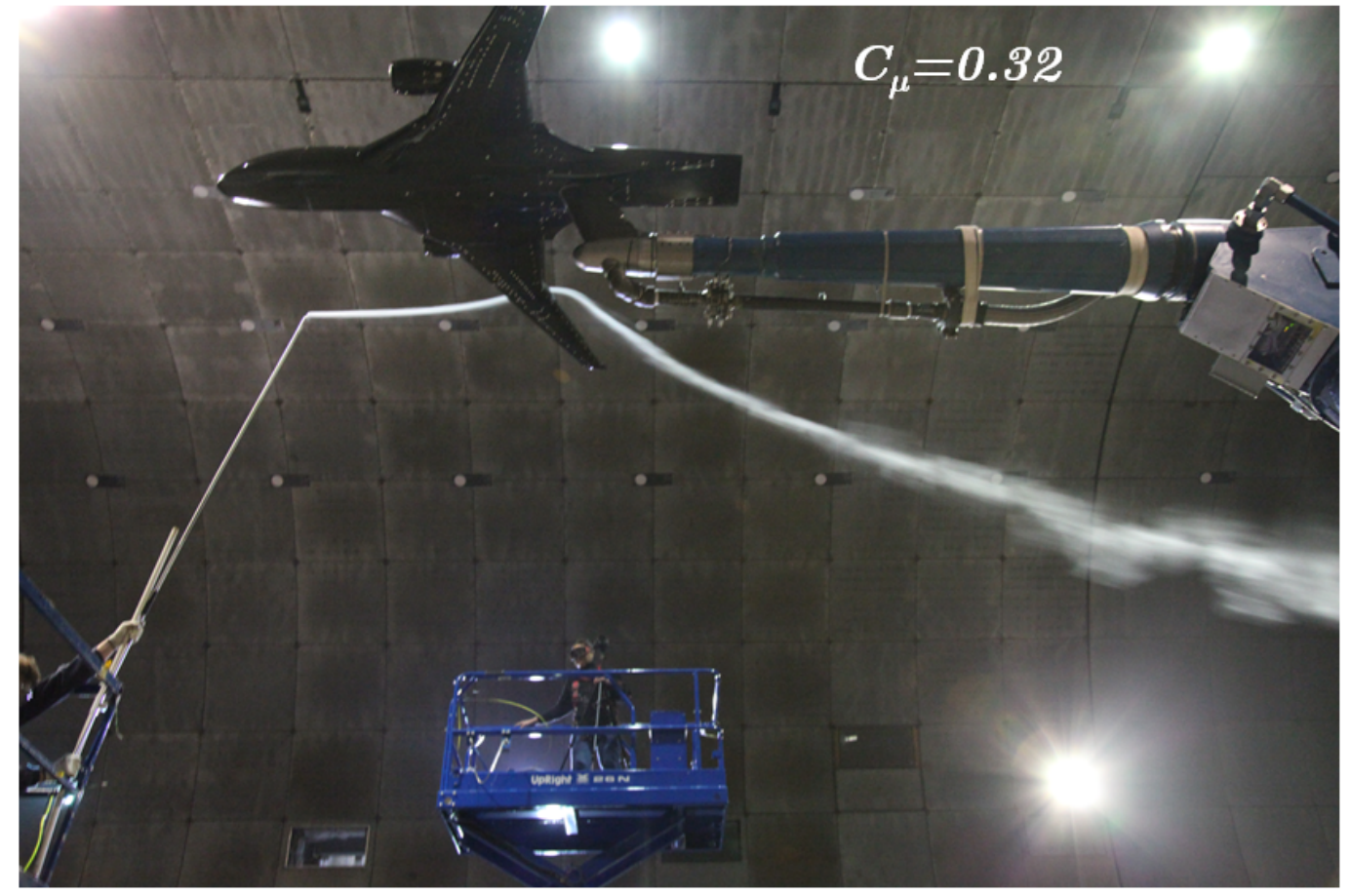

Run $170(01 / 27 / 2012)$ :

$q_{\infty}=5.4 p s f, \alpha=0^{\circ}, C_{\mu}=($ Sweep $), C_{T}=0$, Low Pylon, $80^{\circ}$ flap defl . 


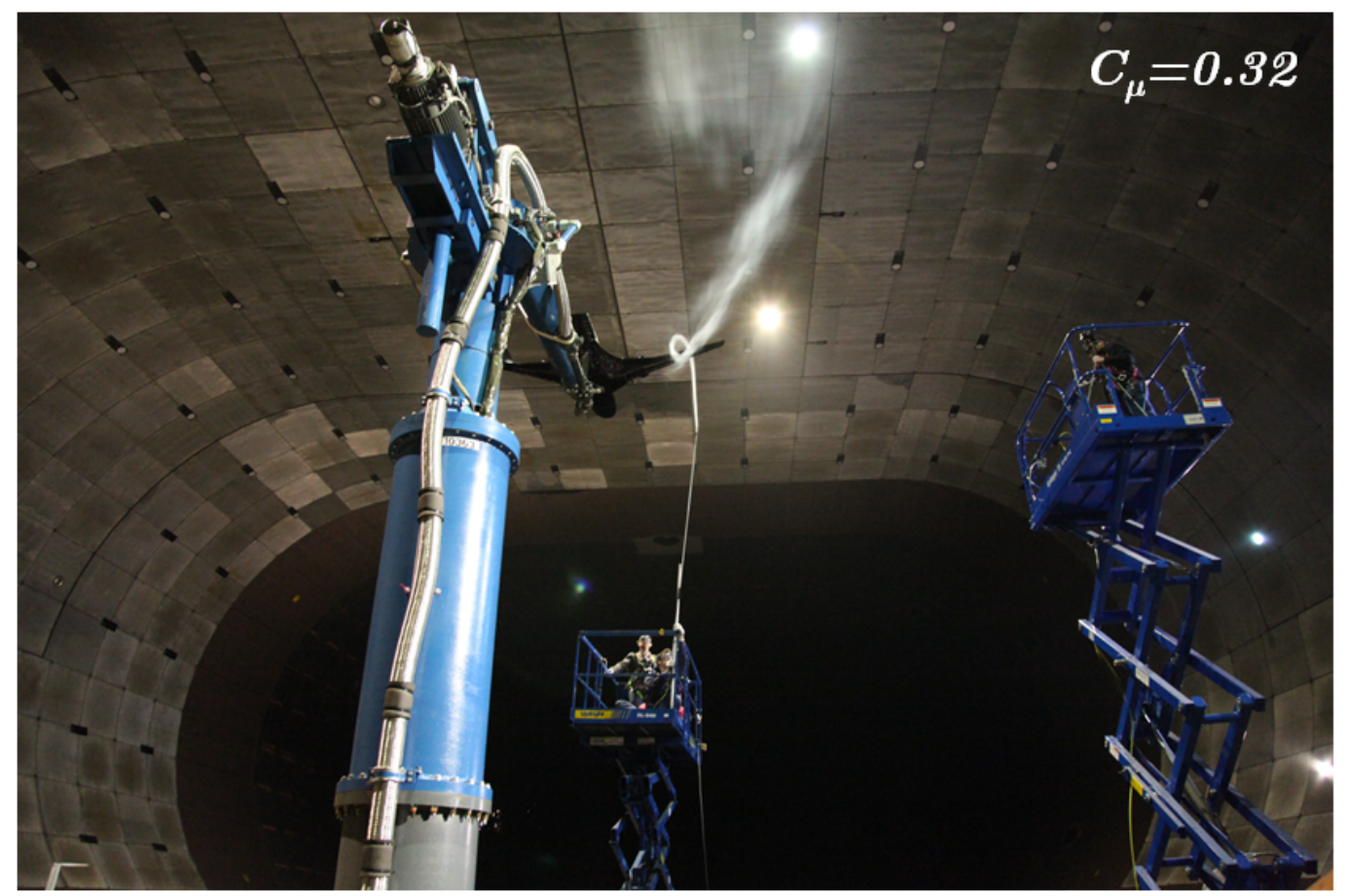

Run $170(01 / 27 / 2012)$ :

$q_{\infty}=5.4 p s f, \alpha=0^{\circ}, C_{\mu}=($ Sweep $), C_{T}=0$, Low Pylon, $80^{\circ}$ flap defl .

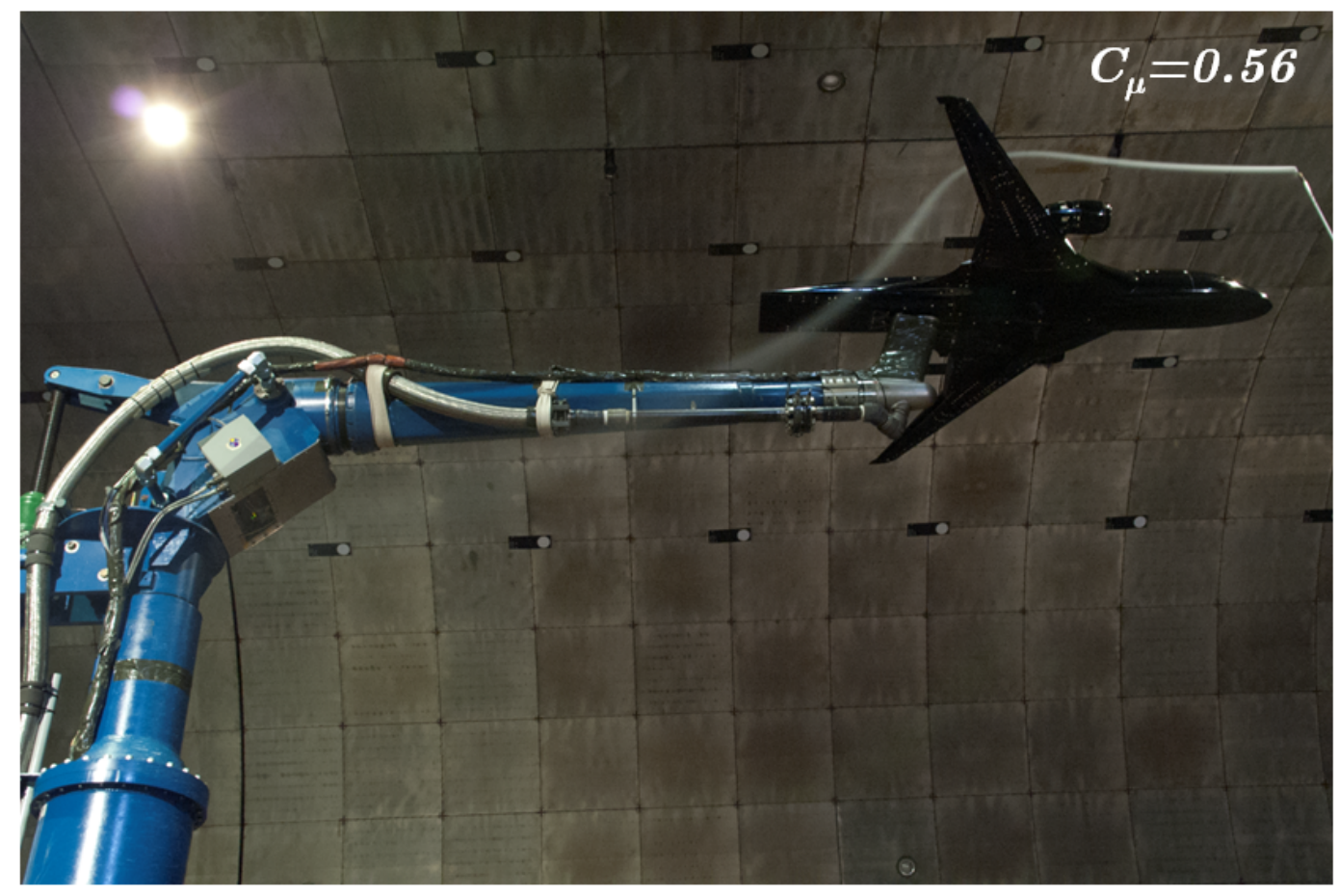

Run $170(01 / 27 / 2012)$ :

$q_{\infty}=5.4 p s f, \alpha=0^{\circ}, C_{\mu}=($ Sweep $), C_{T}=0$, Low Pylon, $80^{\circ}$ flap defl . 


\section{Smoke Case 3}

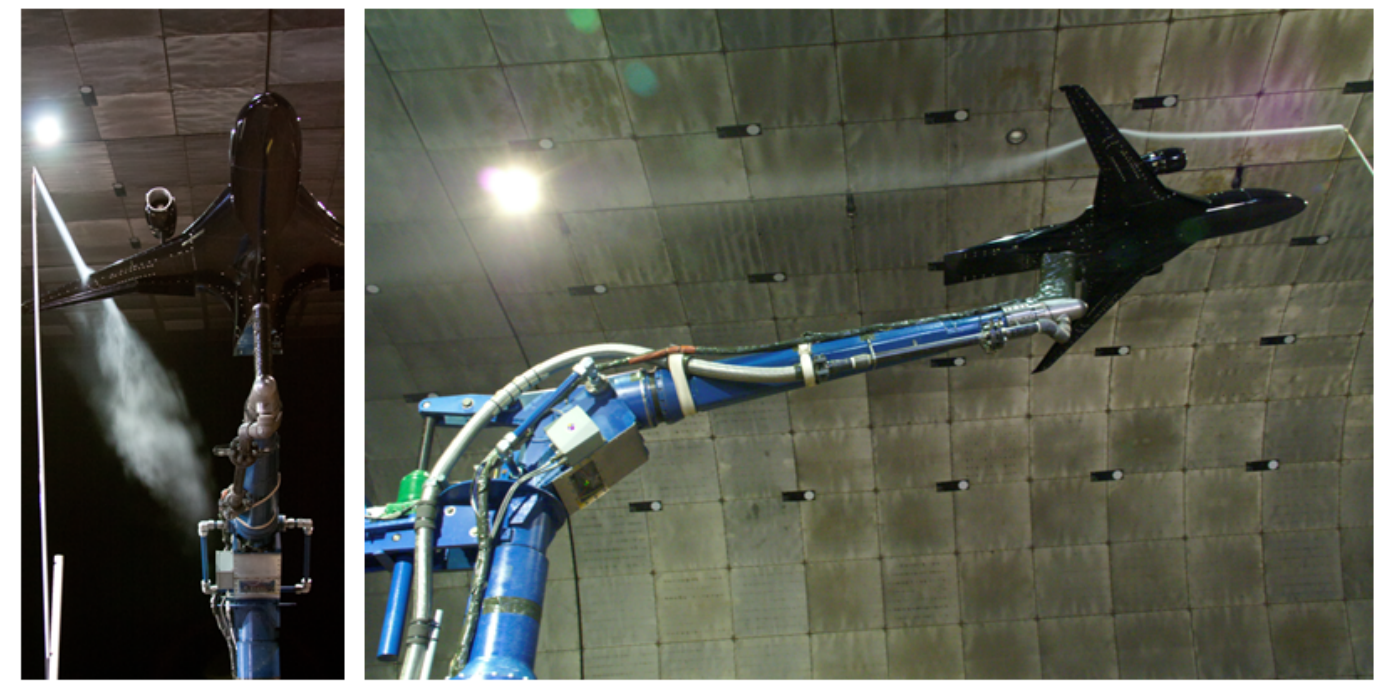

Run $170(01 / 27 / 2012)$ :

$q_{\infty}=5.4$ psf, $\alpha=10^{\circ}, C_{\mu}=0, C_{T}=0$, Low Pylon, $80^{\circ}$ flap defl.

Smoke Case 4 


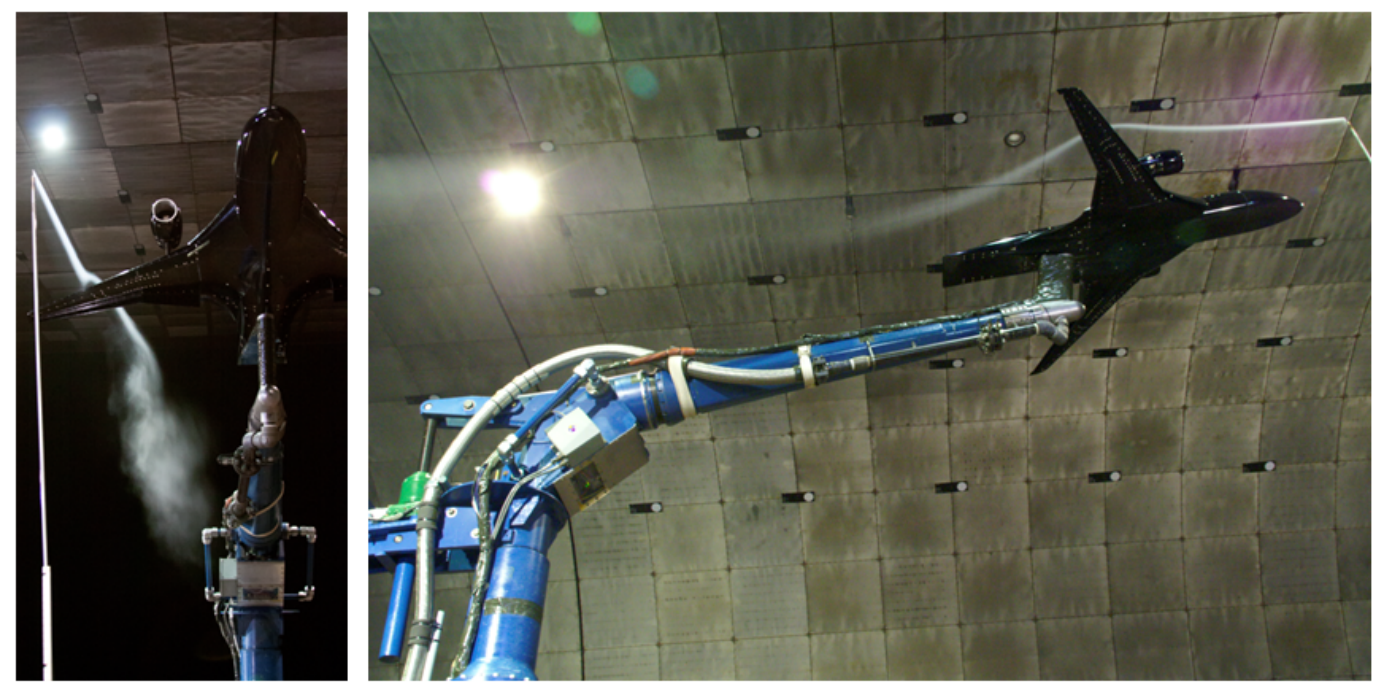

Run $170(01 / 27 / 2012)$ :

$q_{\infty}=5.4 p s f, \alpha=10^{\circ}, C_{\mu}=0.29, C_{T}=0$, Low Pylon, $80^{\circ}$ flap defl .

\section{Smoke Case 5}
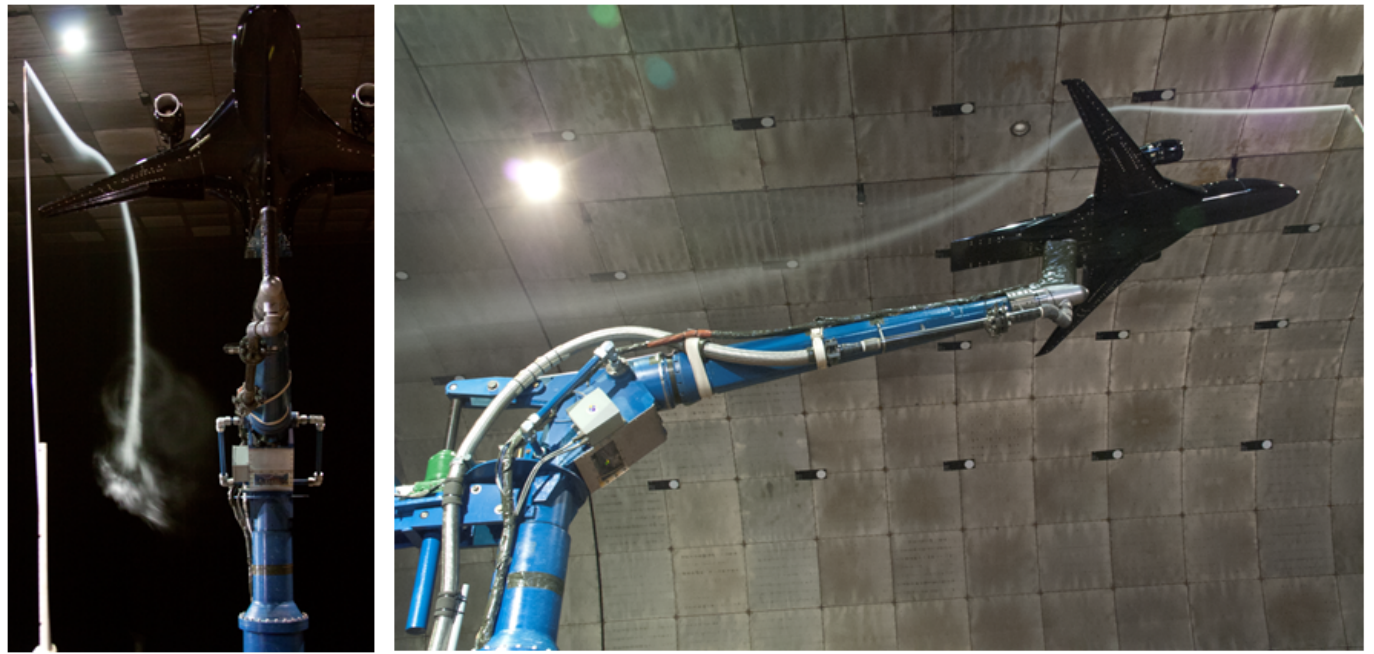

Run $170(01 / 27 / 2012)$ :

$q_{\infty}=5.4 p s f, \alpha=10^{\circ}, C_{\mu}=0.58, C_{T}=0$, Low Pylon, $80^{\circ}$ flap defl .

Smoke Case 6 


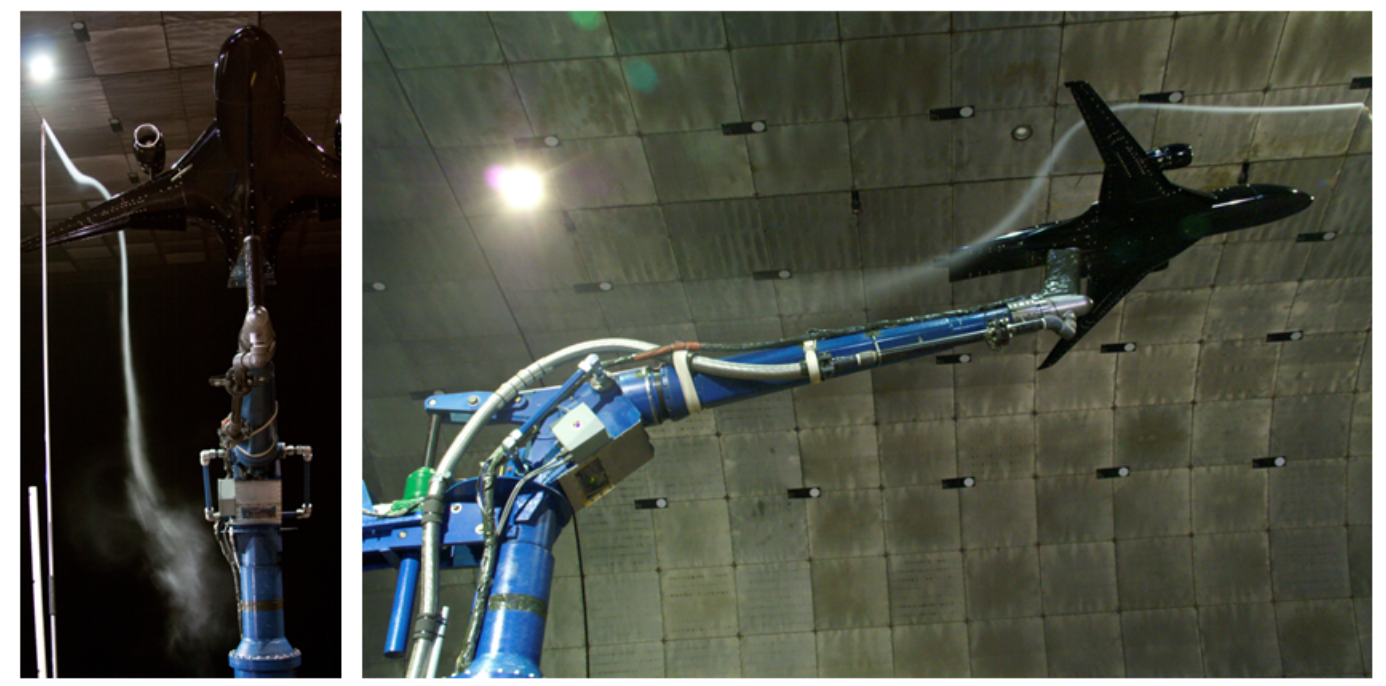

Run $170(01 / 27 / 2012)$ :

$q_{\infty}=5.4$ psf, $\alpha=10^{\circ}, C_{\mu}=0.87, C_{T}=0$, Low Pylon, $80^{\circ}$ flap defl. 